\title{
Validation of the triplet ground state in a persistent derivative of Clar's hydrocarbon
}

Leoš Valenta ${ }^{1}$, Maximilian Mayländer ${ }^{2}$, Pia Kappeler ${ }^{1}$, Olivier Blacque ${ }^{1}$, Tomáš Šlomek ${ }^{3,4 *}$, Sabine Richert ${ }^{2 *}$ and Michal Juríček ${ }^{1,4 *}$

${ }^{1}$ Department of Chemistry, University of Zurich, Zurich, Switzerland. ${ }^{2}$ Institute of Physical Chemistry, University of Freiburg, Freiburg, Germany. ${ }^{3}$ Department of Chemistry, Biochemistry and Pharmacy, University of Bern, Bern, Switzerland. ${ }^{4}$ Prievidza Chemical Society, Prievidza, Slovakia.

*tomas.solomek@dcb.unibe.ch, sabine.richert@physchem.uni-freiburg.de,michal.juricek@chem.uzh.ch
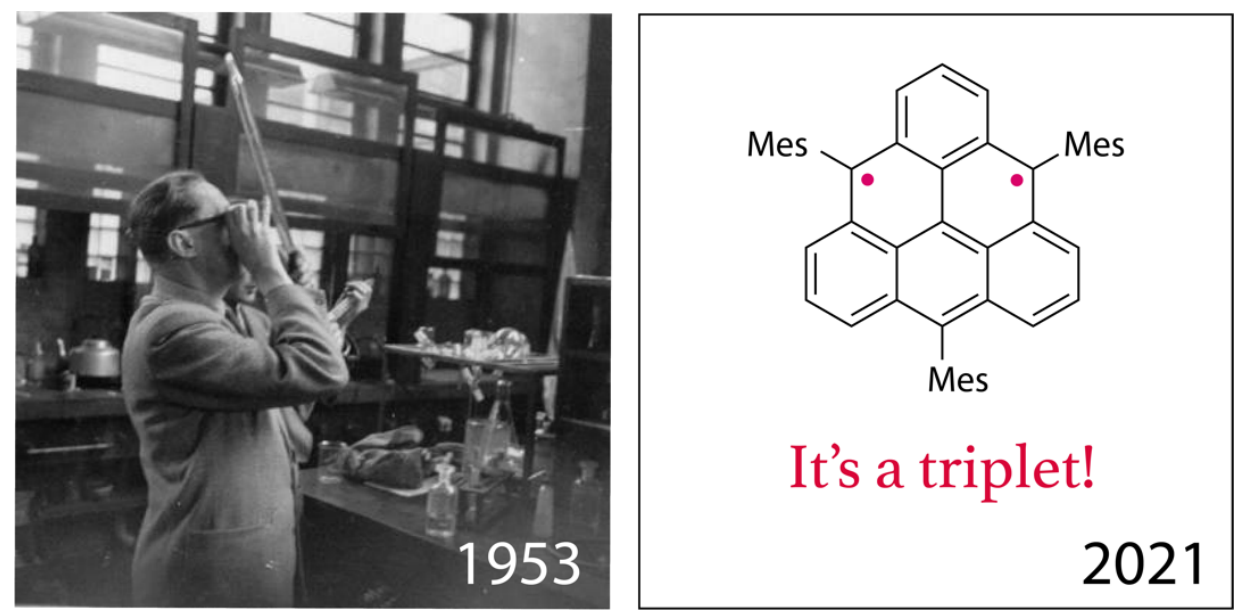

(original image of Erich Clar from Dr. Winfried Willicks (1926-2010), courtesy of Glasgow University, School of Chemistry)

\begin{abstract}
Triangulene is a prototypical non-Kekulé diradical known as Clar's hydrocarbon. It is the smallest non-Kekulé graphene fragment comprised of six benzenoid rings fused in a triangular shape. In accordance with Hund's rule, a triplet ground state is predicted for this hydrocarbon. However, because of its high reactivity, synthesis of a stable or persistent derivative of neutral triangulene to validate this prediction has been an elusive goal for almost 70 years. Herein, we report the synthesis and characterization of the first persistent derivative of triangulene, kinetically stabilized by three sterically demanding substituents installed at the most reactive positions in the centers of the zigzag edges. The triplet ground state of this hydrocarbon is unequivocally confirmed by pulse electron paramagnetic resonance spectroscopy and supported by density functional theory. The realization of a long-sought-after persistent triangulene derivative will motivate the synthesis of analogous open-shell graphene fragments as prospective building blocks of high-spin materials for the newly emerging field of organic spintronics.
\end{abstract}




\section{Introduction}

Isolation of graphene by mechanical exfoliation of graphite $^{1}$ in 2004 and identification of its unique characteristics ${ }^{2-5}$ triggered research on finite graphene fragments with the prospect of utilizing them as components in next-generation electronic devices ${ }^{6,7}$. In this context, fundamental investigation of atomically precise and monodisperse graphene fragments ${ }^{8,9}$ is key for understanding the relationship between their properties and structural parameters like size, shape and edge topology ${ }^{10-13}$. Among the variety of graphene structures, open-shell graphene fragments ${ }^{14-17}$ have recently emerged as promising candidates for materials that can aid and abet the transformation of conventional electronics into spintronics ${ }^{18,19}$. It is envisioned that the spins of unpaired electrons in these materials can function as information carriers and spinbased devices made of these materials can meet the increasing demand for speed and miniaturization in information processing ${ }^{20,21}$. The main advantage of graphene-based materials over other materials like metals is the small spin-orbit coupling of carbon, a prerequisite for achieving long spin-state lifetimes at room temperature ${ }^{22,23}$.

Graphene fragments with two or more unpaired $\pi$-electrons belong to the family of the socalled non-Kekulé conjugated hydrocarbons ${ }^{24}$, which have less $\pi$-bonds than permitted by the standard rule of valence. They are characterized by zigzag edges and ground states of highest possible multiplicity. A prototypical textbook example is the smallest non-Kekule graphene fragment triangulene ${ }^{25,26}$, also known as Clar's hydrocarbon, comprised of six benzenoid rings fused in a triangular shape with three zigzag edges (Fig. 1a). Due to its symmetry, triangulene has two non-bonding molecular orbitals, each occupied by one electron, and a triplet ground state that conforms to Ovchinnikov's rule ${ }^{27}$, or Lieb's theorem ${ }^{28}$ (Fig. 1b). This rule can be applied to any conjugated hydrocarbon that does not possess an odd-membered ring to distinguish between a Kekulé or a non-Kekulé system ${ }^{29}$. The triplet ground state of triangulene is also predicted by multi-configurational calculations ${ }^{30}$, which estimate the energy difference between the triplet ground state and the first singlet excited state to be in the range 13-16 kcal $\mathrm{mol}^{-1}$. However, despite the efforts over the past 70 years, the triplet ground state nature of neutral triangulene has not been fully characterized. Majority of spin density in triangulene is localized at its zigzag edges ${ }^{31}$ (Fig. 1c), which results in its high reactivity. As a result, neither stable nor persistent derivatives of neutral triangulene have been synthesized so far. 
<smiles>c1cc2c3c(c1)Cc1cccc4cc5cccc(c5c-3c14)C2</smiles>

1953 - Clar's attempt 2017 - on surface

d<smiles>[O-]c1c2cccc3c([O-])c4cccc5c([O-])c6cccc1c6c5c4c23</smiles>

1993 - stable (oxygen-free solution)

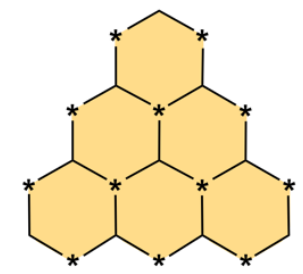

$N_{\mathrm{S}}=12$

$N_{\mathrm{u}}=10$<smiles></smiles>

2001 - detected (frozen matrix)

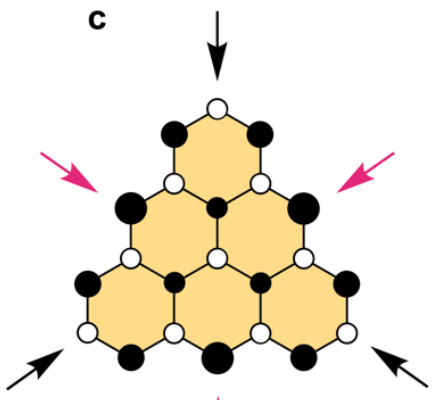

$\uparrow$

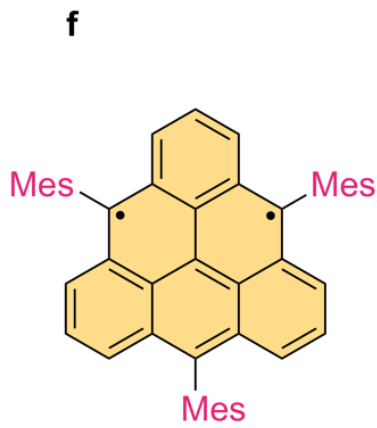

this work - persistent (oxygen-free solution)

Fig. 1 | Historical development of triangulene chemistry. a-c, Structure (a), application of Ovchinnikov's rule ${ }^{29}\left(\mathbf{b}, N_{\mathrm{s}}\right.$ and $N_{\mathrm{u}}=$ number of starred and unstarred atoms, respectively) and spin distribution (c) of triangulene. d-f, Structures of triangulene derivatives reported previously (d,e) and in this work (f).

The chemistry of non-Kekulé hydrocarbons was pioneered by Erich Clar (shown in the abstract graphic), who attempted the first synthesis of pristine triangulene in the early $1950 \mathrm{~s}^{25}$. Although he successfully prepared several direct precursors of triangulene, he could not isolate and characterize this elusive molecule. A possible strategy to thermodynamically stabilize triangulene is an introduction of heteroatom substituents which suppress its propensity toward oligomerization. This strategy was successfully employed by Bushby et al. via installment of oxy groups at the centers of the edges ${ }^{32,33}$ (Fig. 1d). The obtained diradical trianion was stable in oxygen-free solution at room temperature and its triplet ground state was confirmed by the detection of a half-field line in the continuous wave (cw) electron paramagnetic resonance (EPR) spectrum in a frozen matrix at $13 \mathrm{~K}$. Alternatively, introduction of steric hindrance can stabilize triangulene kinetically, which was demonstrated by Nakasuji et al. who installed bulky tert-butyl groups at the vertices of triangulene ${ }^{34}$ (Fig. 1e). Blocking the vertices was only partially successful because the most reactive positions (red arrows in Fig. 1c) remained 
exposed and oligomerization occurred even at temperatures below $0{ }^{\circ} \mathrm{C}$. The EPR characterization of the mixture was performed in frozen solution. Although the $D$ value estimated from the outer wings of the cw EPR spectrum is plausible for the triplet state of triangulene, a fully characterized and resolved EPR spectrum could not be obtained.

The latest advancement in the chemistry of triangulene was achieved on the grounds of recent developments in surface chemistry, which make it possible to synthesize and investigate unsubstituted molecules from the open-shell graphene family. Using this technology, Pavliček et al. synthesized in 2017 pristine triangulene on various surfaces under ultra-high vacuum conditions $^{35}$. Although it was shown that triangulene was formed and does not bond to the surface, using current technology it is not possible to determine the ground-state multiplicity of this molecule. Following this seminal work, the on-surface synthesis of $\pi$-extended [4]- ${ }^{36}$, $[5]-{ }^{37}$ and [7]triangulene ${ }^{38}$ homologs as well as $\pi$-extended triangulene structures, namely, $\operatorname{dimer}^{39}$, bowtie ${ }^{22}$ and a rhombus-shaped graphene fragment ${ }^{23}$, was accomplished. Most recently, Fasel et al. achieved the on-surface synthesis of a spin chain made of triangulene units as a model system to study correlations in quantum spin-liquid phases, demonstrating the possibility to implement measurement-based quantum computation ${ }^{40}$.

All of these achievements demonstrate the urgency for having access to persistent derivatives of triangulene, which can be investigated in solution and ultimately in the solid state and create an opportunity to employ triangulene and related structures as building blocks in materials for applications in the emerging fields of spintronics and quantum computing. In this work, we describe the synthesis of the first persistent derivative of triangulene and present a definitive experimental proof of its triplet ground state.

\section{Results and discussion}

Synthesis. We envisioned that bulky substituents installed in the centers of the edges would result in a sufficient steric protection of all nine reactive positions: the most reactive central (Fig. 1c, red arrows) as well as their neighboring positions. This substitution pattern should provide a persistent derivative that could be fully characterized in an oxygen-free solution at room temperature. We thus explored several approaches to achieve the synthesis of such a trisubstituted triangulene. The first approach ${ }^{41,42}$ relied on the use of triangulene-4,8-dione bearing one aryl substituent, readily available from a hydroxy derivative developed by Clar, and the second approach was based on the methodology developed by Johnson et al. $(2019)^{43}$. The details of these unsuccessful attempts are provided in the Supplementary Figs. 1 and 2. The third and successful approach was based on the method of Wu et al. (2019) ${ }^{37}$ employed in 
the preparation of a precursor for the on-surface synthesis of [5]triangulene. Applying this synthetic strategy, we installed three mesityl substituents in the centers of the triangulene edges (Fig. 1f). The mesityl groups are expected to be oriented almost perpendicularly to the triangulene plane, therefore, spin delocalization to the substituents as well as perturbation of the electronic structure of triangulene should be negligible.

The preparation of the target trisubstituted triangulene (Mes3-Tr, Fig. 1f) was achieved via the synthesis of its direct dihydro-precursor 1, obtained as a mixture of two isomers $\mathbf{1 a}$ and $\mathbf{1 b}$ featuring anthracene (1a) and [4]helicene (1b) substructures, respectively (Fig. 2).

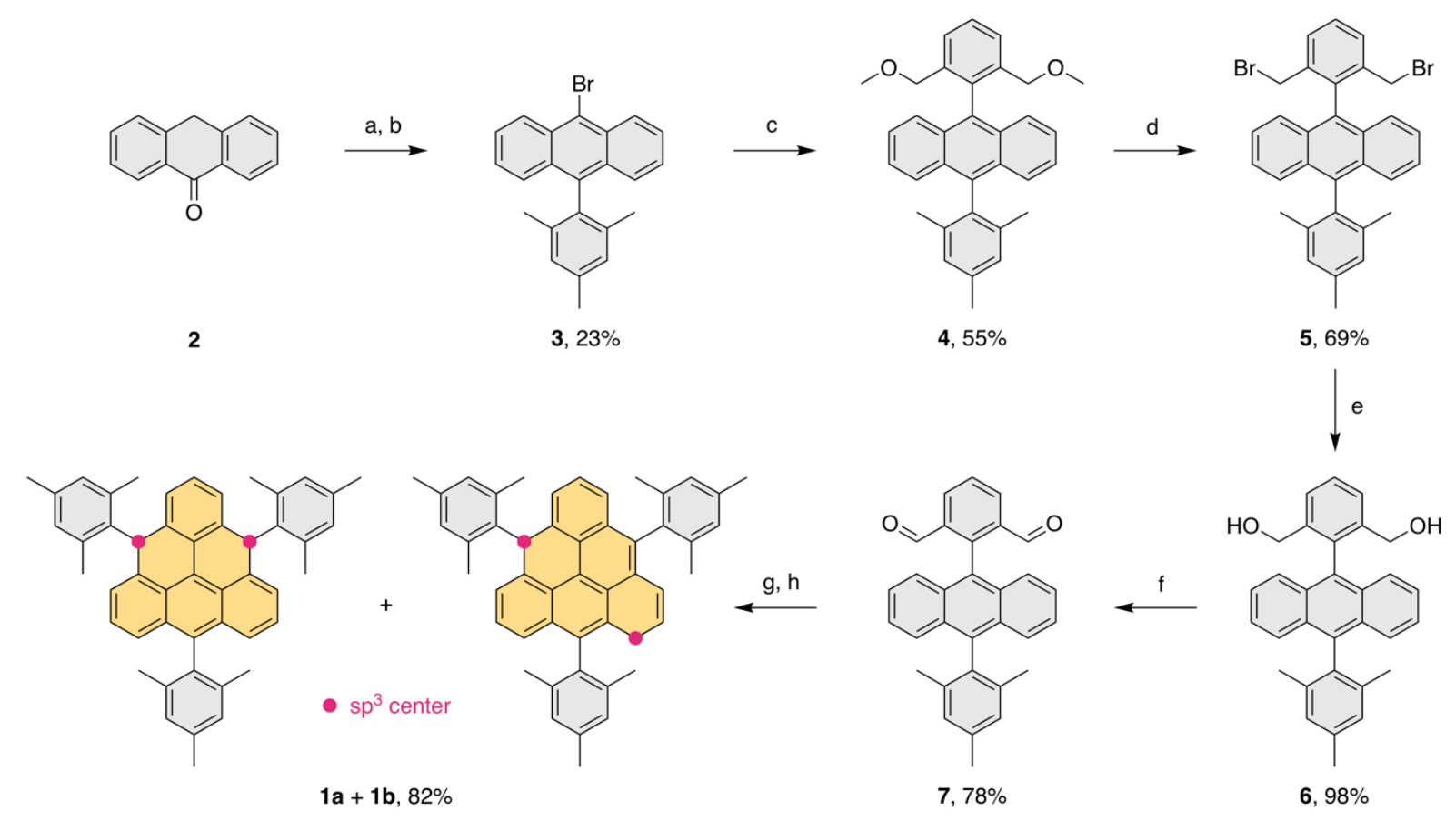

Fig. 2 Synthesis of the triangulene precursor. Reaction conditions: a) (i) MesMgBr, THF, $65^{\circ} \mathrm{C}$, (ii) aq. $\mathrm{HCl}, 65^{\circ} \mathrm{C}$, b) $\mathrm{NBS}, \mathrm{CHCl}_{3}, 60^{\circ} \mathrm{C}$, c) (2,6-bis(methoxymethyl)phenyl)-boronic acid, $\mathrm{K}_{2} \mathrm{CO}_{3}, \mathrm{Pd}_{2} \mathrm{dba}_{3}$, DPEPhos, toluene/ethanol/water, $100{ }^{\circ} \mathrm{C}$, d) $33 \% \mathrm{HBr}$ in $\mathrm{CH}_{3} \mathrm{COOH}$, $\mathrm{DCM}$, rt, e) (i) $\mathrm{CH}_{3} \mathrm{COOK}, \mathrm{TBABr}, \mathrm{DMF}, 100^{\circ} \mathrm{C}$, (ii) $\left.\mathrm{KOH}, \mathrm{THF}, 80^{\circ} \mathrm{C}, \mathrm{f}\right)(\mathrm{COCl})_{2}, \mathrm{DMSO}$, $\mathrm{NEt}_{3}, \mathrm{DCM},-78^{\circ} \mathrm{C}$ to rt, g) $\mathrm{MesMgBr}$, THF, $\left.0{ }^{\circ} \mathrm{C}, \mathrm{h}\right) \mathrm{BF}_{3} \cdot \mathrm{Et}_{2} \mathrm{O}, \mathrm{DCM}$, rt.

The preparation of $\mathbf{1}$ involved two key building blocks: 9-bromo-10-mesitylanthracene (3) and (2,6-bis(methoxymethyl)phenyl)boronic acid. The latter was obtained by following a previously reported procedures ${ }^{44,45}$. Anthracene derivative 3 was synthesized via a nucleophilic addition of mesitylmagnesium bromide to anthrone (2; step a), followed by the in-situ elimination of water and electrophilic bromination (step b). The boronic acid and $\mathbf{3}$ were combined in the Suzuki cross-coupling reaction yielding intermediate 4 (step c). Dialdehyde 
intermediate 7 was prepared in three steps from 4, including the substitution of the methoxy groups with bromide (d), substitution of bromides with acetate followed by ester hydrolysis (e) and Swern oxidation (f). Upon the addition of mesitylmagnesium bromide (step g), the formed dialcohol underwent a Lewis acid-catalyzed cyclization toward dihydro-triangulenes 1a and $\mathbf{1 b}$ (step h), with 1a being the major isomer. Based on DFT which predicts $\mathbf{1 b}$ to be more stable by $\sim 7 \mathrm{kcal} \mathrm{mol}^{-1}$, the composition of the isomeric mixture suggests that the final cyclization step proceeds under kinetic control ${ }^{35,42}$.

UV-vis spectroscopy. The final oxidation to generate $\mathbf{M e s}_{3}$ - $\mathbf{T r}$ was performed with a $2.5 \mathrm{mM}$ toluene solution of 1 with 5 equivalents of $p$-chloranil, which was diluted prior to the UV-vis measurements. The sample was sufficiently stable to be handled outside the glovebox using routine Schlenk techniques and deoxygenated solvents.

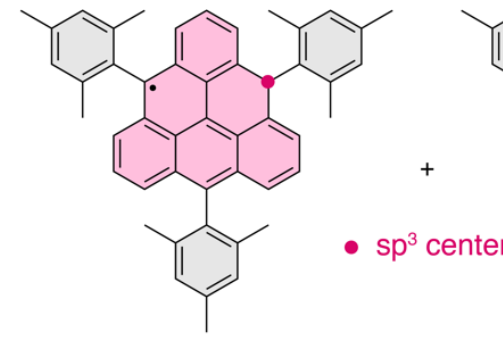

$8 a$

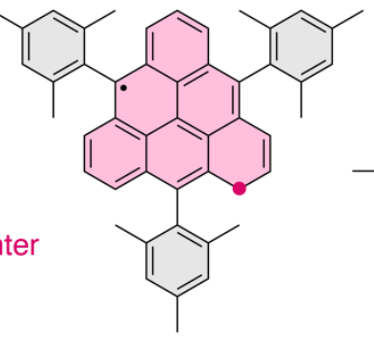

$8 b$

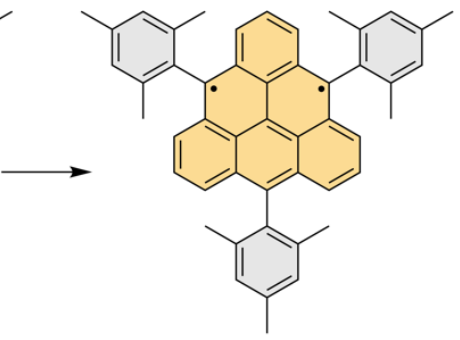

$\mathrm{Mes}_{3}-\mathrm{Tr}$

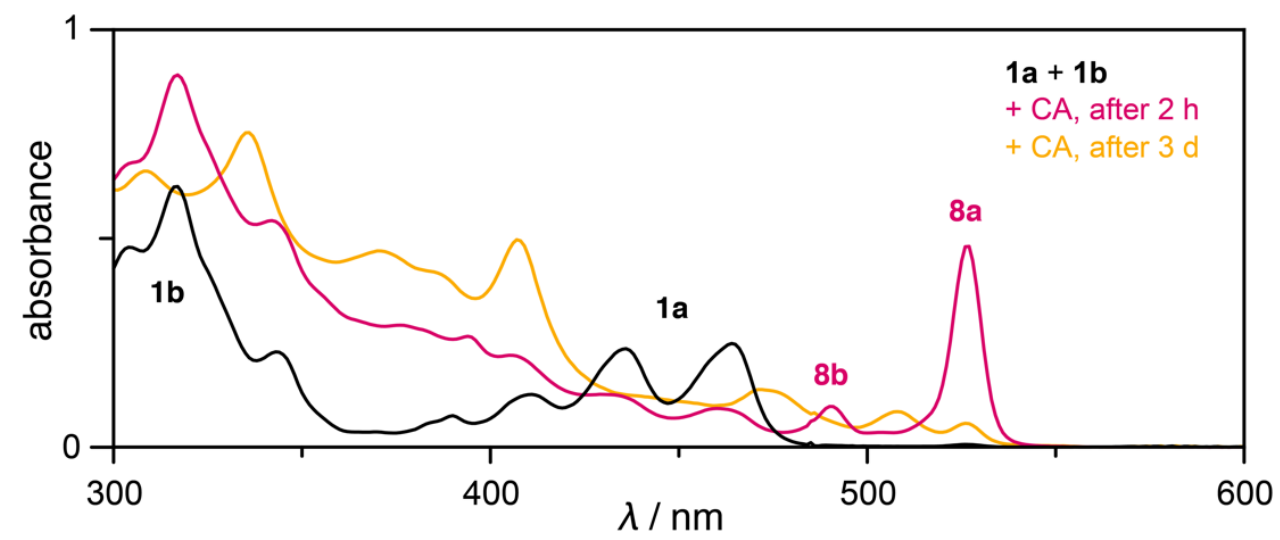

Fig. 3 | Generation of triangulene monoradical and diradical. UV-vis spectra recorded during the oxidation process for toluene solutions of a dihydro-precursor mixture $\mathbf{1 a}+\mathbf{1 b}$ (black trace) with 5 equivalents of $p$-chloranil (CA), providing, after 2 hours, a mixture of monoradical species $\mathbf{8 a}+\mathbf{8 b}$ (red trace) and, after 3 days, the diradical species $\mathbf{M e s}_{3}$ - $\mathbf{T r}$ (yellow trace) together with the excess $\mathrm{CA}$ and formed reduced CA. The oxidation was performed at a concentration of $2.5 \mathrm{mM}$. For the UV-vis measurements, an aliquot sample of this solution was diluted to $2.5 \times 10^{-5} \mathrm{M}$. 
The UV-vis spectrum of $\mathbf{1}$ shows two distinct absorption bands, which can be clearly assigned to 1a and 1b (Fig. 3 and Supplementary Fig. 3) based on the TD-DFT calculations (Supplementary Tables 5 and 6). Isomer 1a shows the characteristic vibronic progression of an anthracene subunit (Supplementary Fig. 4) shifted bathochromically due to an additional coplanar benzene ring in the triangulene core. The oxidation of 1 provided initially a mixture of two monoradical species 8 (Fig. 3). While 8a can be formed from both 1a and 1b, monoradical $\mathbf{8 b}$ ensues only from oxidation of $\mathbf{1 b}$. According to the maximum intensity of the characteristic absorption bands $(527 \mathrm{~nm}, \mathbf{8 a}$ and $490 \mathrm{~nm}, \mathbf{8 b})$ that match the TD-TDF calculations (Supplementary Tables 7 and 8) well, the concentration of both monoradicals 8 reached a maximum in 2 hours and then decreased as $\mathbf{M e s}_{3}-\mathbf{T r}$ was formed.

X-ray diffraction. The structure of the triangular core functionalized at the centers of the edges was unambiguously confirmed by X-ray diffraction analysis of single crystals of monoradical 8a, which were obtained by slow evaporation of pentane under ambient conditions. In the solidstate structure of 8a (Fig. 4), the triangulene core is almost completely planar and the mesityl groups are oriented perpendicularly to the triangulene plane. The experimental bond lengths are in good agreement with those obtained from DFT calculations (Supplementary Table 2).
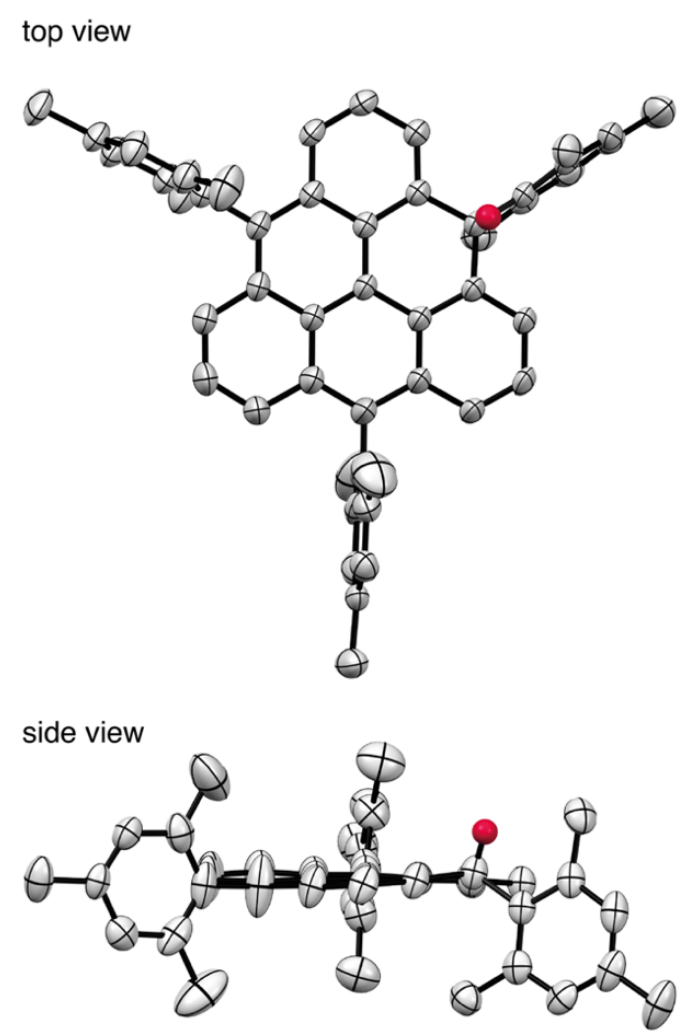

Fig. 4 | Crystallographic characterization of triangulene monoradical. The solid-state structure of monoradical 8a. Thermal ellipsoids are shown at the 50\% probability level. The hydrogen atoms are omitted for clarity except for the $\mathrm{C}_{\mathrm{sp} 3}$ hydrogen atom highlighted in red. 
EPR spectroscopy. To characterize the magnetic properties of the species created after chemical oxidation of $\mathbf{1 a}+\mathbf{1 b}$, EPR experiments were carried out. Figure 5a,b shows the continuous wave EPR spectra measured at the X-band $(9.75 \mathrm{GHz})$ at room temperature at different times after addition of one equivalent of $p$-chloranil to a $0.5 \mathrm{mM}$ solution of $\mathbf{1 a}+\mathbf{1 b}$ in toluene. Both spectra exhibit a width of roughly $3.5 \mathrm{mT}$ and are characterized by a pronounced hyperfine structure originating from the coupling of unpaired electron spin(s) to the protons of the structure. The isotropic $g$ value is very similar in both cases and amounts to 2.0025 and 2.0027, respectively. Details on the sample preparation, experimental setup, and data treatment are given in the Methods section and Supplementary Information.
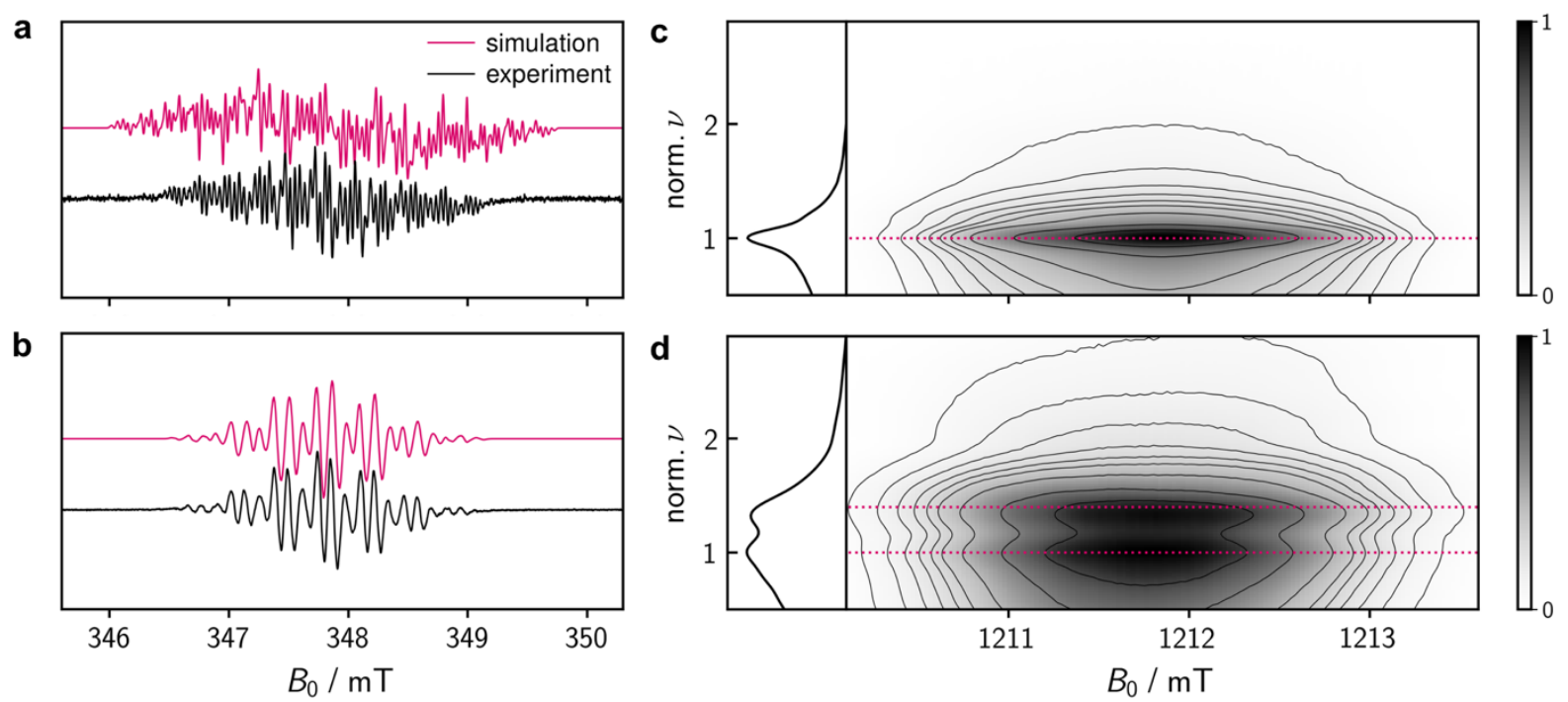

Fig. 5 | EPR characterization of the mono- and diradical species. Monoradical mixture 8a

$+\mathbf{8 b}$ and diradical Mes$_{3}$-Tr formed after chemical oxidation of solutions of a dihydroprecursor mixture $(\mathbf{1 a}+\mathbf{1 b})$ in toluene using $p$-chloranil. a,b, Room temperature cw EPR spectra of a $0.5 \mathrm{mM}$ solution in toluene after addition of 1 equivalent of the oxidant recorded at the X-band about 2 hours (a) and 6 hours (b) after oxidant addition together with a numerical simulation of the data using hyperfine couplings obtained from DFT calculations. c,d, Transient nutation data recorded at the Q-band on frozen solutions $(120 \mathrm{~K})$ of a $2.5 \mathrm{mM}$ solution in toluene shortly after addition of either 0.1 (c) or 5 (d) equivalents of the oxidant. The horizontal dotted lines indicate the expected normalized frequencies of 1.0 for a doublet state (monoradical) and $\sqrt{2}$ for a triplet state (diradical).

When only a short waiting time after oxidant addition was employed or small amounts of the oxidant were added (Fig. 5a), the cw EPR spectrum was found to consist of a range of very narrow lines with an average peak separation of $\sim 0.04 \mathrm{mT}$. In line with our expectations, this spectrum shows close resemblance with the cw EPR spectrum reported previously for the 
monoradical of triangulene with three tert-butyl substituents installed at the vertices ${ }^{34}$ and is therefore assigned to the monoradical species $\mathbf{8 a}+\mathbf{8 b}$. Addition of a large excess of $p$-chloranil or prolonged oxidation time resulted in a different hyperfine pattern indicating the formation of a different species (Fig. 5b). Its symmetric cw EPR spectrum is characterized by much fewer well-resolved lines with an average peak separation of approximately $0.12 \mathrm{mT}$. In a sealed tube, free from oxygen and moisture, this signal was then stable over a time span of at least several days. We tentatively assign the observed spectrum to $\mathbf{M e s}_{3}-\mathbf{T r}$, which is expected to be formed after two-fold oxidation.

To support the tentative assignment of the two measured EPR spectra to the monoradical and triplet diradical species, DFT calculations of the corresponding spin densities and hyperfine coupling constants were carried out using the ORCA program package (Version 4.0) ${ }^{46}$. Details on these calculations are given in the Methods section and Supplementary Information, together with an illustration of the spin densities and an assignment of the hyperfine couplings to the individual protons of the structure. We then simulated the expected EPR spectra only based on the computed isotropic hyperfine coupling constants using the 'pepper' routine ${ }^{47}$ of EasySpin $^{48}$. All calculated couplings smaller than $0.5 \mathrm{MHz}$ were neglected as they are not resolved in the experimental spectra and only contribute to the linewidth. The resulting simulations are shown in Fig. 5a,b and details on the simulations as well as a table with all calculated hyperfine values that were considered in the simulations are presented in the Supplementary Information. When applying a global scaling factor of 0.93 to all calculated proton couplings for the triplet diradical, a near perfect match with the experimental spectrum was obtained (Fig. 5b), strongly supporting our assignment and therefore the triplet nature of Mes $_{3}$-Tr. The simulation of the monoradical spectrum is less straightforward since two different isomers are expected to contribute and it is difficult to determine their ratio. For the simulation of the mixture of monoradicals $\mathbf{8 a}+\mathbf{8 b}$, a ratio of 50:50 was assumed. Although the agreement is not perfect, the size of the hyperfine couplings and main features of the monoradical spectrum are well reproduced (Fig. 5a).

As an additional proof for the assignment of the spectrum in Fig. $5 \mathrm{~b}$ to the triplet diradical Mes $_{3}$-Tr, transient nutation experiments were performed on two different samples of an oxidized mixture of $\mathbf{1 a}+\mathbf{1 b}$ in frozen toluene at $120 \mathrm{~K}$. The measurements were performed at Q-band frequencies $(34.0 \mathrm{GHz})$ using the microwave pulse sequence $\xi-\tau-\pi-\tau-$ echo, with $\tau=140 \mathrm{~ns}$ and $\pi=40 \mathrm{~ns}$, where the flip angle $\xi$ was gradually increased by increasing the corresponding microwave pulse length in steps of $2 \mathrm{~ns}$, starting at $20 \mathrm{~ns}$, that is, $\frac{\pi}{2}$. For every 
magnetic field position, the obtained time traces were subjected to a Fourier transform to yield the frequency maps for 0.1 (Fig. 5c) and 5 equivalents (Fig. 5d) of the oxidant. The sample with 5 equivalents of $p$-chloranil was frozen shortly after oxidant addition to make sure that a mixture of $\mathbf{8}$ and the putative Mes3-Tr is obtained. The contribution of the signal of 8 (pure doublet species) is used here as an internal standard to obtain the reference frequency $\omega_{0}$, needed for a correct normalization of the frequency axis for determination of the spin multiplicity of Mes3-Tr. For a triplet state, a frequency of $\sqrt{2} \omega_{0}$ would be expected according to $\omega_{m_{S}, m_{S}+1}=\omega_{0} \cdot \sqrt{S(S+1)-m_{S}\left(m_{S}+1\right)},{ }^{49-51}$ which is in perfect agreement with our experimental observations, as graphically illustrated in Fig. 5d (horizontal dotted lines). This result can be considered an unambiguous proof of the triplet nature of the triangulene diradical Mes;-Tr. In addition, variable-temperature cw EPR measurements of Mes3-Tr in frozen toluene in the range 120-170 $\mathrm{K}$ showed that the signal intensity decreases with increasing temperature (Supplementary Fig. 8), strongly suggesting that the triplet is the ground state. It is noteworthy that $\mathbf{M e s}_{3}$ - Tr is a rare example of a purely organic triplet diradical, where the triplet state could be detected in isotropic solution at room temperature. The reason might be the scarcity of persistent non-Kekule diradicals prepared until now, which underlines the urgency for the development of synthetic methodologies toward this untamed class of molecules.

\section{Conclusion}

On account of high reactivity, the chemistry of triangulene diradical has until now been limited to ultra-high vacuum and low-temperature conditions. In this work, we presented the first persistent derivative of this iconic non-Kekulé hydrocarbon and the first persistent non-Kekulé hydrocarbon diradical in general ${ }^{34,52}$. The high kinetic stability of this compound at room temperature was achieved via installment of bulky mesityl substituents in the centers of its edges, which sterically shield all nine reactive positions of the triangulene core. The persistence effect of the substituents was demonstrated in solution and by isolation of the monoradical species in the solid state and confirmation of the structure of the functionalized triangulene core by X-ray diffraction. The triplet ground state of triangulene, predicted by Ovchinnikov's rule and multi-configurational calculations, was unambiguously proven by means of continuous wave, pulse and variable-temperature electron paramagnetic resonance spectroscopy. Our results provide an answer to a long-standing question dating back almost 70 years ago. We believe that these findings will set the cornerstone for future developments in the emerging field of spintronics based on carbon materials. 


\section{Methods}

X-ray diffraction. Single-crystal X-ray diffraction data were collected at 160(1) K on a Rigaku OD Synergy/Pilatus detector diffractometer using $\mathrm{Cu} \mathrm{K}_{\alpha}$ radiation $(\lambda=1.54184 \AA)$ from a micro-focus X-ray source and an Oxford Instruments Cryojet XL cooler. The selected suitable single crystal was mounted using polybutene oil on a flexible loop fixed on a goniometer head and immediately transferred to the diffractometer. Pre-experiment, data collection, data reduction and analytical absorption correction ${ }^{53}$ were performed with the program suite CrysAlisPro ${ }^{54}$. Using Olex2 ${ }^{55}$, the structure was solved with the SHELXT ${ }^{56}$ small molecule

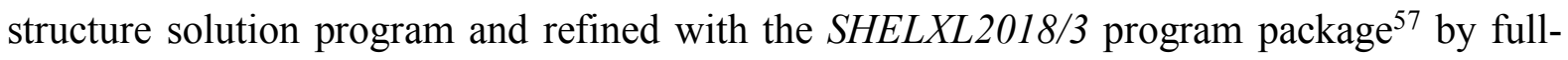
matrix least-squares minimization on $\mathrm{F}^{54} . P L A T O N^{58}$ was used to check the result of the X-ray analysis. For more details about the data collection and refinement parameters, see the CIF file. A solvent mask ${ }^{59}$ was calculated and 123 electrons corresponding to solvent molecules were found per unit cell. We considered one molecule of pentane per asymmetric unit.

UV-vis sample preparation. A mixture of $\mathbf{1 a}+\mathbf{1 b}(2.4 \mathrm{mg}, 3.8 \mu \mathrm{mol})$ and $p$-chloranil (4.6 $\mathrm{mg}, 19 \mu \mathrm{mol}, 5$ equiv) were placed into a Schlenk tube and the atmosphere was exchanged three times with nitrogen. Then, toluene $(1.5 \mathrm{~mL})$ deoxygenated by freeze-pump-thaw technique in three cycles was added. For the measurements, an aliquot sample $(30 \mu \mathrm{L})$ was diluted with deoxygenated toluene $(3.0 \mathrm{~mL})$ to a concentration of $2.5 \times 10^{-5} \mathrm{M}$ in an argonflushed fluorescence cuvette equipped with a septum.

EPR sample preparation. A mixture of $\mathbf{1 a}+\mathbf{1 b}(0.4 \mathrm{mg}, 0.6 \mu \mathrm{mol})$ and $p$-chloranil $(0.8 \mathrm{mg}$, $3 \mu \mathrm{mol}, 5$ equivalents) were placed into separate vials with a screw-cap septum under ambient conditions. The septa were pierced with a needle and the vials were transferred into the glovebox, where $p$-chloranil was dissolved in deoxygenated toluene $(250 \mu \mathrm{L})$ and then transferred into the vial with $\mathbf{1 a}+\mathbf{1 b}$. The reaction mixture was gently shaken, and after about 30 min the solution was transferred into a quartz EPR tube, which was then sealed with Critoseal ${ }^{\circledR}$. Note that the described procedure applies to samples with a concentration of $2.5 \mathrm{mM}$. For different concentrations, the amount of solvent was adapted accordingly. For EPR measurements at the X-or Q-band, quartz EPR tubes with an outer diameter of $3.8 \mathrm{~mm}$ (inner diameter of $\sim 3 \mathrm{~mm}, 125 \mu \mathrm{L}$ of sample solution) or $1.6 \mathrm{~mm}$ (inner diameter of $\sim 1 \mathrm{~mm}, 15 \mu \mathrm{L}$ of sample solution), respectively, were used. For measurements at cryogenic temperatures, the EPR samples were rapidly frozen in liquid nitrogen before insertion into the EPR resonator.

Continuous wave EPR spectroscopy. X-band continuous wave EPR spectra were recorded on a Bruker EMXnano benchtop EPR spectrometer. The modulation frequency was set to 
$100 \mathrm{kHz}$ and the modulation amplitude to $0.01 \mathrm{mT}$ unless stated otherwise. The microwave power was adjusted for every sample to avoid saturation effects. At room temperature, a value of $0.063 \mathrm{~mW}(32 \mathrm{~dB}, 100 \mathrm{~mW}$ source) was found to be optimal, while much lower powers $(0.0025 \mathrm{~mW}$, corresponding to $46 \mathrm{~dB})$ were necessary at $120 \mathrm{~K}$. Room temperature cw EPR measurements at Q-band frequencies were performed on a Bruker ELEXSYS E580 spectrometer using an EN 5107D2 resonator. The modulation frequency was set to $50 \mathrm{kHz}$ and the modulation amplitude to $0.03 \mathrm{mT}$ ( $32 \mathrm{~dB}$ microwave attenuation). After data acquisition, all spectra were baseline-corrected, frequency-corrected to either $9.75 \mathrm{GHz}$ (X-band) or 34.0 GHz (Q-band) and field-corrected using a carbon fiber standard with $g=2.002644 .{ }^{60}$ The $g$ value was calculated from the center of the experimental spectrum according to $g=\frac{h \cdot v}{\beta_{e} B_{0}}$ and further confirmed by numerical simulation of the spectra using EasySpin functions in MATLAB as detailed below.

Continuous wave EPR simulation procedure. For the simulations of the $\mathrm{cw}$ EPR spectra, the calculated hyperfine coupling constants from DFT (cf. Supplementary Table 10) were taken as the basis. Only couplings larger than $0.5 \mathrm{MHz}$ were considered as only these are resolved in the experimental spectra. An empirically determined scaling factor of 0.93 was applied to all calculated isotropic hyperfine coupling constants since this was found to yield the best agreement with the experimental data. The application of a global scaling factor is also in line with the observation in the literature that hyperfine coupling constants computed by DFT are typically in good agreement with the experiment, but are frequently slightly overestimated ${ }^{61}$. The simulations were carried out using the EasySpin routine 'pepper' (instead of 'garlic'). This choice, unusual for the simulation of isotropic cw EPR spectra, was motivated by the fact that common simulation routines for fast motion EPR spectra rely on the Kivelson formulas (for anisotropic linewidths), implying that only systems with $S=0.5$ can be accounted for. Since the 'pepper' routine cannot account for equivalent nuclei, all calculated isotropic hyperfine couplings larger than $0.5 \mathrm{MHz}$ were entered as computed and later multiplied by the scaling factor. The isotropic $g$ value obtained from DFT was adapted slightly to best match the experimental spectrum and an appropriate linewidth $(\sim 0.03-0.04 \mathrm{mT})$ was chosen to account for unresolved hyperfine couplings. Since between 14 and 18 individual protons needed to be considered, it became computationally too expensive to treat all hyperfine couplings exactly, using matrix diagonalization. Instead, matrix diagonalization was only applied for the nuclei with the six largest hyperfine couplings; all other nuclei were treated using perturbation theory, making use of the 'hybrid' method in EasySpin. 
Pulse EPR spectroscopy. The pulse EPR measurements were carried out on a Bruker ELEXSYS E580 spectrometer operated at the Q-band, equipped with an EN 5107D2 resonator. During the measurement, the sample was kept at a constant temperature of $120 \mathrm{~K}$, using an Oxford Instruments nitrogen gas-flow cryostat (CF 935).

Transient nutations. Transient nutation measurements used the microwave pulse sequence $\xi-\tau-\pi-\tau-$ echo where the flip angle $\xi$ was gradually increased by increasing the corresponding microwave pulse length in steps of $2 \mathrm{~ns}$, starting at $20 \mathrm{~ns}$ (i.e., $\frac{\pi}{2}$ ). At every magnetic field position within the region of the EPR spectrum, the integrated echo intensity was then recorded as a function of this pulse length. The magnetic field step size was set to $0.25 \mathrm{G}$ (field scan range of $50 \mathrm{G}, 200$ points). The whole data set was background corrected using a polynomial background function. The (cross-term averaged) Fourier transform was then calculated after dead time reconstruction, windowing using a Hamming window, and zero filling to 2000 data points. The frequency spectra were normalized by division of the frequency axis by the reference frequency obtained for a species with doublet multiplicity $(\mathbf{8 a}$ and $\mathbf{8 b})$. The 2D-data set of the frequency spectra as a function of field is shown in Fig. 5.

DFT calculations of electronic transitions and relative energies. Calculations for the triangulene precursors $\mathbf{1}$, the generated monoradicals $\mathbf{8}$ and triangulene were performed with the Gaussian 09 (Revision D.01) ${ }^{62}$ suite of electronic structure programs. The geometries of the individual molecules were simplified by replacing the mesityl groups by hydrogen atoms. In addition, a pair of molecules with mesityl groups, $\mathbf{1} \mathbf{a}$ and $\mathbf{1 b}$, were calculated to validate the effect of the peripheral substituents on the electronic transitions. The geometries were optimized at the B3LYP/6-31G(d) level of theory with the standard ultrafine integration grid. In the case of $\mathbf{1 a}$ and $\mathbf{1 b}$, a finer integration grid (Superfine grid in Gaussian) was necessary to converge the optimization process to the local minimum. This grid was then used for all calculations of molecules with mesityl groups. The unrestricted formalism was used in calculations of open-shell molecules (doublet and triplet states). A frequency analysis was performed to confirm that the located stationary points represented local energy minima. Single point energies were computed with the B3LYP functional and cc-pVTZ basis set, the level of theory that successfully reproduced the experimental relative energies of $\mathbf{1} \mathbf{a}^{\prime}$ and $\mathbf{1} \mathbf{b}^{\prime}$ (for structures, see Supplementary Tables 3 and 4) determined previously ${ }^{42}$. The reported final energies are at $0 \mathrm{~K}$, that is, they represent the sum of the electronic energy and the zero-point vibrational energy correction. The latter was used unscaled. The electronic transitions were estimated with time-dependent DFT using B3LYP, PBE0 and BMK functionals and the 
6-31G(d) basis set, considering 30 transitions to reduce the integration noise in the important low-energy excitations. Transitions with oscillator strengths $f>0.01$ are reported unless stated otherwise. We found that the mesityl groups do not significantly affect either the energies or the oscillator strengths of individual electronic transitions in the triangular chromophores of $\mathbf{1}$, 8 or triangulene.

DFT calculations of hyperfine coupling constants and spin densities. Calculations for the generated monoradicals 8 and the triplet diradical Mes3-Tr were performed using the ORCA program package (Version 4.0). For the calculation of the spin densities, the structures were first optimized in their doublet or triplet ground states using the B3LYP functional in combination with the def2-TZVP basis set. The RI approximation was employed (RIJCOSX) using the def2/J auxiliary basis set. Magnetic property calculations in the doublet or triplet states used the B3LYP functional in combination with the EPR-II basis set.

\section{Data availability}

Crystallographic data for the structures in this Article have been deposited at the Cambridge Crystallographic Data Centre (CCDC) under deposition no. 2104838 (8a). Copies of data can be obtained free of charge from www.ccdc.cam.ac.uk/structures/. All other data supporting the findings of this study are available within the Article and its Supplementary Information.

\section{Acknowledgements}

This project received funding from the European Research Council (ERC) under the European Union's Horizon 2020 research and innovation programme (Grant Agreement No. 716139), the Swiss National Science Foundation (SNSF, T.Š./PZ00P2_174175, M.J./PZ00P2_148043, PP00P2_170534, PP00P2_198900), and the Deutsche Forschungsgemeinschaft (DFG, German Research Foundation) through Project No. 417643975 (S.R.). The authors acknowledge support by the state of Baden-Württemberg through bwHPC, the German Research Foundation (DFG) through grant number INST 40/575-1 FUGG (JUSTUS 2 cluster), and the Computational Resources on SciCore, the high-performance computing cluster of the University of Basel. We would like to thank Prof. Alan Cooper (University of Glasgow) for providing us with the original photograph of Erich Clar, Prof. Gunnar Jeschke (ETH Zurich) for performing initial EPR experiments, and Gauthier Desmaizieres and Prof. Birgit Esser (University of Freiburg) for access to their glovebox. 


\section{Author contributions}

L.V., T.ŠS., S.R. and M.J. conceived the project, designed the experiments and analyzed the results. L.V. and P.K. synthesized and characterized all compounds. L.V. prepared samples for spectroscopic measurements and performed UV-vis measurements. M.M. and S.R. performed EPR measurements and data analysis. T.S. and S.R. performed DFT calculations. O.B. performed X-ray diffraction analysis. L.V., S.R. and M.J. co-wrote the manuscript with contributions from all authors.

\section{Competing interests}

The authors declare no competing interests.

\section{Additional information}

Correspondence and requests for materials should be addressed to T.Š., S.R. and M.J.

\section{References}

1. Novoselov, K. S. et al. Electric field effect in atomically thin carbon films. Science 306, 666-669 (2004).

2. Geim, A. K. \& Novoselov, K. S. The rise of graphene. Nat. Mater. 6, 183-191 (2007).

3. Castro Neto, A. H., Guinea, F., Peres, N. M. R., Novoselov, K. S. \& Geim, A. K. The electronic properties of graphene. Rev. Mod. Phys. 81, 109-162 (2009).

4. Zhu, Y. et al. Graphene and graphene oxide: synthesis, properties, and applications. Adv. Mater. 22, 3906-3924 (2010).

5. Singh, V. et al. Graphene based materials: past, present and future. Prog. Mater. Sci. 56, 1178-1271 (2011).

6. Yamaguchi, J. et al. Small bandgap in atomically precise 17-atom-wide armchairedged graphene nanoribbons. Commun. Mater. 1, 36 (2020).

7. Yano, Y., Mitoma, N., Ito, H. \& Itami, K. A quest for structurally uniform graphene nanoribbons: synthesis, properties, and applications. J. Org. Chem. 85, 4-33 (2020).

8. Segawa, Y., Ito, H. \& Itami, K. Structurally uniform and atomically precise carbon nanostructures. Nat. Rev. Mater. 1, 15002 (2016).

9. Xu, X., Müllen, K. \& Narita, A. Syntheses and characterizations of functional polycyclic aromatic hydrocarbons and graphene nanoribbons. Bull. Chem. Soc. Jpn. 93, 490-506 (2020).

10. Nakada, K., Fujita, M., Dresselhaus, G. \& Dresselhaus, M. S. Edge state in graphene 
ribbons: nanometer size effect and edge shape dependence. Phys. Rev. B 54, 1795417961 (1996).

11. Enoki, T., Kobayashi, Y. \& Fukui, K.-I. Electronic structures of graphene edges and nanographene. Int. Rev. Phys. Chem. 26, 609-645 (2007).

12. Brey, L. \& Fertig, H. A. Edge states and the quantized Hall effect in graphene. Phys. Rev. B 73, 195408 (2006).

13. Brey, L. \& Fertig, H. A. Electronic states of graphene nanoribbons studied with the Dirac equation. Phys. Rev. B 73, 235411 (2006).

14. Morita, Y., Suzuki, S., Sato, K. \& Takui, T. Synthetic organic spin chemistry for structurally well-defined open-shell graphene fragments. Nat. Chem. 3, 197-204 (2011).

15. Zeng, W. \& Wu, J. Open-shell graphene fragments. Chem 7, 358-386 (2021).

16. Liu, J. \& Feng, X. Synthetic tailoring of graphene nanostructures with zigzag-edged topologies: progress and perspectives. Angew. Chem. Int. Ed. 59, 23386-23401 (2020).

17. Morita, Y. \& Nishida, S. Phenalenyls, cyclopentadienyls, and other carbon-centered radicals. Stable Radicals: Fundamentals and applied aspects of odd-electron compounds. 81-145 (John Wiley \& Sons, Ltd, 2010).

18. Žutić, I., Fabian, J. \& Das Sarma, S. Spintronics: fundamentals and applications. Rev. Mod. Phys. 76, 323-410 (2004).

19. Bullard, Z., Girão, E. C., Owens, J. R., Shelton, W. A. \& Meunier, V. Improved allcarbon spintronic device design. Sci. Rep. 5, 7634 (2015).

20. Sato, K. et al. Molecular electron-spin quantum computers and quantum information processing: pulse-based electron magnetic resonance spin technology applied to matter spin-qubits. J. Mater. Chem. 19, 3739-3754 (2009).

21. Chappert, C., Fert, A. \& Van Dau, F. N. The emergence of spin electronics in data storage. Nat. Mater. 6, 813-823 (2007).

22. Mishra, S. et al. Topological frustration induces unconventional magnetism in a nanographene. Nat. Nanotechnol. 15, 22-28 (2020).

23. Mishra, S. et al. Large magnetic exchange coupling in rhombus-shaped nanographenes with zigzag periphery. Nat. Chem. 13, 581-586 (2021).

24. Minkin, V. I. Glossary of terms used in theoretical organic chemistry. Pure Appl. Chem. 71, 1919-1981 (1999).

25. Clar, E. \& Stewart, D. G. Aromatic hydrocarbons. LXV. Triangulene derivatives. Part I. J. Am. Chem. Soc. 75, 2667-2672 (1953). 
26. Clar, E. \& Stewart, D. G. Aromatic hydrocarbons. LXVIII. Triangulene derivatives. Part II. J. Am. Chem. Soc. 76, 3504-3507 (1954).

27. Ovchinnikov, A. A. Multiplicity of the ground state of large alternant organic molecules with conjugated bonds. Theor. Chim. Acta 47, 297-304 (1978).

28. Lieb, E. H. Two theorems on the Hubbard model. Phys. Rev. Lett. 62, 1201 (1989).

29. Following this rule, a star is placed on alternating $\mathrm{sp}^{2}$-carbon atoms in such a way that no two starred or unstarred atoms are adjacent. When the number of starred $\left(N_{\mathrm{s}}\right)$ and unstarred $\left(N_{\mathrm{u}}\right)$ carbon atoms is equal $\left(N_{\mathrm{s}}=N_{\mathrm{u}}\right)$, a Kekulé system is obtained, for which at least one Kekulé resonance structure with all electrons paired can be drawn. When $N_{\mathrm{s}}>N_{\mathrm{u}}$, it is not possible to draw a standard Kekulé resonance structure and these molecules are classified as non-Kekulé. In these systems, the number of unpaired electrons occupying nonbonding molecular orbitals is equal to $N_{\mathrm{s}}-N_{\mathrm{u}}$ and the ground state is of highest possible multiplicity, $S=\left(N_{\mathrm{s}}-N_{\mathrm{u}}\right) / 2$, satisfying Hund's rule. In the case of triangulene, the "star rule" gives $N_{\mathrm{s}}=12$ and $N_{\mathrm{u}}=10$ (Fig. 1b) and predicts two non-bonding orbitals, each occupied by one electron, and thus a triplet ground state $(S=1)$.

30. Das, A., Müller, T., Plasser, F. \& Lischka, H. Polyradical character of triangular nonKekulé structures, zethrenes, $p$-quinodimethane-linked bisphenalenyl, and the Clar goblet in comparison: an extended multireference study. J. Phys. Chem. A 120, 16251636 (2016).

31. Ortiz, R. et al. Exchange rules for diradical $\pi$-conjugated hydrocarbons. Nano Lett. 19, 5991-5997 (2019).

32. Allinson, G., Bushby, R. J., Paillaud, J. L., Oduwole, D. \& Sales, K. ESR spectrum of a stable triplet $\pi$ biradical: trioxytriangulene. J. Am. Chem. Soc. 115, 2062-2064 (1993).

33. Allinson, G., Bushby, R. J., Paillaud, J.-L. \& Thornton-Pett, M. Synthesis of a derivative of triangulene; the first non-Kekulé polynuclear aromatic. J. Chem. Soc. Perkin Trans. I 4, 385-390 (1995).

34. Inoue, J. et al. The first detection of a Clar's hydrocarbon, 2,6,10-tri-tertbutyltriangulene: a ground-state triplet of non-Kekulé polynuclear benzenoid hydrocarbon. J. Am. Chem. Soc. 123, 12702-12703 (2001).

35. Pavliček, N. et al. Synthesis and characterization of triangulene. Nat. Nanotechnol. 12, 308-311 (2017). 
36. Mishra, S. et al. Synthesis and characterization of $\pi$-extended triangulene. J. Am. Chem. Soc. 141, 10621-10625 (2019).

37. Su, J. et al. Atomically precise bottom-up synthesis of $\pi$-extended [5]triangulene. Sci. $A d v$. 5, eaav7717 (2019).

38. Mishra, S. et al. Synthesis and characterization of [7]triangulene. Nanoscale 13, 1624$1628(2021)$.

39. Mishra, S. et al. Collective all-carbon magnetism in triangulene dimers. Angew. Chem. Int. Ed. 59, 12041-12047 (2020).

40. Mishra, S., Catarina, G., Wu, F., Ortiz, R. \& Jacob, D. Observation of fractional edge excitations in nanographene spin chains. arXiv:2105.09102 (2021).

41. Ribar, P., Valenta, L., Šolomek, T. \& Juríček, M. Rules of nucleophilic additions to zigzag nanographene diones. Angew. Chem. Int. Ed. 60, 13521-13528 (2021).

42. Ribar, P., Šolomek, T. \& Juríček, M. Gram-scale synthesis and supramolecular complex of precursors of Clar's hydrocarbon triangulene. Org. Lett. 21, 7124-7128 (2019).

43. Holt, C. J., Wentworth, K. J. \& Johnson, R. P. A short and efficient synthesis of the [3]triangulene ring system. Angew. Chem. Int. Ed. 58, 15793-15796 (2019).

44. Gu, Y., Wu, X., Gopalakrishna, T. Y., Phan, H. \& Wu, J. Graphene-like molecules with four zigzag edges. Angew. Chem. Int. Ed. 57, 6541-6545 (2018).

45. van de Kuil, L. A. et al. Electronic tuning of arylnickel(II) complexes by para substitution of the terdentate monoanionic 2,6-bis[(dimethylamino)methyl]phenyl ligand. Organometallics 13, 468-477 (1994).

46. Neese, F. Software update: the ORCA program system, version 4.0. WIREs Comput. Mol. Sci. 8, e1327 (2018).

47. The 'pepper' routine was used here since routines typically used for cw EPR simulations in the fast motion regime cannot account for species with $S=1$.

48. Stoll, S. \& Schweiger, A. EasySpin, a comprehensive software package for spectral simulation and analysis in EPR. J. Magn. Reson. 178, 42-55 (2006).

49. Astashkin, A. V \& Schweiger, A. Electron-spin transient nutation: a new approach to simplify the interpretation of ESR spectra. Chem. Phys. Lett. 174, 595-602 (1990).

50. Mizuochi, N., Ohba, Y. \& Yamauchi, S. A two-dimensional EPR nutation study on excited multiplet states of fullerene linked to a nitroxide radical. J. Phys. Chem. A 101, 5966-5968 (1997).

51. Mizuochi, N., Ohba, Y. \& Yamauchi, S. First observation of the photoexcited quintet 
state in fullerene linked with two nitroxide radicals. J. Phys. Chem. A 103, 7749-7752 (1999).

52. Li, Y. et al. A kinetically blocked 1,14:11,12-dibenzopentacene: a persistent triplet diradical of a non-Kekulé polycyclic benzenoid hydrocarbon. Chem. Sci. 5, 1908-1914 (2014).

53. Clark, R. C. \& Reid, J. S. The analytical calculation of absorption in multifaceted crystals. Acta Crystallogr. Sect. A 51, 887-897 (1995).

54. CrysAlisPro (version 1.171.40.68a), Rigaku Oxford Diffraction Ltd, Yarnton, Oxfordshire, England (2019).

55. Dolomanov, O. V, Bourhis, L. J., Gildea, R. J., Howard, J. A. K. \& Puschmann, H. A complete structure solution, refinement and analysis program. J. Appl. Crystallogr. $\mathbf{4 2}$, 339-341 (2009).

56. Sheldrick, G. M. SHELXT - Integrated space-group and crystal-structure determination. Acta Crystallogr. Sect. A 71, 3-8 (2015).

57. Sheldrick, G. M. Crystal structure refinement with SHELXL. Acta Crystallogr. Sect. C 71, 3-8 (2015).

58. Spek, A. L. Structure validation in chemical crystallography. Acta Crystallogr. Sect. D 65, 148-155 (2009).

59. Spek, A. L. PLATON SQUEEZE: a tool for the calculation of the disordered solvent contribution to the calculated structure factors. Acta Crystallogr. Sect. C 71, 9-18 (2015)

60. Herb, K., Tschaggelar, R., Denninger, G. \& Jeschke, G. Double resonance calibration of $\mathrm{g}$ factor standards: carbon fibers as a high precision standard. J. Magn. Reson. 289, 100-106 (2018).

61. Improta, R. \& Barone, V. Interplay of electronic, environmental, and vibrational effects in determining the hyperfine coupling constants of organic free radicals. Chem. Rev. 104, 1231-1254 (2004).

62. Gaussian 09, Revision D.01, M. J. Frisch, et al. Gaussian, Inc. (Wallingford CT, 2016). 
Supplementary information for

\section{Validation of the triplet ground state in a persistent derivative of Clar's hydrocarbon}

Leoš Valenta ${ }^{1}$, Maximilian Mayländer ${ }^{2}$, Pia Kappeler ${ }^{1}$, Olivier Blacque ${ }^{1}$, Tomáš Šolomek ${ }^{3,4 *}$, Sabine Richert ${ }^{2 *}$ and Michal Juríček ${ }^{1,4 *}$

${ }^{1}$ Department of Chemistry, University of Zurich, Zurich, Switzerland. ${ }^{2}$ Institute of Physical Chemistry, University of Freiburg, Freiburg, Germany. ${ }^{3}$ Department of Chemistry, Biochemistry and Pharmacy, University of Bern, Bern, Switzerland. ${ }^{4}$ Prievidza Chemical Society, Prievidza, Slovakia.

\section{Table of contents}

$\begin{array}{ll}\text { S1. Supporting figures } & \text { S2 }\end{array}$

S2. General information $\quad$ S5

S3. Synthesis and characterization $\quad$ S5

S4. X-ray crystallography $\quad$ S11

S5. EPR spectroscopy $\quad$ S13

$\begin{array}{ll}\text { S6. DFT calculations } & \text { S19 }\end{array}$

S7. Copies of NMR and HRMS spectra $\quad$ S30

S8. Cartesian coordinates $\quad$ S49

$\begin{array}{ll}\text { S9. References } & \text { S72 }\end{array}$ 


\section{S1. Supplementary figures}

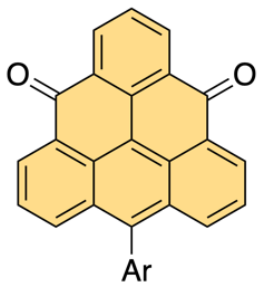

1) $\mathrm{ArMgBr}$

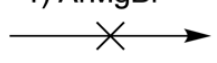

1) $\mathrm{ArMgBr}$

2) $I_{2}$<smiles></smiles>

1) $\mathrm{ArMgBr}$

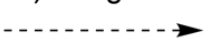<smiles>[R]c1c2cccc3c2c2c4c(cccc14)C([3H])([Al])c1cccc(c1-2)C3([3H])[O-]</smiles>

1) $\mathrm{ArMgBr}$

2) $\mathrm{I}_{2}$

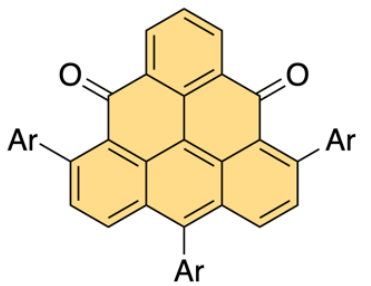

Fig. S1 | First attempt. An attempt to prepare a trisubstituted triangulene precursor via a nucleophilic addition of a Grignard reagent to monoarylated triangulene-4,8-dione, readily available from a hydroxy derivative developed by Clar (top). Unexpectedly, a 1,4-addition instead of the desired 1,2-addition to the ketone occurred (bottom). Even though a trisubstituted derivative could be obtained using this method, the installment of the fourth substituent led to an $\mathrm{sp}^{3}$ center, which impeded further transformations towards persistent triangulene ${ }^{1}$.<smiles>OCc1ccccc1Br</smiles>$$
\text { 2) } \underset{(\mathrm{EtO})_{2} \mathrm{CO}}{\stackrel{n-\mathrm{BuLi}}{\mathrm{X}}}
$$

2) $(\mathrm{EtO})_{2} \mathrm{CO}$

$$
\underset{\text { 2) }(\mathrm{EtO})_{2} \mathrm{CO}}{\stackrel{n-\mathrm{BuLi}}{\longrightarrow}}
$$<smiles>OCc1ccccc1C(O)(c1ccccc1CO)c1ccccc1CO</smiles>

$74 \%$<smiles>OC(Br)c1ccccc1Br</smiles>

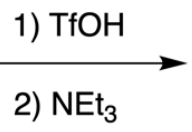

1) $\mathrm{TfOH}$

2) $\mathrm{NEt}_{3}$<smiles></smiles>

$66 \%$<smiles></smiles>

$\operatorname{Ar}=$ mesityl or 3,5-di-tert-butylphenyl

Fig. S2 | Second attempt. A method reported by Johnson et al. for the synthesis of the dihydroprecursor of triangulene involving a three-fold ring-closure of a pre-functionalized precursor to dihydro-triangulene ${ }^{2}$ (top). Our attempt to prepare a tetrahydroxy precursor for the acidcatalyzed ring-closure was not successful, most likely due to the crowdedness during the formation of the desired tetraol to synthesize a trisubstituted triangulene precursor (bottom). 

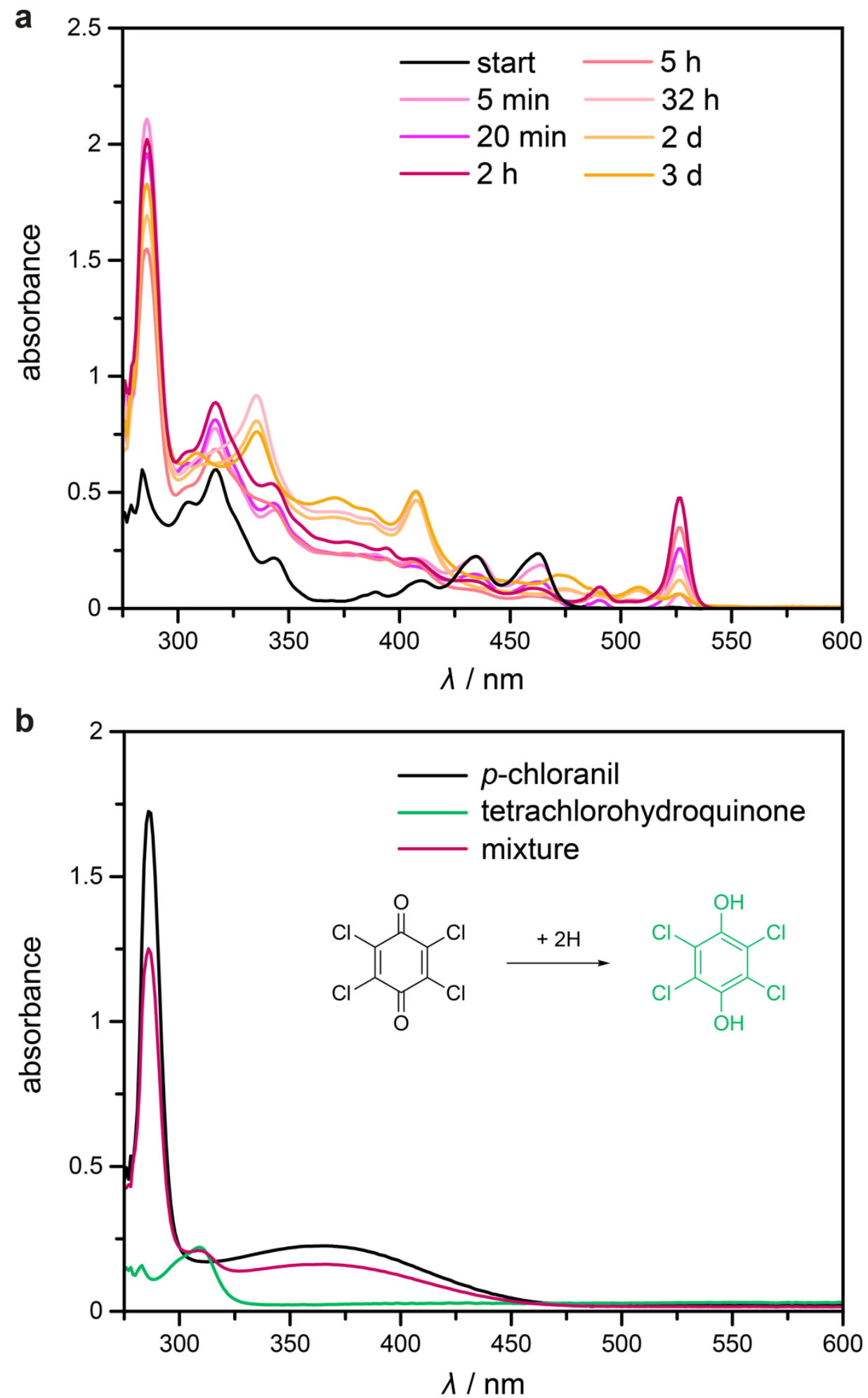

Fig. S3 | Reaction monitoring. a, UV-vis spectra for toluene solutions of a mixture of $\mathbf{1 a}+\mathbf{1 b}$ with 5 equivalents of $p$-chloranil recorded before and after the oxidant addition (as indicated). The oxidation was performed at $2.5 \mathrm{mM}$ concentration. For the UV-vis measurements, an aliquot sample of this solution was diluted to $2.5 \times 10^{-5} \mathrm{M}$. b, UV-vis spectra for toluene solutions of $p$-chloranil $\left(1.25 \times 10^{-4} \mathrm{M}\right)$, its reduced form $\left(2.5 \times 10^{-5} \mathrm{M}\right)$ and a $4: 1$ mixture of $p$-chloranil and reduced $p$-chloranil (tetrachlorohydroquinone). 


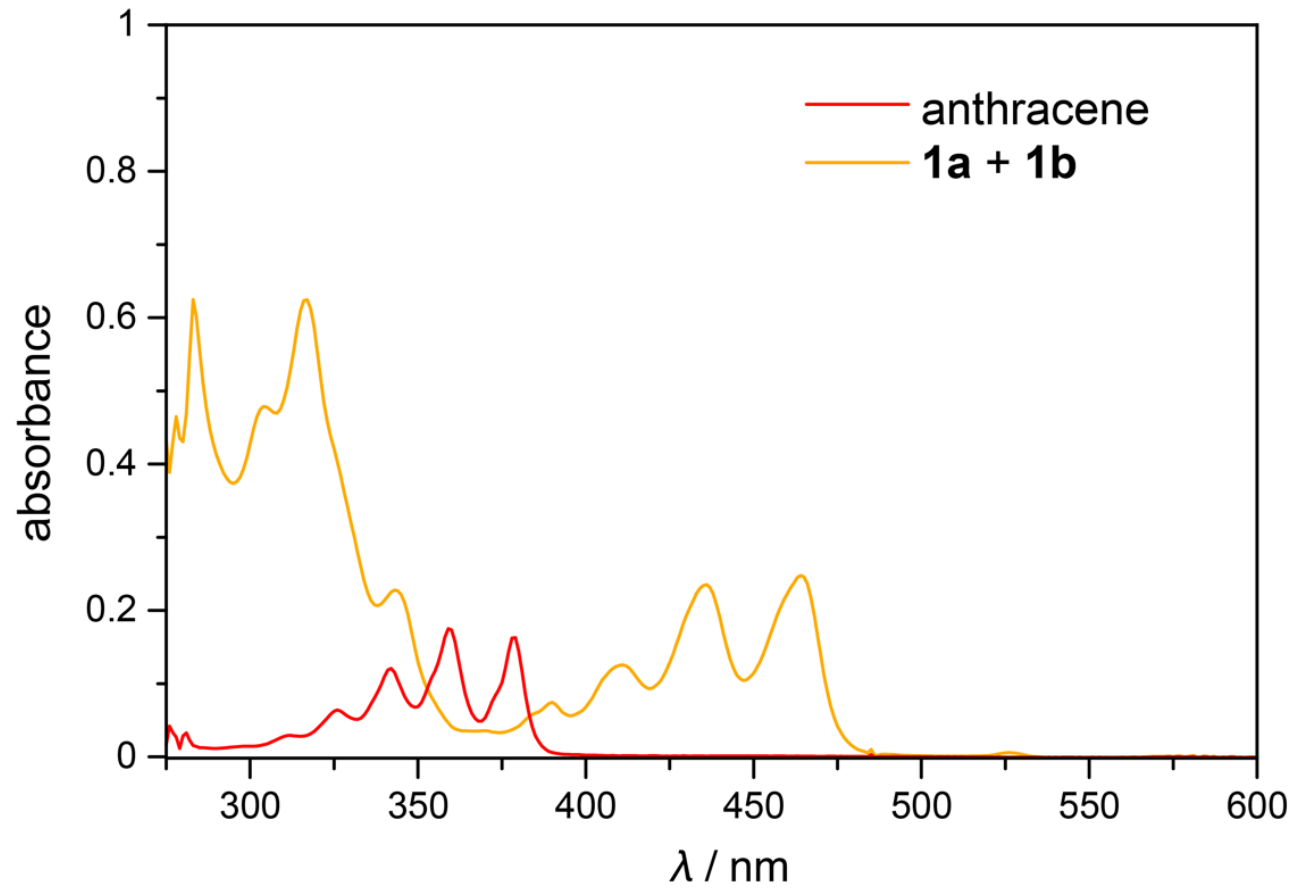

Fig. S4 | Anthracene vibronic progression. UV-vis spectra for toluene solutions of anthracene and $\mathbf{1 a}+\mathbf{1 b}$ (both $\left.2.5 \times 10^{-5} \mathrm{M}\right)$. 


\section{S2. General information}

Anhydrous solvents and chemical reagents were purchased from commercial sources and used without further purification unless stated otherwise. The silica-gel column chromatography was performed using Merck 60 silica gel (40-63 $\mu \mathrm{m})$. (2,6-Bis(methoxymethyl)phenyl)boronic acid was prepared according to the literature ${ }^{3,4}$. The NMR experiments were performed on NMR spectrometers operating at 400, 500 or $600 \mathrm{MHz}$ proton frequencies. Standard pulse sequences were used. Chemical shifts $(\delta)$ are reported in parts per million (ppm) relative to the solvent residual peak ${ }^{5}\left({ }^{1} \mathrm{H}\right.$ and ${ }^{13} \mathrm{C} \mathrm{NMR}$, respectively): $\mathrm{CDCl}_{3}(\delta=7.26$ and $77.16 \mathrm{ppm}), \mathrm{CD}_{2} \mathrm{Cl}_{2}(\delta=$ 5.32 and 53.84 ppm). High-resolution mass spectra (HRMS) were measured as HR-ESI-MS, HR-APCI-MS or HR-EI-MS.

\section{S3. Synthesis and characterization}<smiles>O=C1c2ccccc2Cc2ccccc21</smiles>

2

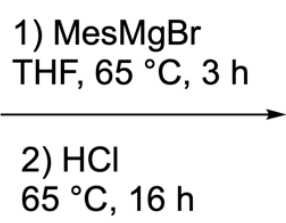

$65^{\circ} \mathrm{C}, 16 \mathrm{~h}$

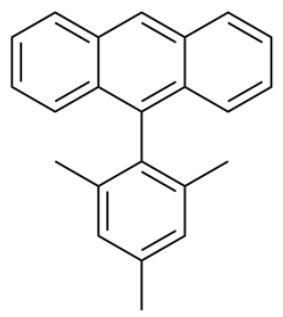

9

9-Mesitylanthracene (9). A solution of 2-mesitylmagnesium bromide (4.1 mL, $4.1 \mathrm{mmol}$, 1.0 $\mathrm{M}$ in THF) was added to a solution of anthrone $(500 \mathrm{mg}, 2.57 \mathrm{mmol})$ in dry THF $(20 \mathrm{~mL})$ under a nitrogen atmosphere. The reaction mixture was stirred at $65{ }^{\circ} \mathrm{C}$ for $3 \mathrm{~h}$ before conc. $\mathrm{HCl}(4.3 \mathrm{~mL})$ was added and the reaction mixture was stirred overnight at $65{ }^{\circ} \mathrm{C}$. The mixture was extracted with DCM $(3 \times 30 \mathrm{~mL})$. The combined organic layers were washed with brine, dried over anhydrous $\mathrm{MgSO}_{4}$ and filtered. After evaporation of the solvents, the residue was purified by column chromatography $\left(\mathrm{SiO}_{2}\right.$, cyclohexane/ethyl acetate, 50:1) to afford the product (240 mg, 32\%) as a white solid. ${ }^{1} \mathrm{H}$ NMR (400 MHz, $\left.\mathrm{CDCl}_{3}, \mathrm{ppm}\right): \delta 8.51(\mathrm{~s}, 1 \mathrm{H}), 8.09$ $(\mathrm{d}, J=8.5 \mathrm{~Hz}, 2 \mathrm{H}), 7.53$ (d, $J=8.8 \mathrm{~Hz}, 2 \mathrm{H}), 7.49$ (ddd, $J=8.1,6.4,1.2 \mathrm{~Hz}, 2 \mathrm{H}), 7.36$ (ddd, $J$ $=8.3,6.5,1.3 \mathrm{~Hz}, 2 \mathrm{H}), 7.14(\mathrm{~s}, 2 \mathrm{H}), 2.50(\mathrm{~s}, 3 \mathrm{H}), 1.76(\mathrm{~s}, 6 \mathrm{H}) \cdot{ }^{13} \mathrm{C} \mathrm{NMR}\left(101 \mathrm{MHz}, \mathrm{CDCl}_{3}\right.$, ppm): $\delta 137.7,137.2,135.9,134.6,131.8,129.9,128.8,128.4,126.2,126.1,125.7,125.3,21.4$, 20.1. This compound was prepared previously using a different procedure. The NMR data are in agreement with those reported ${ }^{6}$. 
<smiles>Cc1cc(C)c(-c2c3ccccc3cc3ccccc23)c(C)c1</smiles>

9

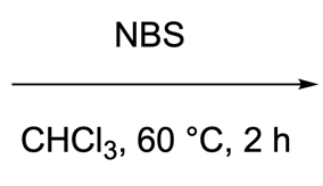

$\mathrm{CHCl}_{3}, 60^{\circ} \mathrm{C}, 2 \mathrm{~h}$

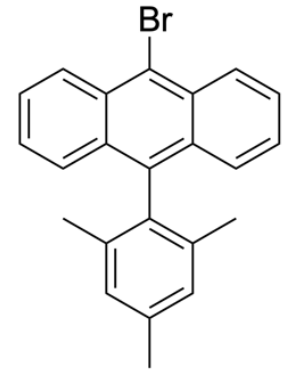

3

9-Bromo-10-mesitylanthracene (3). $N$-Bromsuccinimide (NBS; $613 \mathrm{mg}, 3.44 \mathrm{mmol}$ ) was added in one portion to a solution of $9(850 \mathrm{mg}, 2.87 \mathrm{mmol})$ in $\mathrm{CHCl}_{3}(30 \mathrm{~mL})$ and the reaction mixture was stirred at $60{ }^{\circ} \mathrm{C}$ for $2 \mathrm{~h}$. Upon cooling to room temperature, water $(40 \mathrm{~mL})$ was added and the mixture was extracted with DCM $(3 \times 50 \mathrm{~mL})$. The combined organic phases were dried over $\mathrm{MgSO}_{4}$ and the solvent was evaporated. The residue was purified by column chromatography ( $\mathrm{SiO}_{2}$, cyclohexane) to afford the product $(790 \mathrm{mg}, 73 \%)$ as a pale yellow solid. ${ }^{1} \mathrm{H}$ NMR (400 MHz, $\mathrm{CDCl}_{3}, \mathrm{ppm}$ ): $\delta 8.64$ (d, $\left.J=8.9 \mathrm{~Hz}, 2 \mathrm{H}\right), 7.60$ (ddd, $J=8.8,6.5,1.3$ $\mathrm{Hz}, 2 \mathrm{H}), 7.52(\mathrm{~d}, J=8.7 \mathrm{~Hz}, 2 \mathrm{H}), 7.37$ (ddd, $J=8.8,6.5,1.2 \mathrm{~Hz}, 2 \mathrm{H}), 7.11(\mathrm{~s}, 2 \mathrm{H}), 2.47$ (s, $3 \mathrm{H}), 1.72(\mathrm{~s}, 6 \mathrm{H}) .{ }^{13} \mathrm{C} \mathrm{NMR}\left(101 \mathrm{MHz}, \mathrm{CDCl}_{3}, \mathrm{ppm}\right): \delta 137.60,137.56,136.7,134.2,130.7$, $130.6,128.5,128.2,127.2,126.5,126.0,122.4,21.4,20.1$. This compound was prepared previously using a similar procedure. The NMR data are in agreement with those reported ${ }^{7}$.<smiles>Cc1cc(C)c(-c2c3ccccc3c(Br)c3ccccc23)c(C)c1</smiles>

3

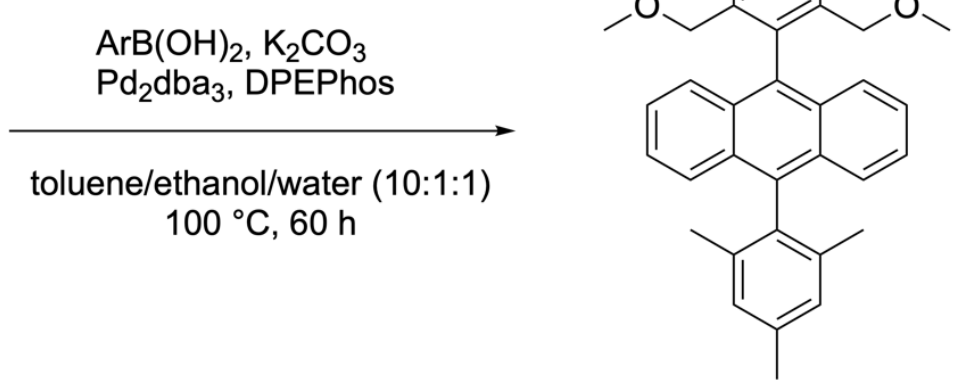

4

9-(2,6-Bis(methoxymethyl)phenyl)-10-mesitylanthracene (4). A mixture of 3 (563 mg, 1.50 mmol), (2,6-bis(methoxymethyl)phenyl)boronic acid (600 mg, $2.85 \mathrm{mmol})$, DPEPhos (81 mg, $0.15 \mathrm{mmol}), \mathrm{Pd}_{2} \mathrm{dba}_{3}(69 \mathrm{mg}, 0.075 \mathrm{mmol})$ and $\mathrm{K}_{2} \mathrm{CO}_{3}(1.2 \mathrm{~g}, 9.0 \mathrm{mmol})$ in toluene $(20 \mathrm{~mL})$, ethanol $(2 \mathrm{~mL})$ and water $(2 \mathrm{~mL})$ was deoxygenated in a Schlenk flask by freeze-pump-thaw technique in three cycles and then stirred at $100^{\circ} \mathrm{C}$ for $60 \mathrm{~h}$. Upon cooling to room temperature, water $(30 \mathrm{~mL})$ was added and the mixture was extracted with DCM $(3 \times 20 \mathrm{~mL})$. The combined 
organic phases were dried over $\mathrm{MgSO}_{4}$ and the solvent was evaporated. The residue was purified by column chromatography $\left(\mathrm{SiO}_{2}\right.$, cyclohexane/ethyl acetate, 25:1) to afford the product (383 mg, 55\%) as an off-white solid. ${ }^{1} \mathrm{H}$ NMR (500 MHz, $\left.\mathrm{CDCl}_{3}, \mathrm{ppm}\right): \delta 7.68(2 \times \mathrm{d}$, avg. $J=7.5 \mathrm{~Hz}, 2 \mathrm{H}), 7.63(\mathrm{dd}, J=8.7,6.5 \mathrm{~Hz}, 1 \mathrm{H}), 7.56-7.51(\mathrm{~m}, 2 \mathrm{H}), 7.48-7.44(\mathrm{~m}, 2 \mathrm{H})$, 7.34-7.28 (m, 4H), $7.13(\mathrm{~s}, 2 \mathrm{H}), 3.87(\mathrm{~s}, 4 \mathrm{H}), 2.95(\mathrm{~s}, 6 \mathrm{H}), 2.48(\mathrm{~s}, 3 \mathrm{H}), 1.78(\mathrm{~s}, 6 \mathrm{H}) .{ }^{13} \mathrm{C} \mathrm{NMR}$ (126 MHz, $\left.\mathrm{CDCl}_{3}, \mathrm{ppm}\right): \delta 138.4,137.6,137.4,136.4,135.6,134.8,131.9,130.1,129.6$, $128.52,128.46,126.6,126.5,126.4,125.7,125.6,72.2,58.4,21.4,20.1$. HRMS (ESI) $\mathrm{m} / \mathrm{z}$ : [M $+\mathrm{Na}]^{+}$Calcd for $\mathrm{C}_{33} \mathrm{H}_{32} \mathrm{O}_{2}$ 483.22945; Found 483.22931.

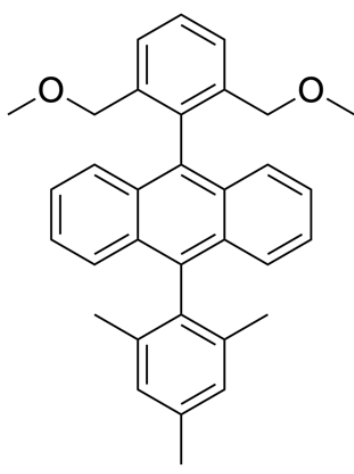

4

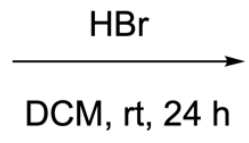

9-(2,6-Bis(bromomethyl)phenyl)-10-mesitylanthracene was placed into flame-dried Schlenk flask and the atmosphere was exchanged three times with nitrogen before dry DCM (4 mL) was added. To this solution, $\mathrm{HBr}(1.2 \mathrm{~mL}, 6.5$ mmol, $33 \%$ in acetic acid) was added and the reaction mixture was stirred at room temperature for $24 \mathrm{~h}$. The mixture was poured into water and extracted with DCM $(3 \times 20 \mathrm{~mL})$. The combined organic phases were dried over $\mathrm{MgSO}_{4}$ and the solvent was evaporated. The residue was purified by column chromatography ( $\mathrm{SiO}_{2}$, cyclohexane/ethyl acetate, 40:1) to afford the product (250 mg, 69\%) as a white solid. ${ }^{1} \mathrm{H}$ NMR (400 MHz, $\left.\mathrm{CDCl}_{3}, \mathrm{ppm}\right): \delta 7.74(2 \times \mathrm{d}$, avg. $J=7.7 \mathrm{~Hz}, 2 \mathrm{H}), 7.62(\mathrm{dd}, J=8.3,7.1 \mathrm{~Hz}, 1 \mathrm{H}), 7.57(\mathrm{ddd}, J=6.7,4.0,2.0 \mathrm{~Hz}, 2 \mathrm{H}), 7.47-7.41$ (m, 2H), 7.38-7.31 (m, 4H), $7.14(\mathrm{~s}, 2 \mathrm{H}), 4.02(\mathrm{~s}, 4 \mathrm{H}), 2.49(\mathrm{~s}, 3 \mathrm{H}), 1.80(\mathrm{~s}, 6 \mathrm{H}) .{ }^{13} \mathrm{C} \mathrm{NMR}$ (101 MHz, $\left.\mathrm{CDCl}_{3}, \mathrm{ppm}\right): \delta 138.3,138.2,137.6,137.5,137.4,134.6,131.2,130.4,130.0,129.7$, 129.4, 128.5, 126.7, 126.5, 126.0, 125.8, 31.4, 21.4, 20.1. HRMS (EI) $\mathrm{m} / z$ : $[M]^{+}$Calcd for $\mathrm{C}_{31} \mathrm{H}_{26} \mathrm{Br}_{2}$ 556.03958; Found 556.03945. 
<smiles>Cc1cc(C)c(-c2c3ccccc3c(-c3c(CBr)cccc3CBr)c3ccccc23)c(C)c1</smiles>

5

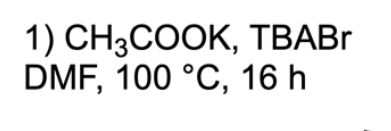

2) $\mathrm{KOH}$

$\mathrm{THF}, 80^{\circ} \mathrm{C}, 6 \mathrm{~h}$

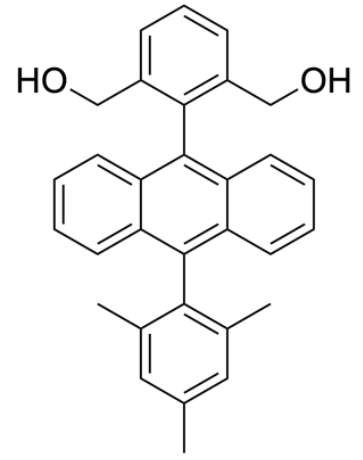

6

(2-(10-Mesitylanthracen-9-yl)-1,3-phenylene)dimethanol (6). A solution of 5 (250 $\mathrm{mg}$, $0.448 \mathrm{mmol})$, potassium acetate $(440 \mathrm{mg}, 4.48 \mathrm{mmol})$ and tetrabutylammonium bromide (144 $\mathrm{mg}, 0.448 \mathrm{mmol})$ in DMF $(5 \mathrm{~mL})$ was stirred at $100{ }^{\circ} \mathrm{C}$ for $16 \mathrm{~h}$ under a nitrogen atmosphere. Upon cooling, the reaction mixture was poured over ice and extracted with DCM $(3 \times 15 \mathrm{~mL})$. The combined organic phases were extracted twice with an excess of water, aq. $\mathrm{LiCl}(5 \%)$ and then dried over $\mathrm{MgSO}_{4}$. The crude pale yellow oil was dissolved in THF (4 mL) and added to a solution of $\mathrm{KOH}(252 \mathrm{mg}, 4.50 \mathrm{mmol})$ in ethanol $(4 \mathrm{~mL})$ and water $(2 \mathrm{~mL})$, and the mixture was stirred at $80^{\circ} \mathrm{C}$ for $6 \mathrm{~h}$. Then, sat. $\mathrm{NH}_{4} \mathrm{Cl}(10 \mathrm{~mL})$ was added and the mixture was extracted with DCM $(3 \times 15 \mathrm{~mL})$. The combined organic phases were dried over $\mathrm{MgSO}_{4}$ and the solvent was evaporated. The residue was purified by column chromatography $\left(\mathrm{SiO}_{2}\right.$, cyclohexane/ethyl acetate, $3: 1)$ to afford the product ( $190 \mathrm{mg}, 98 \%$ over two steps) as a pale yellow solid. ${ }^{1} \mathrm{H} \mathrm{NMR}$ (400 MHz, $\left.\mathrm{CDCl}_{3}, \mathrm{ppm}\right): \delta 7.74(2 \times \mathrm{d}$, avg. $J=7.6 \mathrm{~Hz}, 2 \mathrm{H}), 7.68(\mathrm{dd}, J=8.7,6.4 \mathrm{~Hz}, 1 \mathrm{H})$, 7.58-7.52 (m, 2H), 7.49-7.43 (m, 2H), 7.37-7.29 (m, 4H), $7.13(\mathrm{~s}, 2 \mathrm{H}), 4.14(\mathrm{~s}, 4 \mathrm{H}), 2.48$ (s, $3 \mathrm{H}), 1.77$ (s, 6H). ${ }^{13} \mathrm{C} \mathrm{NMR}\left(101 \mathrm{MHz}, \mathrm{CDCl}_{3}, \mathrm{ppm}\right): \delta 140.6,137.6,137.5,137.0,135.1,134.5$, 131.3, 130.1, 129.7, 129.1, 128.5, 127.1, 126.8, 126.5, 125.82, 125.79, 63.3, 21.4, 20.2. HRMS (ESI) $m / z:[M+\mathrm{Na}]^{+}$Calcd for $\mathrm{C}_{31} \mathrm{H}_{28} \mathrm{O}_{2}$ 455.19815; Found 455.19794.<smiles>Cc1cc(C)c(-c2c3ccccc3c(-c3c(CO)cccc3CO)c3ccccc23)c(C)c1</smiles>

$(\mathrm{COCl})_{2}, \mathrm{DMSO} \mathrm{NEt}_{3}$

DCM, $-78^{\circ} \mathrm{C}$ to rt, $5.5 \mathrm{~h}$<smiles>Cc1cc(C)c(-c2c3ccccc3c(-c3c(C=O)cccc3C=O)c3ccccc23)c(C)c1</smiles>

7 
2-(10-Mesitylanthracen-9-yl)isophthalaldehyde (7). To a cooled $\left(-78^{\circ} \mathrm{C}\right)$ mixture of oxalyl chloride $(0.12 \mathrm{~mL}, 1.4 \mathrm{mmol})$ in dry DCM $(5 \mathrm{~mL})$, DMSO $(0.2 \mathrm{~mL}, 3 \mathrm{mmol})$ was added dropwise and the mixture was stirred at $-78{ }^{\circ} \mathrm{C}$ for $30 \mathrm{~min}$ before a solution of 6 (195 $\mathrm{mg}, 0.451$ $\mathrm{mmol})$ in dry DCM $(8 \mathrm{~mL})$ was added. The reaction mixture was stirred at $-78^{\circ} \mathrm{C}$ for $1 \mathrm{~h}$, then triethylamine $(3.75 \mathrm{~mL}, 27.0 \mathrm{mmol})$ was added dropwise and the mixture was stirred at $-78^{\circ} \mathrm{C}$ for $2 \mathrm{~h}$ and then at room temperature for $2 \mathrm{~h}$. The mixture was quenched by the addition of aq. $\mathrm{HCl}(10 \mathrm{~mL}, 1 \mathrm{M})$ and extracted with DCM $(3 \times 10 \mathrm{~mL})$. The combined organic phases were dried over $\mathrm{MgSO}_{4}$ and the solvent was evaporated. The residue was purified by column chromatography $\left(\mathrm{SiO}_{2}, \mathrm{DCM} /\right.$ cyclohexane, 3:1) to afford the product $(150 \mathrm{mg}, 78 \%)$ as a yellow solid. ${ }^{1} \mathrm{H}$ NMR (400 MHz, $\left.\mathrm{CDCl}_{3}, \mathrm{ppm}\right): \delta 9.32$ (s, 2H), 8.50 (d, J=7.7 Hz, 2H), 7.89 (t, $J=7.7 \mathrm{~Hz}, 1 \mathrm{H}), 7.64-7.58(\mathrm{~m}, 2 \mathrm{H}), 7.45-7.33(\mathrm{~m}, 6 \mathrm{H}), 7.14(\mathrm{~s}, 2 \mathrm{H}), 2.49(\mathrm{~s}, 3 \mathrm{H}), 1.78(\mathrm{~s}$, 6H). $\left.{ }^{13} \mathrm{C} \mathrm{NMR} \mathrm{(101} \mathrm{MHz,} \mathrm{CDCl}_{3}, \mathrm{ppm}\right): \delta 190.9,146.2,138.8,137.8,137.5,136.4,134.0$, 133.1, 131.9, 129.3, 129.2, 128.6, 127.3, 126.9, 126.1, 126.0, 125.2, 21.4, 20.2. HRMS (ESI) $m / z:[M+\mathrm{H}]^{+}$Calcd for $\mathrm{C}_{31} \mathrm{H}_{24} \mathrm{O}_{2}$ 429.18491; Found 429.18557.

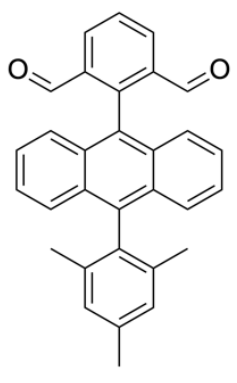

7

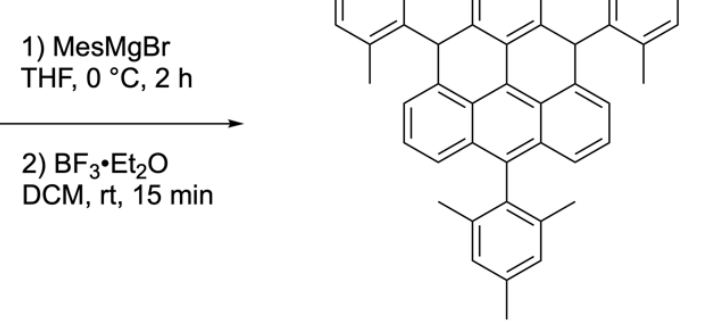

$1 \mathrm{a}$

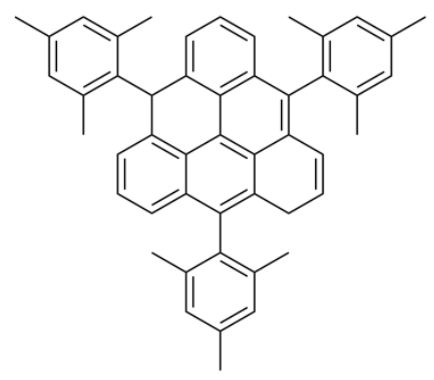

1b

\section{4,8,12-Trimesityl-4,8-dihydrodibenzo[cd,mn]pyrene (1a) + 4,8,12-trimesityl-1,8-dihydro-} dibenzo $[\boldsymbol{c d}, \boldsymbol{m n}]$ pyrene (1b). To a cooled $\left(0^{\circ} \mathrm{C}\right)$ solution of 7 in dry THF $(3 \mathrm{~mL}), 2$-mesitylmagnesium bromide $(0.47 \mathrm{~mL}, 0.47 \mathrm{mmol}, 1.0 \mathrm{M}$ in THF) was added dropwise and the reaction mixture was allowed to warm to room temperature and then it was stirred for additional $2 \mathrm{~h}$. The mixture was quenched by the addition of water $(5 \mathrm{~mL})$ and then extracted with DCM $(3 \times$ $5 \mathrm{~mL}$ ). The combined organic phases were dried over $\mathrm{Na}_{2} \mathrm{SO}_{4}$ and the solvent was evaporated. The oily residue was heated to $35^{\circ} \mathrm{C}$ and kept under high vacuum for $24 \mathrm{~h}$ in order to remove all residual mesitylene. The crude dihydroxy intermediate was used in the next step without further purification. It was dissolved in dry DCM $(10 \mathrm{~mL})$ and deoxygenated by freeze-pumpthaw technique in three cycles before $\mathrm{BF}_{3} \cdot \mathrm{Et}_{2} \mathrm{O}(73 \mu \mathrm{L}, 0.28 \mathrm{mmol})$ was added slowly. The reaction mixture was stirred at room temperature for $15 \mathrm{~min}$, then quenched by the addition of cold deoxygenated methanol $(0.5 \mathrm{~mL})$. The solvent was evaporated using a Schlenk line and 
the residue was purified by column chromatography $\left(\mathrm{SiO}_{2}\right.$, cyclohexane/DCM, 3:1) under inert conditions using deoxygenated silica gel and solvent (see image on the right). A yellow fluorescent compound was collected into a Schlenk flask and the solvent was evaporated using a Schlenk line. The product ( $24 \mathrm{mg}, 81 \%$ ), which is a pale yellow solid, was obtained as a mixture of two structural isomers 1a and $\mathbf{1 b}$, where isomer $\mathbf{1 a}$ is present as a mixture of two stereoisomers syn-1a and anti-1a (for structures, see Section S7). Because of significant overlap in the aromatic region, ${ }^{1} \mathrm{H}$ NMR spectrum cannot be fully described. However, analysis of the spectrum using the characteristic signals (6.42 (s, 2H, syn-1a), 6.37 (s, 2H, anti-1a), 6.60 (s, $1 \mathrm{H}, \mathbf{1 b}), 6.24$ (dt, $J=10.0,2.2 \mathrm{~Hz}, 1 \mathrm{H}, \mathbf{1 b}), 5.97$ (dt, $J=$ 10.1, 4.0 Hz, 1H, 1b), $3.46(\mathrm{dd}, J=4.1,2.3 \mathrm{~Hz}, 2 \mathrm{H}, \mathbf{1 b}))$ allowed us to estimate the composition of the mixture: syn$\mathbf{1 a} /$ anti-1a/1 $/ \mathbf{b} \sim 1: 0.4: 1$. Considering the rate of rotation of the mesityl groups relative to the NMR time-scale $(3 \times$ slow for syn-1a, $3 \times$ fast for anti-1a, $2 \times$ slow and $1 \times$ fast for $\mathbf{1 b}), 18$ methyl $(\mathrm{Me})$ resonances are expected, which matches well the observation (18 Me signals in ${ }^{1} \mathrm{H}$ and 17 in ${ }^{13} \mathrm{C}$ NMR). Considering the isomeric ratio, the aromatic

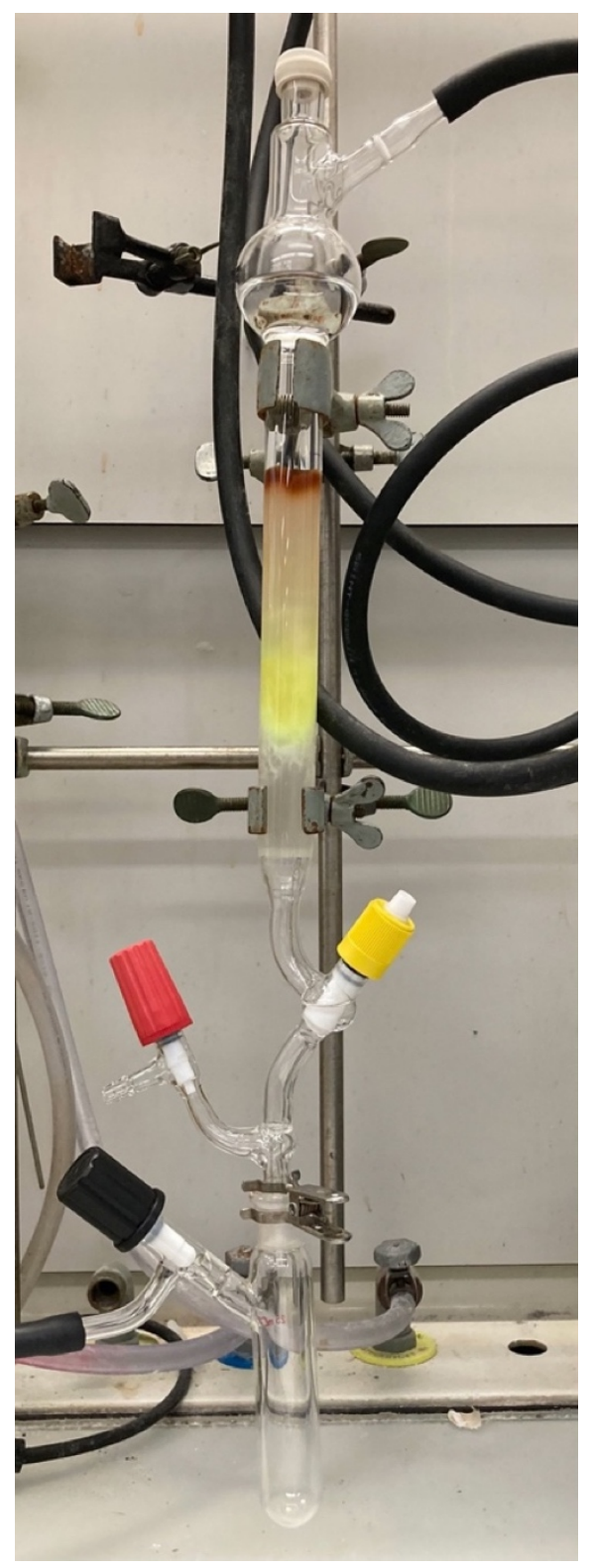
signals should integrate to roughly $35 \mathrm{H}$, which also matches well the observation. In addition, all 80 expected ${ }^{13} \mathrm{C}$ NMR signals in the aromatic region are visible. For details, see Section S7. ${ }^{13} \mathrm{C}$ NMR (151 MHz, $\left.\mathrm{CD}_{2} \mathrm{Cl}_{2}, \mathrm{ppm}\right): \delta 142.43,142.24,141.90,138.43,138.39,138.37,138.22$, $137.98,137.96,137.89$, 137.79, 137.75, 137.70, 137.65, 137.58, 137.54, 137.51, 137.42, 137.40, 137.39, 137.09, 136.66, 136.64, 136.59, 136.34, 136.32, 135.89, 135.84, 135.75, 135.62 , 135.55, 135.52, 135.22, 132.91, 131.67, 131.64, 131.62, 131.40, 130.80, 130.24, $130.16,129.87,129.37,129.28,129.26,129.03,129.01,128.87,128.71,128.70,128.68$, $128.66,128.65,128.59,128.57,128.50,128.44,127.97,127.81,127.23,127.10,126.98$, $126.34,126.26,126.18,126.15,125.44,125.09$, 125.05, 124.66, 124.45, 124.25, 123.98, $123.89,123.77,123.71,123.61,123.58,123.26,122.62,44.19,44.05,43.80,30.10,21.43$, 21.34, 21.33, 21.30, 21.26, 21.04, 21.01, 20.64, 20.57, 20.23, 20.20, 20.07, 20.02, 19.97, 19.80, 19.79, 19.73. HRMS (APCI) $m / z:[M+\mathrm{H}]^{+}$Calcd for $\mathrm{C}_{49} \mathrm{H}_{44}$ 633.34430; Found 633.35148. 


\section{Table S1 | Crystal data for 8a}

CCDC no.

Empirical formula

Formula weight

Temperature / K

Crystal system

Space group

$a / \AA$

$b / \AA$

$c / \AA$

$\alpha /{ }^{\circ}$

$\beta / \circ$

$\gamma /{ }^{\circ}$

Volume / $\AA^{3}$

Z

$\rho_{\text {calc }} / \mathrm{g} \mathrm{cm}^{-3}$

$\mu / \mathrm{mm}^{-1}$

$F(000)$

Crystal size / $\mathrm{mm}^{3}$

Radiation

$2 \Theta$ range for data collection $/{ }^{\circ}$

Index ranges

Reflections collected

Independent reflections

Data/restraints/parameters

Goodness-of-fit on $F^{2}$

Final $R$ indexes $[I \geq 2 \sigma(I)]$

Final $R$ indexes [all data]

Largest diff. peak/hole / e $\AA^{-3}$
2104838

$\mathrm{C}_{51.5} \mathrm{H}_{49}$

667.90

160(1)

triclinic

P-1

13.0757(6)

$17.7775(8)$

$18.1806(8)$

$80.129(4)$

$70.657(4)$

$89.633(4)$

$3922.8(3)$

4

1.131

0.475

1432.0

$0.14 \times 0.06 \times 0.02$

$\mathrm{Cu} \mathrm{K \alpha}(\lambda=1.54184)$

5.236 to 149.006

$-16 \leq h \leq 16,-22 \leq k \leq 22,-22 \leq l \leq 22$

73678

$16006\left[R_{\text {int }}=0.0755, R_{\text {sigma }}=0.0556\right]$

$16006 / 144 / 901$

1.033

$R_{1}=0.0840, \mathrm{w} R_{2}=0.2320$

$R_{1}=0.1293, \mathrm{w} R_{2}=0.2680$

$0.43 /-0.31$ 
Table S2 | Comparison of bond lengths obtained from XRD and DFT for 8a

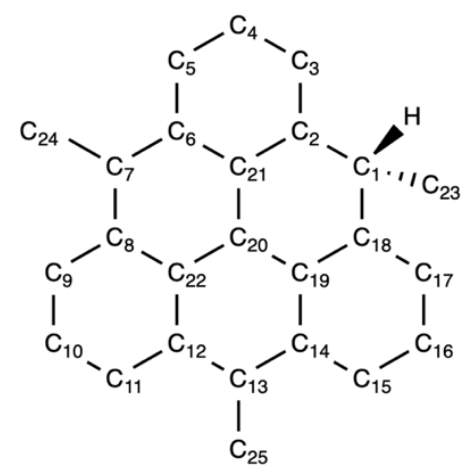

\begin{tabular}{|c|c|c|}
\hline Bond & DFT / $\AA$ & XRD / $\AA$ \\
\hline $\mathrm{C}_{1}-\mathrm{C}_{2}$ & 1.527 & 1.511 \\
\hline $\mathrm{C}_{2}-\mathrm{C}_{3}$ & 1.387 & 1.395 \\
\hline $\mathrm{C}_{3}-\mathrm{C}_{4}$ & 1.407 & 1.392 \\
\hline $\mathrm{C}_{4}-\mathrm{C}_{5}$ & 1.376 & 1.375 \\
\hline $\mathrm{C}_{5}-\mathrm{C}_{6}$ & 1.423 & 1.408 \\
\hline $\mathrm{C}_{6}-\mathrm{C}_{7}$ & 1.426 & 1.442 \\
\hline $\mathrm{C}_{7}-\mathrm{C}_{8}$ & 1.412 & 1.411 \\
\hline $\mathrm{C}_{8}-\mathrm{C}_{9}$ & 1.424 & 1.439 \\
\hline $\mathrm{C}_{9}-\mathrm{C}_{10}$ & 1.390 & 1.395 \\
\hline $\mathrm{C}_{10}-\mathrm{C}_{11}$ & 1.390 & 1.390 \\
\hline $\mathrm{C}_{11}-\mathrm{C}_{12}$ & 1.424 & 1.445 \\
\hline $\mathrm{C}_{12}-\mathrm{C}_{13}$ & 1.412 & 1.393 \\
\hline $\mathrm{C}_{13}-\mathrm{C}_{14}$ & 1.426 & 1.419 \\
\hline $\mathrm{C}_{14}-\mathrm{C}_{15}$ & 1.423 & 1.418 \\
\hline $\mathrm{C}_{15}-\mathrm{C}_{16}$ & 1.376 & 1.370 \\
\hline $\mathrm{C}_{16}-\mathrm{C}_{17}$ & 1.407 & 1.402 \\
\hline $\mathrm{C}_{17}-\mathrm{C}_{18}$ & 1.387 & 1.378 \\
\hline $\mathrm{C}_{18}-\mathrm{C}_{1}$ & 1.527 & 1.522 \\
\hline $\mathrm{C}_{18}-\mathrm{C}_{19}$ & 1.420 & 1.418 \\
\hline $\mathrm{C}_{19}-\mathrm{C}_{14}$ & 1.436 & 1.434 \\
\hline $\mathrm{C}_{19}-\mathrm{C}_{20}$ & 1.441 & 1.427 \\
\hline $\mathrm{C}_{20}-\mathrm{C}_{21}$ & 1.441 & 1.444 \\
\hline $\mathrm{C}_{20}-\mathrm{C}_{22}$ & 1.408 & 1.408 \\
\hline $\mathrm{C}_{21}-\mathrm{C}_{2}$ & 1.420 & 1.410 \\
\hline $\mathrm{C}_{21}-\mathrm{C}_{6}$ & 1.436 & 1.417 \\
\hline $\mathrm{C}_{22}-\mathrm{C}_{8}$ & 1.446 & 1.423 \\
\hline $\mathrm{C}_{22}-\mathrm{C}_{12}$ & 1.446 & 1.441 \\
\hline $\mathrm{C}_{23}-\mathrm{C}_{1}$ & 1.534 & 1.535 \\
\hline $\mathrm{C}_{24}-\mathrm{C}_{7}$ & 1.500 & 1.508 \\
\hline $\mathrm{C}_{25}-\mathrm{C}_{13}$ & 1.500 & 1.507 \\
\hline $\mathrm{C}_{1}-\mathrm{H}$ & 1.098 & 1.000 \\
\hline
\end{tabular}




\section{S5. EPR spectroscopy}

\section{Comments on the continuous wave EPR simulations}

Using the simulation procedure described in the Methods section of the main text, a near perfect fit was obtained for the spectrum with 5 equivalents of the oxidant, leaving little doubt about the triplet nature of the triangulene diradical Mes3-Tr. In contrast, the simulation of the spectrum with 0.1 equivalents turned out to be less straightforward. In that case, the simulation is complicated by the fact that two isomers $\mathbf{8 a}$ and $\mathbf{8 b}$ are thought to contribute significantly to the spectrum of the triangulene monoradical $\mathbf{8}$ and that the exact ratio of these two contributing species is unknown. In addition, also experimentally it is challenging to obtain a spectrum of 'pure' monoradical. Even if a very small amount of the oxidant was added ( 0.1 equivalents), we observed slightly different shapes of the cw EPR spectra when the experiment was repeated several times, suggesting that a small part of the molecules nevertheless undergoes further oxidation to the diradical. However, despite these complications, the agreement between simulation and experiment is surprisingly good, especially with respect to the magnitude of the hyperfine couplings and thus confirms our assignment.

\section{Additional cw EPR data}

On a sample of $\mathbf{1 a}+\mathbf{1 b}$ with oxidant in toluene, room temperature cw EPR spectra were acquired at two different microwave frequencies (X and Q-band) to verify if additional features can be resolved in the spectra when the experiments are performed at higher microwave frequencies. These experiments were performed for 0.1 and 5 equivalents of the oxidant and are shown in Fig. S5. Since no significant differences in the spectral shape were observed, all further cw EPR spectra were recorded at X-band frequencies only. 

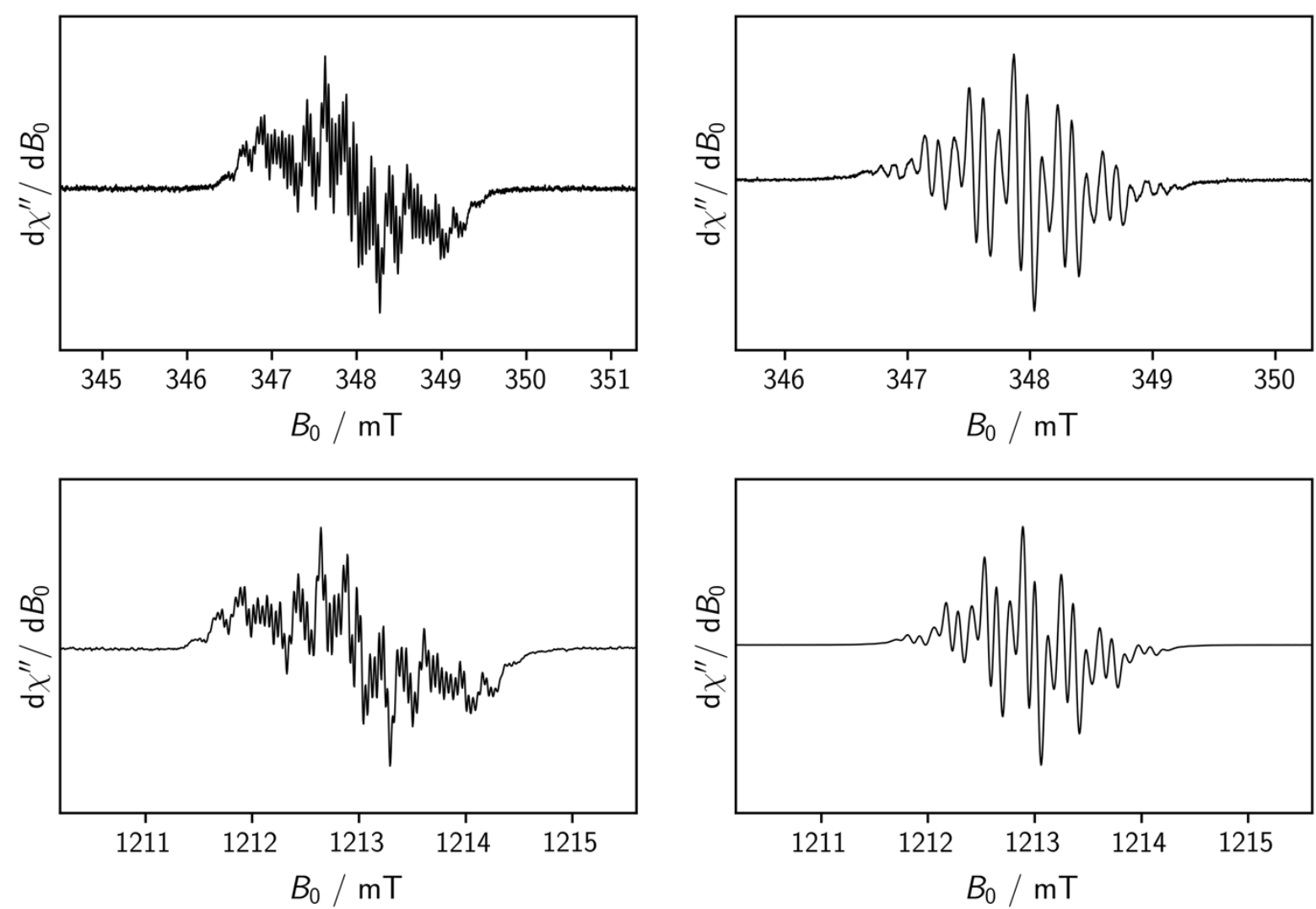

Fig. S5 | Room temperature cw EPR spectra of a $2.5 \mathrm{mM}$ solution of $\mathbf{1 a}+\mathbf{1 b}$ in toluene with 0.1 (left) and 5 (right) equivalents of the oxidant recorded at X- (top) and Q-band (bottom) frequencies.

To find suitable conditions for pulse EPR experiments and verify the reproducibility of the data, cw EPR spectra were recorded using different concentrations of $\mathbf{1 a}+\mathbf{1 b}$, different oxidant equivalents and different waiting times after oxidant addition. It was found that the same spectrum is obtained when either (i) adding more of the oxidant and recording the spectrum shortly after oxidant addition or (ii) adding less oxidant and leaving the sample to react for a longer time. This behavior is expected for a chemical oxidation to the diradical Mes $\mathbf{M}_{3} \mathbf{T r}$ and underlines the reproducibility of the spectral shape. An exemplary data set is shown in Fig. S6. The 'best' spectrum for monoradical 8 could be obtained when using low concentrations of $\mathbf{1 a}+\mathbf{1 b}(\leq 0.5 \mathrm{mM})$ and oxidant equivalents lower or equal than one. 

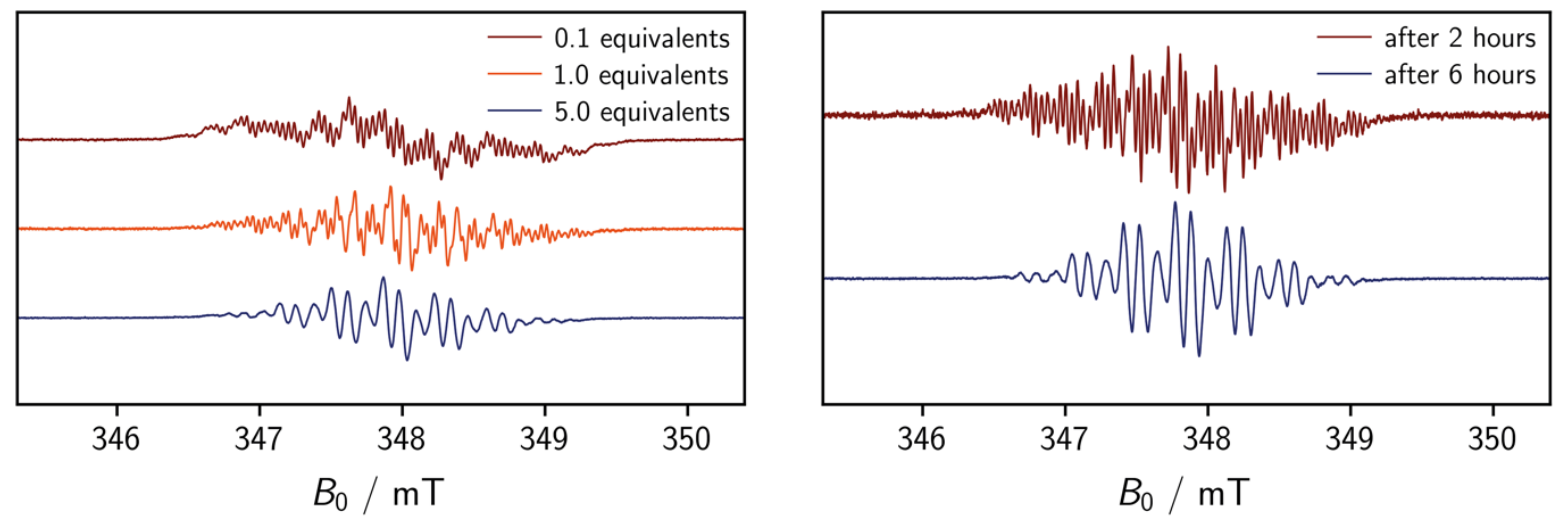

Fig. S6 | Room temperature cw EPR spectra of a $1 \mathrm{mM}$ solution of $\mathbf{1 a}+\mathbf{1 b}$ in toluene at different oxidant concentrations (as indicated, left) and a $0.5 \mathrm{mM}$ solution of $\mathbf{1 a}+\mathbf{1 b}$ in toluene with 1 equivalent of the oxidant at different times after oxidant addition (as indicated, right).

Figure S7 shows the cw EPR spectra for the samples of a $2.5 \mathrm{mM}$ solution of $\mathbf{1 a}+\mathbf{1 b}$ and oxidant in toluene that were used for the pulse EPR measurements (transient nutations). For these experiments, we deliberately employed only a short waiting time after oxidant addition since we did not want the monoradical species $\mathbf{8}$ to react any further in case of the sample with 0.1 equivalents and wanted to obtain a mixture of $\mathbf{8}$ and $\mathbf{M e s}_{3}-\mathbf{T r}$ in the case of the sample with 5 equivalents in order to be able to use the monoradical species $\mathbf{8}$ as an internal standard. The spectra in Fig. S7 are compared with the spectra that we assigned to 8 and $\mathbf{M e s}_{3}-\mathbf{T r}$, respectively. The comparison clearly shows that the sample with 5 equivalents is a mixture of mono- and diradical species, as we had aimed for.
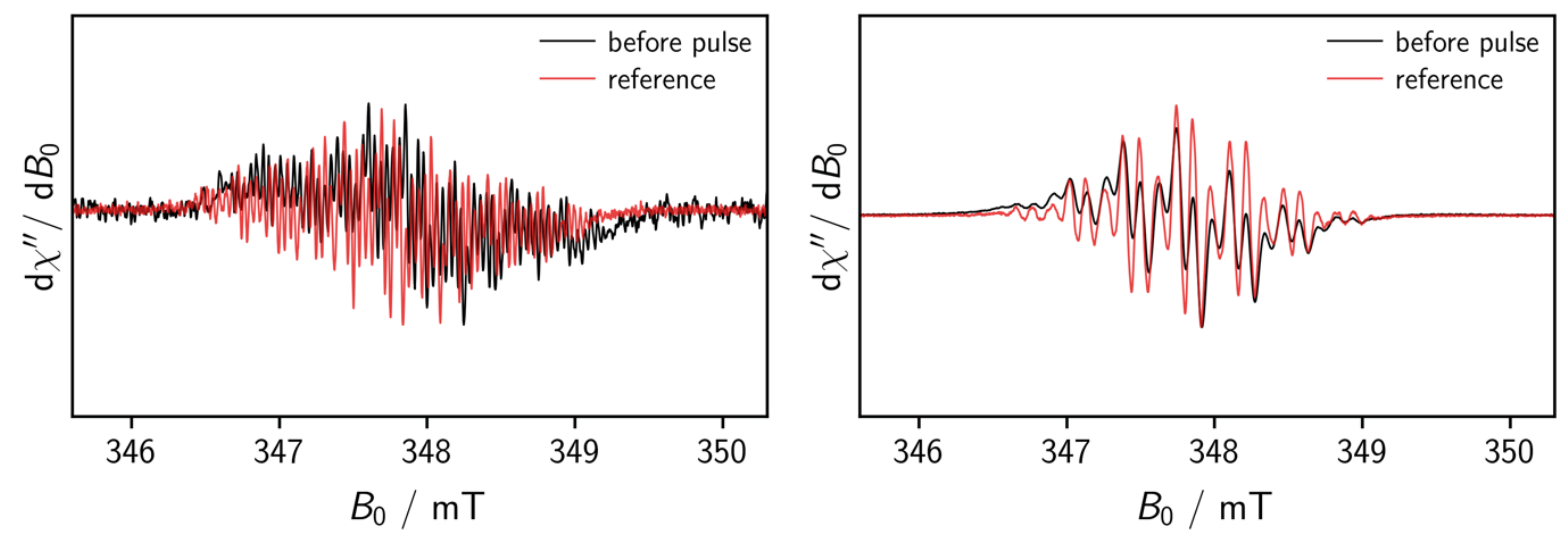

Fig. S7 | Comparison of the room temperature cw EPR spectra of a $2.5 \mathrm{mM}$ solution of $\mathbf{1 a}+\mathbf{1 b}$ in toluene with 0.1 (left) and 5 equivalents (right) of the oxidant, recorded directly before the pulse EPR measurements, with the corresponding reference spectrum assigned to the monoradical 8 (left) and diradical Mes; $-\mathbf{T r}$ (right), respectively. 
If the triplet state of $\mathbf{M e s}_{3}-\mathbf{T r}$ corresponds to the electronic ground state of the molecule, the EPR signal intensity is expected to increase when the temperature is lowered. To demonstrate this behavior, continuous wave EPR spectra were also recorded in frozen solution between 120 and $170 \mathrm{~K}$. Figure S8 shows the corresponding spectra recorded with a sample of a $1 \mathrm{mM}$ solution of $\mathbf{1 a}+\mathbf{1 b}$ with 5 equivalents of $p$-chloranil approximately 5 hours after oxidant addition. The microwave attenuation was set to $46 \mathrm{~dB}(0.0025 \mathrm{~mW})$ and the modulation amplitude to $1 \mathrm{G}$. All experimental settings were kept the same between the measurements to assure that the relative signal intensities are comparable. From Fig. S8 it can clearly be seen that the signal intensity decreases with increasing temperature, strongly suggesting a triplet ground state. Likely due to the small expected $D$ value, no half-field line could be detected for the diradical species Mes;-Tr.

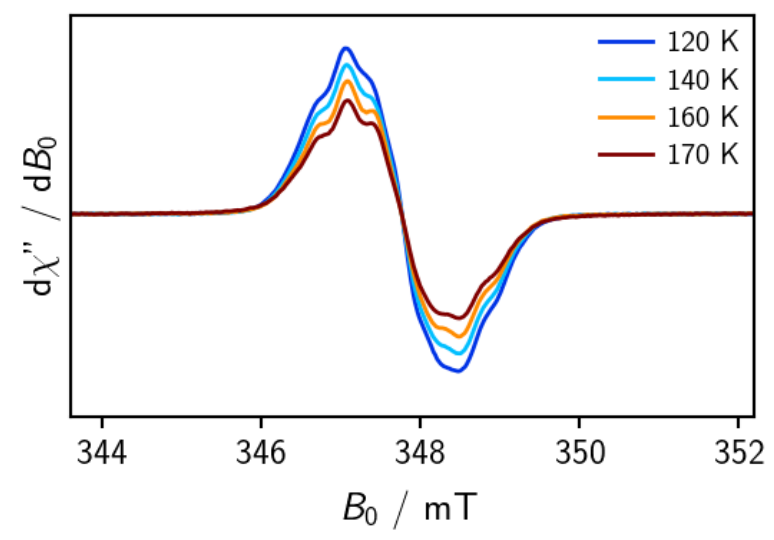

Fig. S8 | Continuous wave EPR spectra of a $1 \mathrm{mM}$ solution of $1 \mathbf{a}+\mathbf{1 b}$ with 5 equivalents of the oxidant, recorded in frozen toluene solution at variable temperatures (as indicated) using a modulation amplitude of $1 \mathrm{G}$ and a microwave attenuation of $46 \mathrm{~dB}$.

\section{Echo-detected field sweep}

Echo-detected field-swept EPR spectra at the Q-band $(34 \mathrm{GHz})$ were recorded using the sequence $\frac{\pi}{2}-\tau-\pi-\tau-$ echo with $\tau=140$ ns and a $\pi$-pulse length of $40 \mathrm{~ns}$. Figure S9 shows the spectra recorded for a $2.5 \mathrm{mM}$ solution of $\mathbf{1 a}+\mathbf{1 b}$ with either 0.1 or 5 equivalents of $p$-chloranil in frozen toluene solution at $120 \mathrm{~K}$. The spectra were frequency corrected to $34.0 \mathrm{GHz}$ and normalized for a comparison of the spectral shape. 


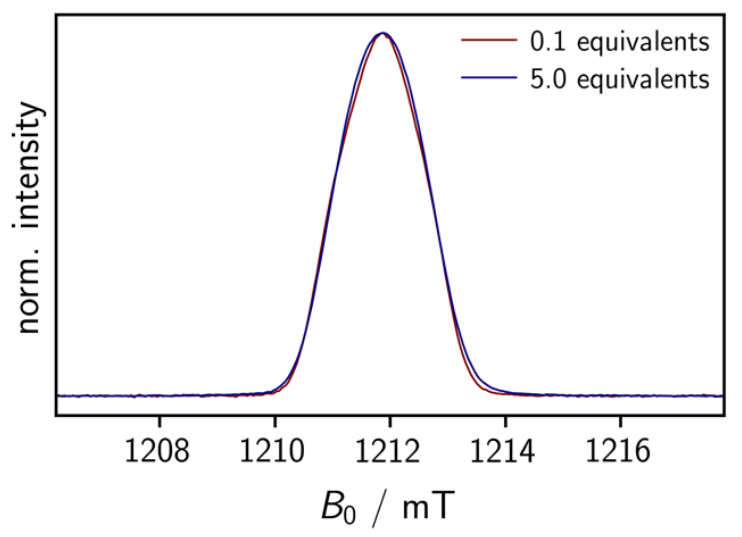

Fig. S9 | Comparison of the echo-detected field-swept EPR spectra of frozen $2.5 \mathrm{mM}$ solutions of $1 \mathbf{a}+\mathbf{1 b}$ in toluene with 0.1 and 5 equivalents of the oxidant, recorded at $120 \mathrm{~K}$.

\section{Relaxation measurements}

Spin coherence times $\left(T_{\mathrm{m}}\right)$ were measured using the pulse sequence $\frac{\pi}{2}-\tau-\pi-\tau-$ echo, where $\tau$ was gradually increased in steps of 16 or $4 \mathrm{~ns}$, for the samples with 0.1 and 5 equivalents, respectively. A fit to the experimental data was performed assuming a monoexponential decay of the form

$$
I(\tau)=A \exp \left(-\frac{2 \tau}{T_{\mathrm{m}}}\right)
$$

For the sample with 0.1 equivalents of the oxidant, a $T_{\mathrm{m}}$ value of $2.0 \mu \mathrm{s}$ was measured, while for the sample with 5 equivalents a value of $0.6 \mu$ s was obtained at the position of the intensity maximum of the field-swept EPR spectrum (center of the spectrum).

The decay traces measured in frozen toluene at $120 \mathrm{~K}$ are shown in Fig. S10. As it would be expected for a diradical system with strong coupling between the unpaired spins, the phase memory time is considerably reduced in the sample with 5 equivalents of $p$-chloranil. 


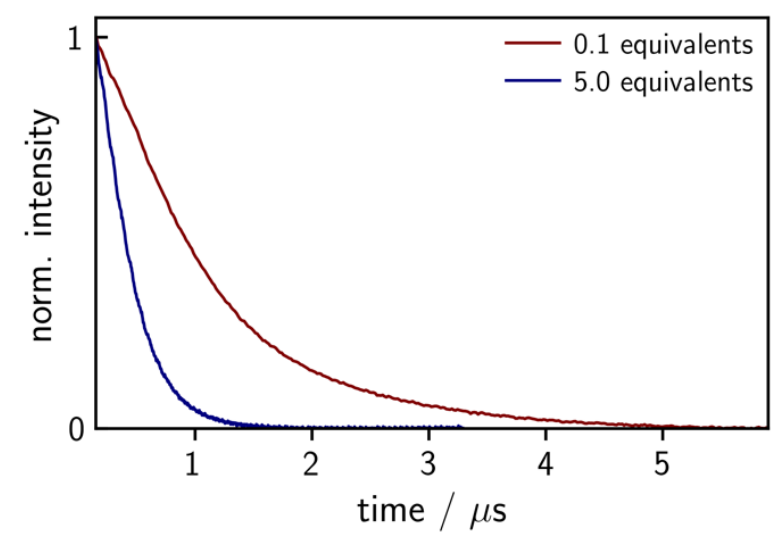

Fig. S10 | Measurement of the spin coherence time $\left(\boldsymbol{T}_{\boldsymbol{m}}\right)$ of frozen $2.5 \mathrm{mM}$ solutions of $\mathbf{1 a}+\mathbf{1 b}$ with 0.1 and 5 equivalents of the oxidant, recorded at $120 \mathrm{~K}$ at a magnetic field position corresponding to the intensity maximum (center) of the respective EPR spectra. 
Table S3 | TD-DFT-calculated relative energies, absorption maxima and corresponding oscillator strengths (only $f>0.01$ are shown) for $1 \mathrm{a}^{\prime}$

\section{Dihydro-precursor 1a'}

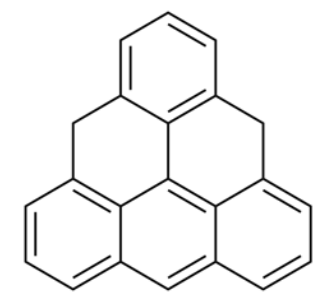

Relative energy $=1.3 \mathrm{kcal} \mathrm{mol}^{-1}$

\section{B3LYP}

$\begin{array}{lccc} & \text { Energy } / \mathrm{eV} & \text { Wavelength } / \mathrm{nm} & \text { Oscillator strength } f \\ \mathbf{S}_{\mathbf{1}} & \mathbf{2 . 7 6 6 8} & \mathbf{4 4 8 . 1 1} & \mathbf{0 . 1 7 5 3} \\ \mathrm{S}_{5} & 4.1369 & 299.70 & 0.0174 \\ \mathrm{~S}_{7} & 4.3912 & 282.35 & 0.0573 \\ \mathrm{~S}_{9} & 4.8780 & 254.17 & 0.8244\end{array}$

BMK

$\begin{array}{lrrc} & \text { Energy } / \mathrm{eV} & \text { Wavelength } / \mathrm{nm} & \text { Oscillator strength } f \\ \mathbf{S}_{\mathbf{1}} & \mathbf{3 . 0 2 3 0} & \mathbf{4 1 0 . 1 4} & \mathbf{0 . 2 1 5 5} \\ \mathrm{S}_{4} & 4.4826 & 276.59 & 0.0175 \\ \mathrm{~S}_{5} & 4.6325 & 267.64 & 0.0829 \\ \mathrm{~S}_{6} & 4.8843 & 253.84 & 0.0447 \\ \mathrm{~S}_{8} & 4.9955 & 248.19 & 0.1241\end{array}$

\section{PBEO}

$\begin{array}{lccc} & \text { Energy } / \mathrm{eV} & \text { Wavelength } / \mathrm{nm} & \text { Oscillator strength } f \\ \mathbf{S}_{\mathbf{1}} & \mathbf{2 . 8 3 7 6} & \mathbf{4 3 6 . 9 3} & \mathbf{0 . 1 8 5 6} \\ \mathrm{S}_{5} & 4.2802 & 289.67 & 0.0275 \\ \mathrm{~S}_{7} & 4.5293 & 273.74 & 0.0553 \\ \mathrm{~S}_{8} & 4.7055 & 263.49 & 0.0158 \\ \mathrm{~S}_{9} & 4.9917 & 248.38 & 0.8715\end{array}$


Table S4 | TD-DFT-calculated relative energies, absorption maxima and corresponding oscillator strengths (only $f>0.01$ are shown) for $1 \mathrm{~b}^{\prime}$

\section{Dihydro-precursor 1 $\mathbf{b}^{\prime}$}

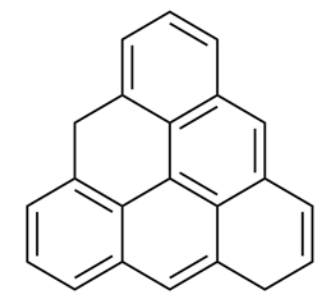

Relative energy $=0.0 \mathrm{kcal} \mathrm{mol}^{-1}$

\section{B3LYP}

$\begin{array}{lccc} & \text { Energy } / \mathrm{eV} & \text { Wavelength } / \mathrm{nm} & \text { Oscillator strength } f \\ \mathbf{S}_{\mathbf{3}} & \mathbf{3 . 7 8 8 6} & \mathbf{3 2 7 . 2 5} & \mathbf{0 . 1 6 2 5} \\ \mathbf{S}_{\mathbf{4}} & \mathbf{4 . 0 3 0 5} & \mathbf{3 0 7 . 6 1} & \mathbf{0 . 4 8 0 6} \\ \mathrm{S}_{5} & 4.3379 & 285.81 & 0.0126 \\ \mathrm{~S}_{6} & 4.4823 & 276.61 & 0.0101 \\ \mathrm{~S}_{7} & 4.6456 & 266.88 & 0.0188 \\ \mathrm{~S}_{9} & 4.8616 & 255.03 & 0.0569\end{array}$

\section{BMK}

$\begin{array}{ccc}\text { Energy } / \mathrm{eV} & \text { Wavelength } / \mathrm{nm} & \text { Oscillator strength } f \\ \mathbf{4 . 2 7 6 4} & \mathbf{2 8 9 . 9 3} & \mathbf{0 . 2 9 4 6} \\ \mathbf{4 . 3 9 3 5} & \mathbf{2 8 2 . 2 0} & \mathbf{0 . 5 9 0 4} \\ 4.6958 & 264.03 & 0.0117 \\ 5.0110 & 247.42 & 0.0160\end{array}$

\section{PBE0}

$\mathbf{S}_{3}$

$\mathbf{S}_{4}$

$\mathrm{S}_{5}$

$\mathrm{S}_{6}$

$\begin{array}{lr} & \text { Energy } / \mathrm{eV} \\ \mathbf{S}_{\mathbf{3}} & \mathbf{4 . 2 7 6 4} \\ \mathrm{S}_{\mathbf{4}} & \mathbf{4 . 3 9 3 5} \\ \mathrm{S}_{5} & 4.6958 \\ \mathrm{~S}_{6} & 5.0110\end{array}$

Energy /eV

$\mathbf{S}_{3}$

$\mathrm{S}_{4}$

$\mathrm{S}_{5}$

$\mathrm{S}_{6}$

$\mathrm{S}_{7}$

$\mathrm{S}_{9}$
3.9211

4.1323

4.4428

4.6229

4.8059

5.0075
Wavelength / nm

316.20

300.03

279.07

268.19

257.98

247.60
Oscillator strength $f$
0.1873
0.5135
0.0136
0.0115
0.0204
0.0489 
Table S5 | TD-DFT-calculated relative energies, absorption maxima and corresponding oscillator strengths (only $f>0.01$ are shown) for 1 a

\section{Dihydro-precursor 1a}

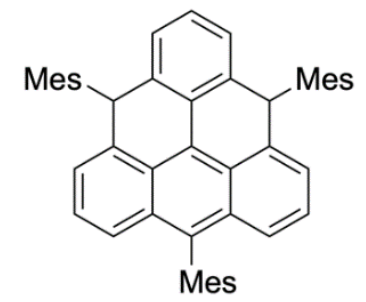

Relative energy $(s y n)=6.6 \mathrm{kcal} \mathrm{mol}^{-1}$

Relative energy $(a n t i)=6.5 \mathrm{kcal} \mathrm{mol}^{-1}$

$\begin{array}{cccc}\text { B3LYP } & & & \\ \text { syn-1a } & \text { Energy / eV } & \text { Wavelength / nm } & \text { Oscillator strength } f \\ & \mathbf{2 . 6 9 9 7} & \mathbf{4 5 9 . 2 6} & \mathbf{0 . 2 6 2 5} \\ \mathbf{S}_{\mathbf{1}} & 4.3625 & 284.20 & 0.0347 \\ \mathrm{~S}_{15} & 4.4533 & 278.41 & 0.0347 \\ \mathrm{~S}_{17} & 4.4940 & 275.89 & 0.0610 \\ \mathrm{~S}_{18} & 4.5353 & 273.38 & 0.0226 \\ \mathrm{~S}_{19} & 4.6049 & 269.25 & 0.0110 \\ \mathrm{~S}_{20} & 4.7832 & 259.21 & 0.7509 \\ \mathrm{~S}_{21} & & & \\ & & & \\ \text { B3LYP } & & \text { Oscillator strength } f \\ \text { anti-1a } & \text { Energy / eV } & \mathbf{4 5 8 . 1 9} & \mathbf{0 . 2 6 3 3} \\ & \mathbf{2 . 7 0 6 0} & 328.60 & 0.0133 \\ \mathbf{S}_{\mathbf{1}} & 3.7731 & 284.67 & 0.0143 \\ \mathrm{~S}_{4} & 4.3554 & 282.72 & 0.0291 \\ \mathrm{~S}_{15} & 4.3855 & 278.10 & 0.0457 \\ \mathrm{~S}_{16} & 4.4583 & 276.62 & 0.0512 \\ \mathrm{~S}_{17} & 4.4821 & 272.67 & 0.0224 \\ \mathrm{~S}_{18} & 4.5471 & 270.03 & 0.0112 \\ \mathrm{~S}_{19} & 4.5914 & 259.16 & 0.7520 \\ \mathrm{~S}_{20} & 4.7841 & & \end{array}$


Table S6 | TD-DFT-calculated relative energies, absorption maxima and corresponding oscillator strengths (only $f>0.01$ are shown) for $1 \mathrm{~b}$

\section{Dihydro-precursor 1b}

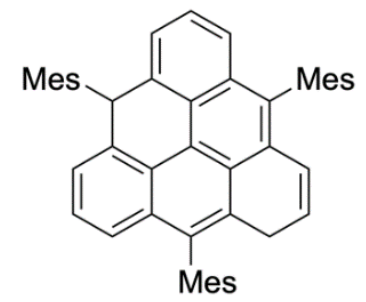

Relative energy $=0.0 \mathrm{kcal} \mathrm{mol}^{-1}$

\section{B3LYP}

$$
\text { Energy / eV Wavelength / nm Oscillator strength } f
$$

$\begin{array}{llll}\mathrm{S}_{2} & 3.5530 & 348.95 & 0.0159 \\ \mathbf{S}_{\mathbf{3}} & \mathbf{3 . 7 4 2 1} & \mathbf{3 3 1 . 3 3} & \mathbf{0 . 2 3 1 0} \\ \mathbf{S}_{\mathbf{4}} & \mathbf{3 . 9 4 4 7} & \mathbf{3 1 4 . 3 1} & \mathbf{0 . 6 0 2 2} \\ \mathrm{S}_{6} & 4.2893 & 289.06 & 0.0248 \\ \mathrm{~S}_{7} & 4.3203 & 286.98 & 0.0127 \\ \mathrm{~S}_{11} & 4.5093 & 274.95 & 0.0186 \\ \mathrm{~S}_{12} & 4.5193 & 274.34 & 0.0135 \\ \mathrm{~S}_{25} & 4.8379 & 256.28 & 0.0535 \\ \mathrm{~S}_{27} & 4.8864 & 253.73 & 0.0154 \\ \mathrm{~S}_{30} & 4.9563 & 250.15 & 0.0324\end{array}$


Table S7 | TD-DFT-calculated relative energies, absorption maxima and corresponding oscillator strengths (only $f>0.01$ are shown) for $8 \mathrm{a}^{\prime}$

\section{Monoradical 8a'}

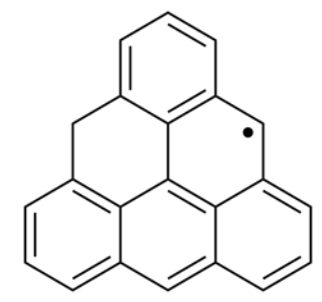

Relative energy $\left(\mathbf{8} \mathbf{a}^{\prime}\right)=-2.3 \mathrm{kcal} \mathrm{mol}^{-1}$

Relative energy $(\mathbf{8 a})=-3.4 \mathrm{kcal} \mathrm{mol}^{-1}$

\section{B3LYP}

$\mathbf{S}_{2}$

$\mathrm{S}_{7}$

$\mathrm{S}_{8}$

$\mathrm{S}_{10}$

$\mathrm{S}_{12}$

$\mathrm{S}_{15}$

$\mathrm{S}_{22}$

$\mathrm{S}_{26}$

Energy / eV
$\mathbf{2 . 4 6 5 2}$
3.2076
3.3752
3.6383
3.9346
4.2365
4.6804
4.8537

Wavelength / nm

Oscillator strength $f$

$\mathbf{5 0 2 . 9 3}$

0.0566

386.54

0.0484

367.34

0.0900

340.77

0.1001

315.11

0.3539

292.66

0.0108

264.90

0.0161

255.44

0.2241

\section{BMK}

\section{Energy / eV}

$\mathbf{S}_{3}$

$\mathrm{S}_{6}$

$\mathrm{S}_{8}$

$\mathrm{S}_{10}$

$\mathrm{S}_{12}$

$\mathrm{S}_{15}$
2.7794

3.4860

3.6531

4.0335

4.3015

4.6524
Wavelength / nm

446.09

355.67

339.40

307.38

288.23

266.49
Oscillator strength $f$

$$
\begin{aligned}
& \mathbf{0 . 0 7 1 6} \\
& 0.0675 \\
& 0.2046 \\
& 0.0724 \\
& 0.4292 \\
& 0.0179
\end{aligned}
$$

\section{PBE0}

$\begin{array}{ccc}\text { Energy / eV } & \text { Wavelength } / \mathrm{nm} & \text { Oscillator strength } f \\ \mathbf{2 . 6 3 0 6} & \mathbf{4 7 1 . 3 1} & \mathbf{0 . 0 6 0 3} \\ 3.3539 & 369.67 & 0.0474 \\ 3.5340 & 350.83 & 0.1219 \\ 3.8186 & 324.68 & 0.0714 \\ 4.0497 & 306.16 & 0.3815 \\ 4.8390 & 256.22 & 0.0220\end{array}$


Table S8 | TD-DFT-calculated relative energies, absorption maxima and corresponding oscillator strengths (only $f>0.01$ are shown) for $8 b^{\prime}$

\section{Monoradical 8b'}

Relative energy $\left(\mathbf{8 b}^{\prime}\right)=0.0 \mathrm{kcal} \mathrm{mol}^{-1}$<smiles>c1cc2c3c(cccc3c1)-c1cccc3cccc(c13)C2</smiles>

Relative energy $(\mathbf{8 b})=0.0 \mathrm{kcal} \mathrm{mol}^{-1}$

\section{B3LYP}

$\mathbf{S}_{2}$

$\mathrm{S}_{6}$

$\mathrm{S}_{7}$

$\mathrm{S}_{9}$

$\mathrm{S}_{10}$

$\mathrm{S}_{11}$

$\mathrm{S}_{19}$

$\mathrm{S}_{26}$
Energy / eV

2.4132

3.2157

3.3861

3.4685

3.6547

3.7784

4.3762

4.8973

BMK

$\mathbf{S}_{\mathbf{2}}$

$\mathrm{S}_{6}$

$\mathrm{S}_{7}$

$\mathrm{S}_{9}$

$\mathrm{S}_{10}$

$\mathrm{S}_{19}$
Energy / eV

2.4132

3.2157

3.3861

3.4685

3.6547

4.8579
Wavelength / nm

$\mathbf{5 1 3 . 7 7}$

385.55

366.15

357.46

339.24

328.14

283.31

253.17
Oscillator strength $f$

0.1377

0.0430

0.0222

0.0196

0.0305

0.0712

0.0220

0.1184

\section{PBE0}

$\begin{array}{lcrc} & \text { Energy } / \mathrm{eV} & \text { Wavelength } / \mathrm{nm} & \text { Oscillator strength } f \\ \mathbf{S}_{\mathbf{2}} & \mathbf{2 . 4 1 3 2} & \mathbf{5 1 3 . 7 7} & \mathbf{0 . 1 3 7 7} \\ \mathrm{S}_{6} & 3.2157 & 385.55 & 0.0430 \\ \mathrm{~S}_{7} & 3.3861 & 366.15 & 0.0222 \\ \mathrm{~S}_{9} & 3.4685 & 357.46 & 0.0196 \\ \mathrm{~S}_{10} & 3.6547 & 339.24 & 0.0305 \\ \mathrm{~S}_{11} & 3.7784 & 328.14 & 0.0712 \\ \mathrm{~S}_{19} & 4.3762 & 283.31 & 0.0220 \\ \mathrm{~S}_{23} & 4.8517 & 255.55 & 0.0694\end{array}$


Table S9 | TD-DFT-calculated relative energies, absorption maxima and corresponding oscillator strengths (only $\boldsymbol{f}>\mathbf{0 . 0 1}$ are shown) for triangulene

\section{Triangulene}<smiles></smiles>

\section{B3LYP}

$\mathrm{S}_{1}$

$\mathrm{S}_{2}$

$\mathrm{S}_{3}$

$\mathrm{S}_{4}$

$\mathrm{S}_{8}$

$\mathrm{S}_{9}$

$\mathrm{S}_{10}$

$\mathrm{S}_{11}$

$\mathrm{S}_{12}$

$\mathrm{S}_{13}$

$\mathrm{S}_{15}$

$\mathrm{S}_{16}$
Energy / eV

2.6461

2.6472

2.9103

2.9111

3.2289

3.2290

3.2908

3.2920

3.4227

3.4235

3.9160

3.9162
Wavelength / nm

468.56

468.35

426.02

425.91

383.98

383.97

376.76

376.62

362.24

362.15

316.61

316.60
Oscillator strength $f$

0.0004

0.0004

0.0018

0.0018

0.0184

0.0186

0.0082

0.0082

0.0122

0.0126

0.4307

0.4308

BMK

$\mathrm{S}_{1}$

$\mathrm{S}_{2}$

$\mathrm{S}_{3}$

$\mathrm{S}_{4}$

$\mathrm{S}_{7}$

$\mathrm{S}_{8}$

$\mathrm{S}_{10}$

$\mathrm{S}_{11}$

$\mathrm{S}_{12}$

$\mathrm{S}_{13}$

$\mathrm{S}_{14}$

$S_{15}$
Energy / eV

2.8626

2.8643

3.1045

3.1053

3.5433

3.5437

3.7185

3.7200

3.8195

3.8197

4.2291

4.2300
Wavelength / nm

433.12

432.87

399.37

399.27

349.91

349.88

333.43

333.29

324.61

324.59

293.17

293.11
Oscillator strength $f$

0.0004

0.0004

0.0020

0.0020

0.0321

0.0319

0.0203

0.0208

0.0466

0.0476

0.5181

0.5173 


$\begin{array}{lccc}\text { PBE0 } & \text { Energy / eV } & \text { Wavelength } / \mathrm{nm} & \text { Oscillator strength } f \\ \mathrm{~S}_{1} & 2.7851 & 445.17 & 0.0005 \\ \mathrm{~S}_{2} & 2.7864 & 444.97 & 0.0005 \\ \mathrm{~S}_{3} & 3.0307 & 409.09 & 0.0019 \\ \mathrm{~S}_{4} & 3.0314 & 409.00 & 0.0020 \\ \mathrm{~S}_{8} & 3.4070 & 363.91 & 0.0237 \\ \mathrm{~S}_{9} & 3.4071 & 363.90 & 0.0235 \\ \mathrm{~S}_{10} & 3.5050 & 353.74 & 0.0110 \\ \mathrm{~S}_{11} & 3.5063 & 353.60 & 0.0111 \\ \mathrm{~S}_{12} & 3.6317 & 341.40 & 0.0156 \\ \mathrm{~S}_{13} & 3.6323 & 341.34 & 0.0161 \\ \mathrm{~S}_{15} & \mathbf{4 . 0 8 1 9} & \mathbf{3 0 3 . 7 4} & \mathbf{0 . 4 5 3 0} \\ \mathrm{S}_{16} & \mathbf{4 . 0 8 2 2} & \mathbf{3 0 3 . 7 2} & \mathbf{0 . 4 5 3 0} \\ \mathrm{S}_{21} & 4.8597 & 255.13 & 0.0011 \\ \mathrm{~S}_{22} & 4.8614 & 255.04 & 0.0012\end{array}$

\section{DFT calculations of hyperfine coupling constants and spin densities}

DFT predicts near identical $g$ values for all three structures of 2.0026. A visual representation of the optimized molecular structures and calculated spin densities (iso value of 0.001) is shown in Fig. S11. Figure S12 shows a visual representation of the calculated anisotropic proton hyperfine coupling tensors for the three structures and gives an overview over the corresponding isotropic values which were used in the simulations. A summary of the isotropic values is provided in Table S10. All hyperfine couplings smaller than $0.5 \mathrm{MHz}$ were neglected here since they are not resolved in the experimental spectra and only contribute to the linewidth. 

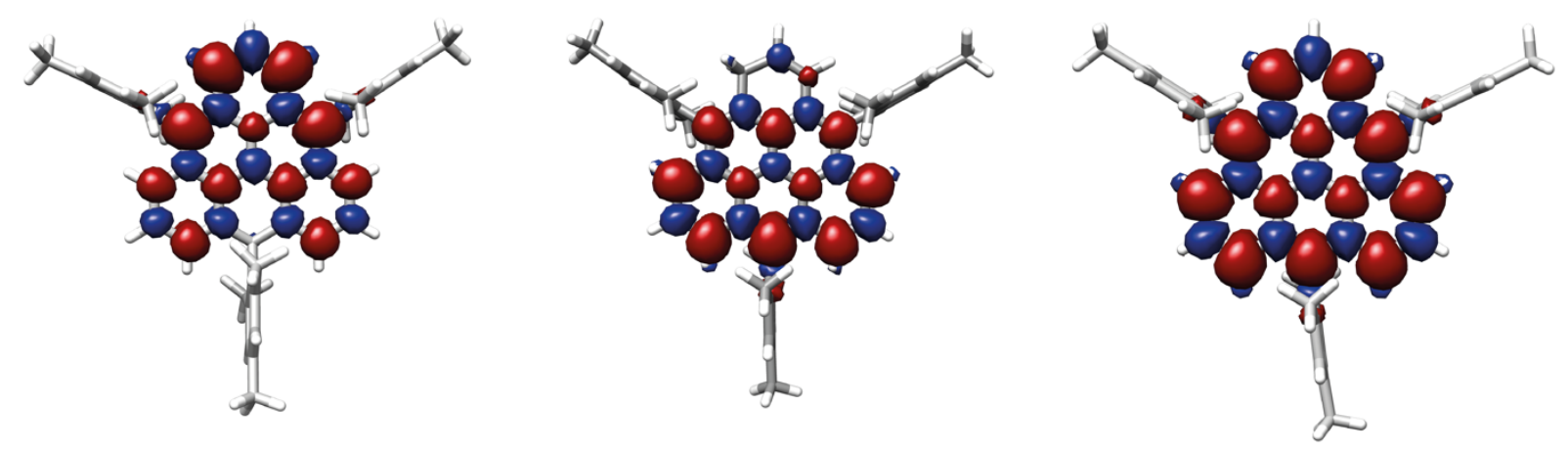

Fig. S11 | Visualization of the spin density in the doublet state of $8 \mathbf{a}$ and $\mathbf{8 b}$ (left and center, respectively) and in the triplet state of Mes3-Tr (right) as predicted by DFT calculations.
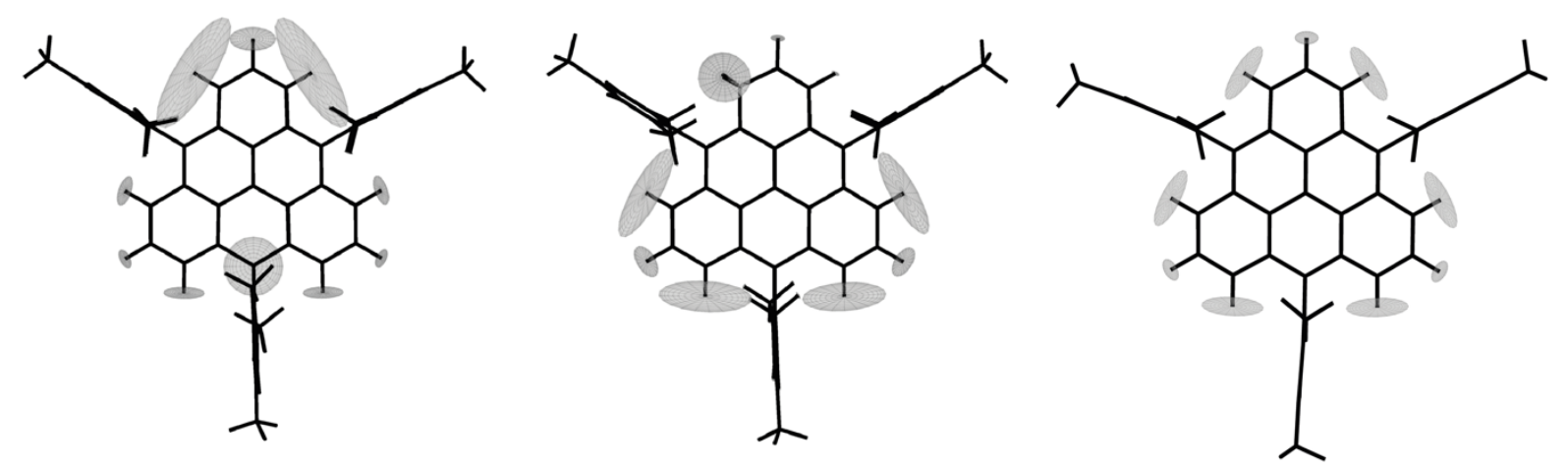

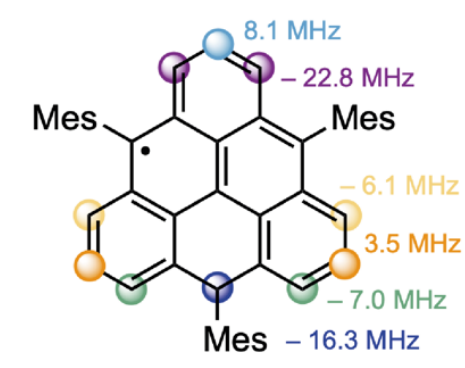

on Mes: $0.9-1.0 \mathrm{MHz}(x 4)$

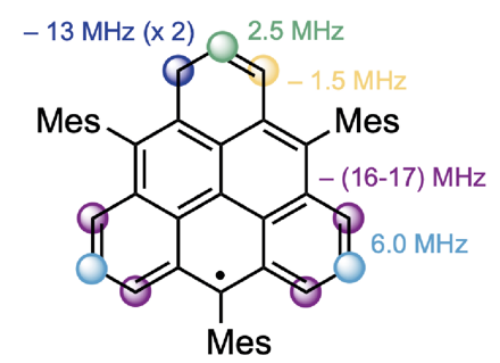

on Mes: $1.3-1.4 \mathrm{MHz}(x 2)$ $0.6 \mathrm{MHz}(x 6)$

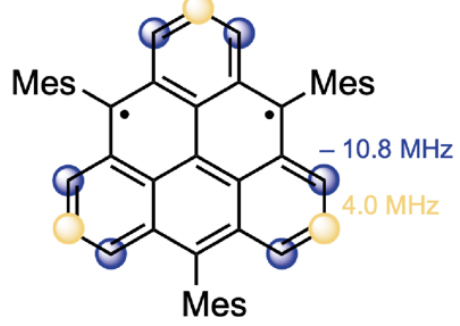

on Mes: $\sim 0.6 \mathrm{MHz}(x 6)$

Fig. S12 | Visualization of the calculated proton hyperfine coupling tensors associated with the doublet state of $\mathbf{8 a}$ and $\mathbf{8 b}$ (left and center, respectively) and the triplet state of Mes 3 - $\mathbf{T r}$ (right). The tensors are placed at the position of the individual protons and have been scaled by the same value in all cases for illustration purposes. The illustration below shows the corresponding isotropic hyperfine coupling constants as needed for the simulations of the room temperature cw EPR spectra. Similar values have been grouped and only calculated hyperfine coupling constants larger than $0.5 \mathrm{MHz}$ are considered. All smaller couplings are assumed to contribute to the linewidth only. 
Table S10 | Overview of the calculated isotropic ${ }^{1} \mathbf{H}$ hyperfine coupling constants for 8a, $8 \mathrm{~b}$ and $\mathrm{Mes}_{3}-\mathrm{Tr}$ as used in the simulations

\begin{tabular}{llll} 
Set & Monoradical 8a & Monoradical 8b & Diradical Mes3-Tr \\
\hline $\mathbf{1}$ & $-22.9 \mathrm{MHz}(\times 1)$ & $-17.4 \mathrm{MHz}(\times 1)$ & $-10.9 \mathrm{MHz}(\times 1)$ \\
$\mathbf{2}$ & $-22.7 \mathrm{MHz}(\times 1)$ & $-17.1 \mathrm{MHz}(\times 1)$ & $-10.8 \mathrm{MHz}(\times 4)$ \\
$\mathbf{3}$ & $-16.4 \mathrm{MHz}(\times 1)$ & $-16.0 \mathrm{MHz}(\times 1)$ & $-10.7 \mathrm{MHz}(\times 1)$ \\
$\mathbf{4}$ & $8.1 \mathrm{MHz}(\times 1)$ & $-15.6 \mathrm{MHz}(\times 1)$ & $4.0 \mathrm{MHz}(\times 3)$ \\
$\mathbf{5}$ & $-7.0 \mathrm{MHz}(\times 1)$ & $-13.7 \mathrm{MHz}(\times 1)$ & $0.6 \mathrm{MHz}(\times 6)$ \\
$\mathbf{6}$ & $-6.9 \mathrm{MHz}(\times 1)$ & $-12.6 \mathrm{MHz}(\times 1)$ & - \\
$\mathbf{7}$ & $-6.2 \mathrm{MHz}(\times 1)$ & $6.1 \mathrm{MHz}(\times 1)$ & - \\
$\mathbf{8}$ & $-6.1 \mathrm{MHz}(\times 1)$ & $5.7 \mathrm{MHz}(\times 1)$ & - \\
$\mathbf{9}$ & $3.5 \mathrm{MHz}(\times 2)$ & $2.5 \mathrm{MHz}(\times 1)$ & - \\
$\mathbf{1 0}$ & $1.0 \mathrm{MHz}(\times 1)$ & $-1.5 \mathrm{MHz}(\times 1)$ & - \\
$\mathbf{1 1}$ & $0.97 \mathrm{MHz}(\times 1)$ & $1.4 \mathrm{MHz}(\times 1)$ & - \\
$\mathbf{1 2}$ & $0.96 \mathrm{MHz}(\times 1)$ & $1.3 \mathrm{MHz}(\times 1)$ & - \\
$\mathbf{1 3}$ & $0.95 \mathrm{MHz}(\times 1)$ & $0.66 \mathrm{MHz}(\times 3)$ & \\
$\mathbf{1 4}$ & - & $0.60 \mathrm{MHz}(\times 3)$ &
\end{tabular}

Near identical values were grouped to form sets of equivalent protons and only couplings larger than $0.5 \mathrm{MHz}$ were considered. The couplings of the methyl group protons on the mesityl side groups were averaged since the methyl group is assumed to be freely rotating. The number of equivalent protons is given in parentheses and the couplings of protons on the mesityl side groups are marked in gray. In the simulations of the spectra, shown in Fig. 5, a scaling factor of 0.93 was applied to all proton couplings listed above. 


\section{Calculation of the singlet-triplet energy gap for $\mathrm{Mes}_{3}-\mathrm{Tr}$}

The exchange coupling parameter $J$ was calculated by comparing the energies of triplet and broken-symmetry (singlet) wavefunctions, using the Yamaguchi formalism ${ }^{8,9}$

$$
J=\frac{E_{\mathrm{BS}}-E_{\mathrm{T}}}{\left\langle S^{2}\right\rangle_{\mathrm{T}}-\left\langle S^{2}\right\rangle_{\mathrm{BS}}}
$$

where $E_{\mathrm{BS}}$ is the energy of the broken-symmetry (singlet) state, $E_{\mathrm{T}}$ is the energy of the triplet state, and $\left\langle S^{2}\right\rangle_{\mathrm{BS}}$ and $\left\langle S^{2}\right\rangle_{\mathrm{T}}$ are the expectation values of $S^{2}$ for the broken symmetry and triplet states. The SCF convergence criteria were set to $10^{-8}$ (default) and $10^{-12}$ for the geometry optimizations and single-point calculations, respectively.

From an initial converged triplet geometry and wavefunction, a broken symmetry guess at the triplet geometry was converged to generate the singlet solution. This yielded a $J$ value of $2235 \mathrm{~cm}^{-1}$.

Since the DFT calculations make use of the following Hamiltonian

$$
\widehat{\mathcal{H}}_{\mathrm{J}}=-2 J \hat{\mathcal{S}}_{1} \hat{\mathcal{S}}_{2}
$$

a positive $J$ value indicates ferromagnetic coupling $\left(E_{\mathrm{T}}<E_{\mathrm{S}}\right)$, in agreement with the experimental observations. From this calculation, the singlet-triplet gap $(2 J)$ is thus estimated to be about $12.8 \mathrm{kcal} \mathrm{mol}^{-1}$.

Using the same procedure for the parent triangulene molecule without the three mesityl side groups, a value of $13.2 \mathrm{kcal} \mathrm{mol}^{-1}$ is obtained, which is in good agreement with previous literature results ${ }^{10}$. 


\section{S7. Copies of NMR and HRMS spectra}

${ }^{1} \mathrm{H} \mathrm{NMR} \mathrm{/} 400 \mathrm{MHz} / \mathrm{CDCl}_{3}$
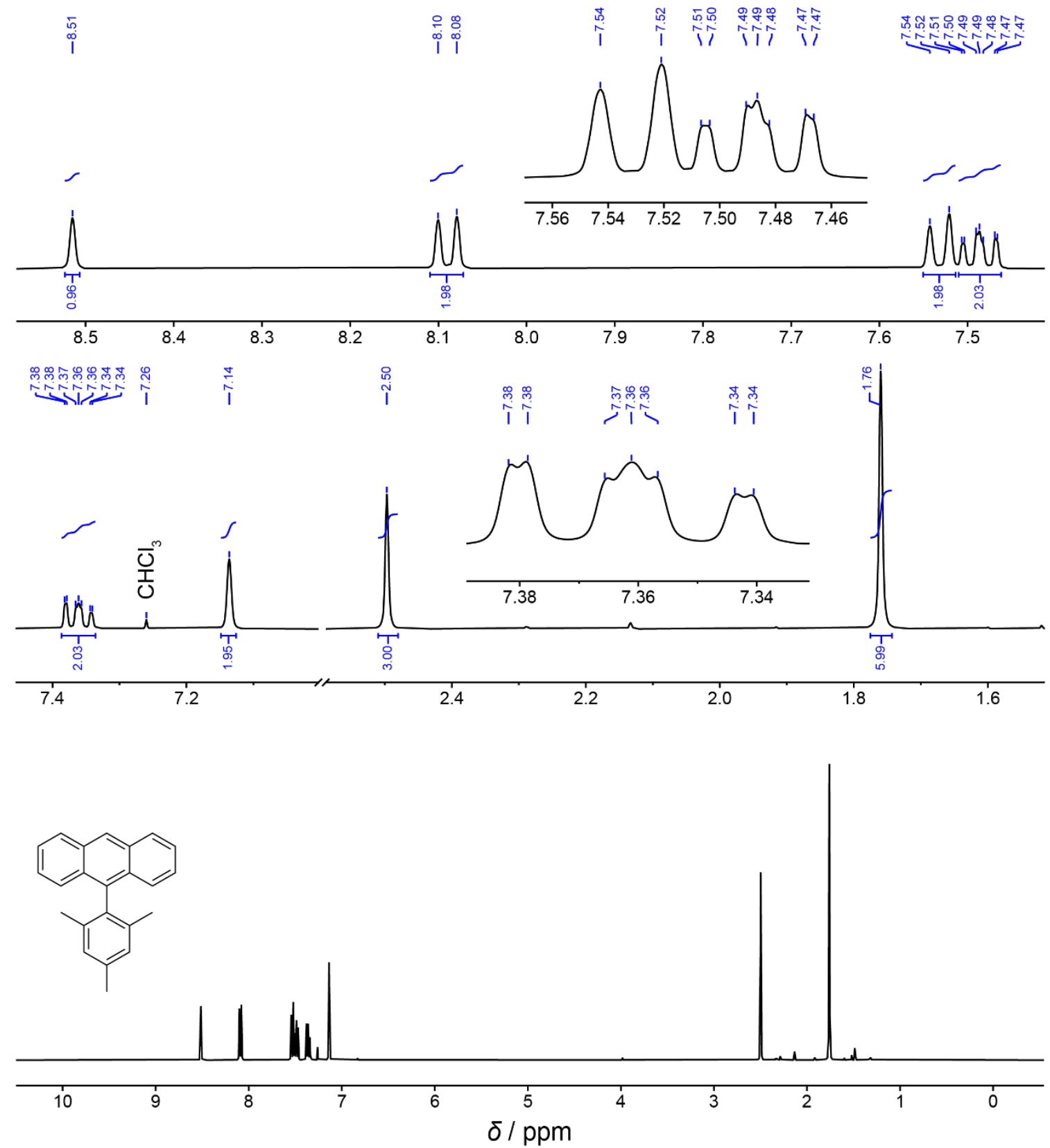
${ }^{13} \mathrm{C}$ NMR / $101 \mathrm{MHz} / \mathrm{CDCl}_{3}$
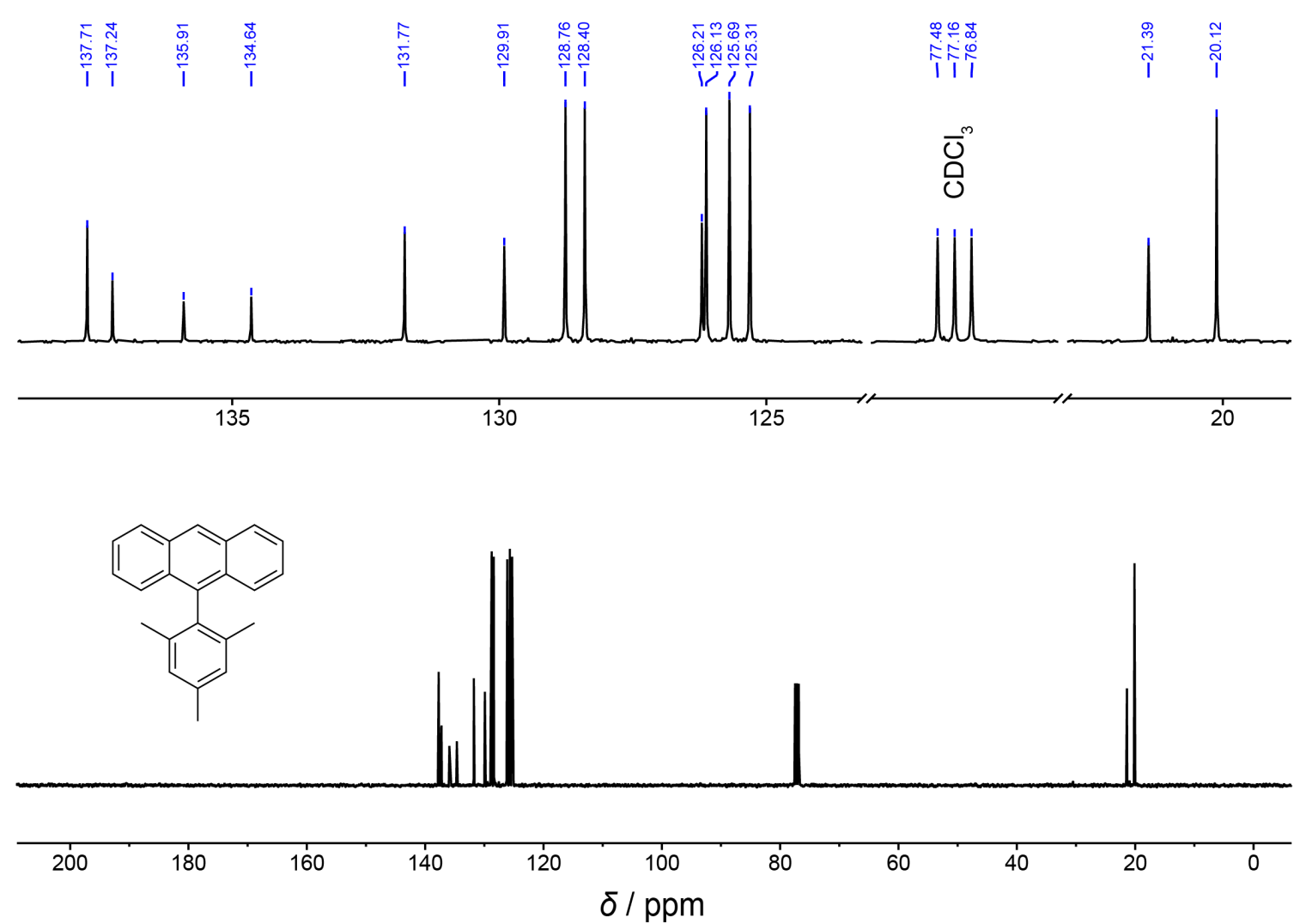
${ }^{1} \mathrm{H} \mathrm{NMR} / 400 \mathrm{MHz} / \mathrm{CDCl}_{3}$

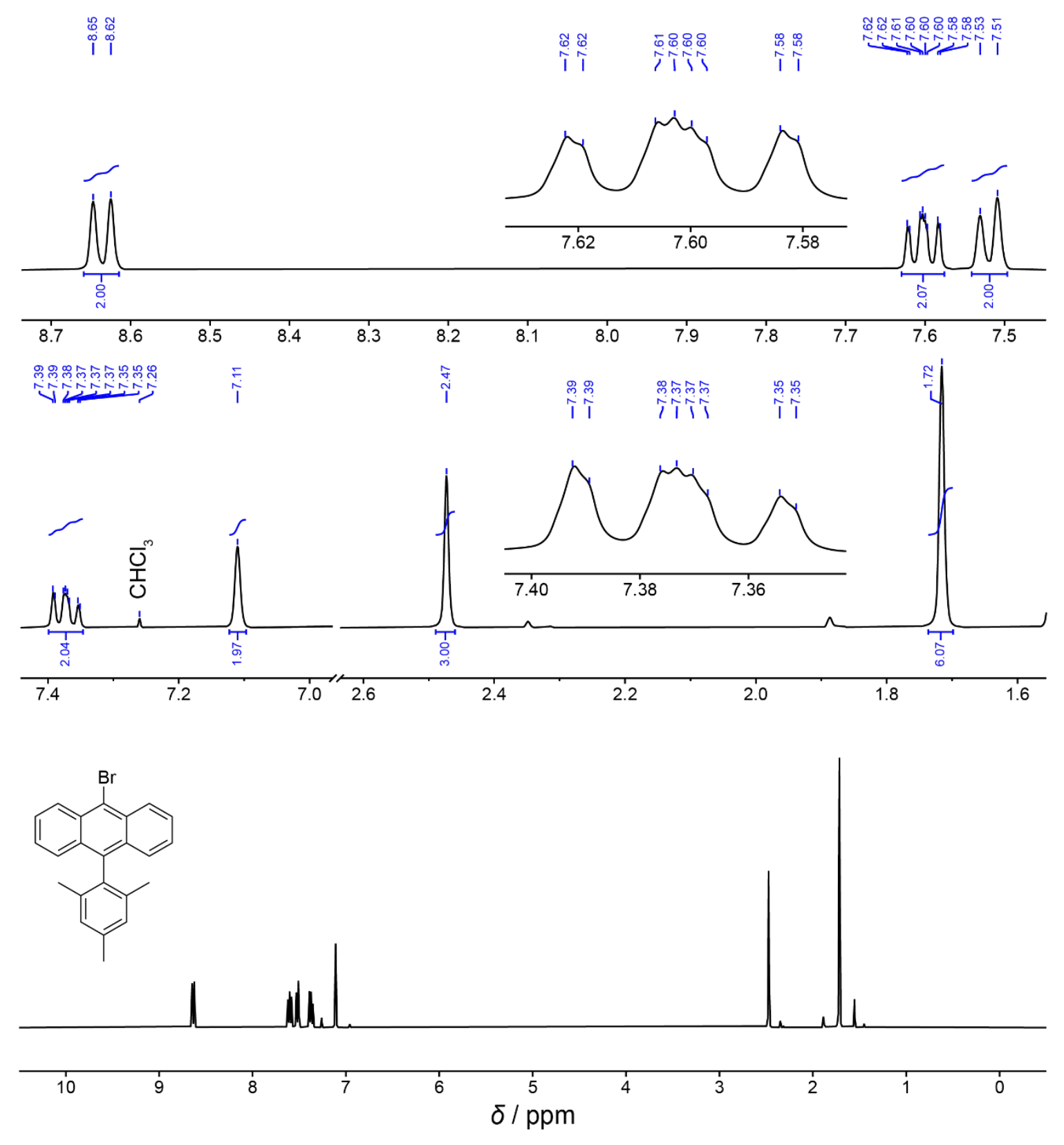


${ }^{13} \mathrm{C} \mathrm{NMR} \mathrm{/} 101 \mathrm{MHz} / \mathrm{CDCl}_{3}$
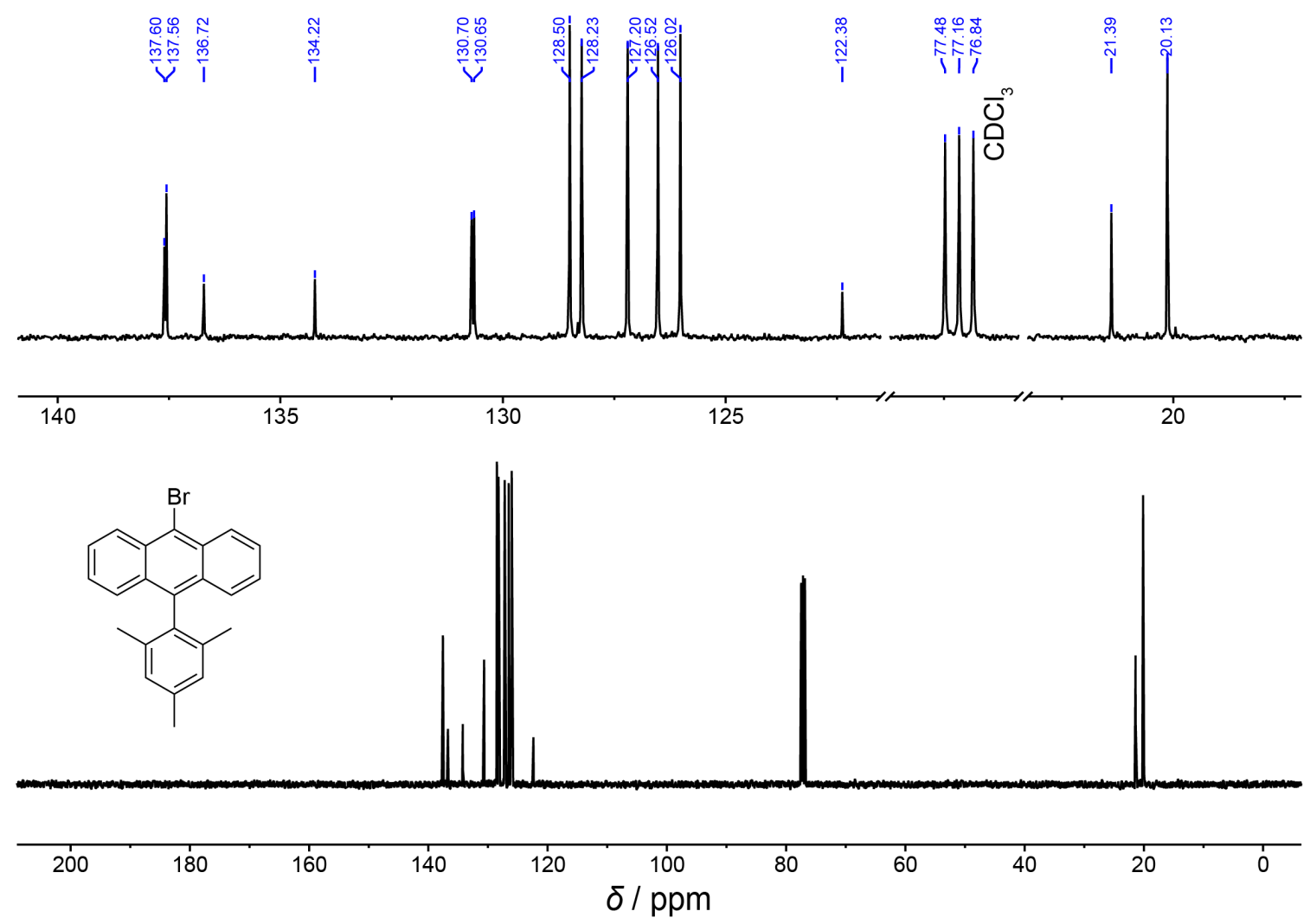
${ }^{1} \mathrm{H} \mathrm{NMR} \mathrm{/} 500 \mathrm{MHz} / \mathrm{CDCl}_{3}$

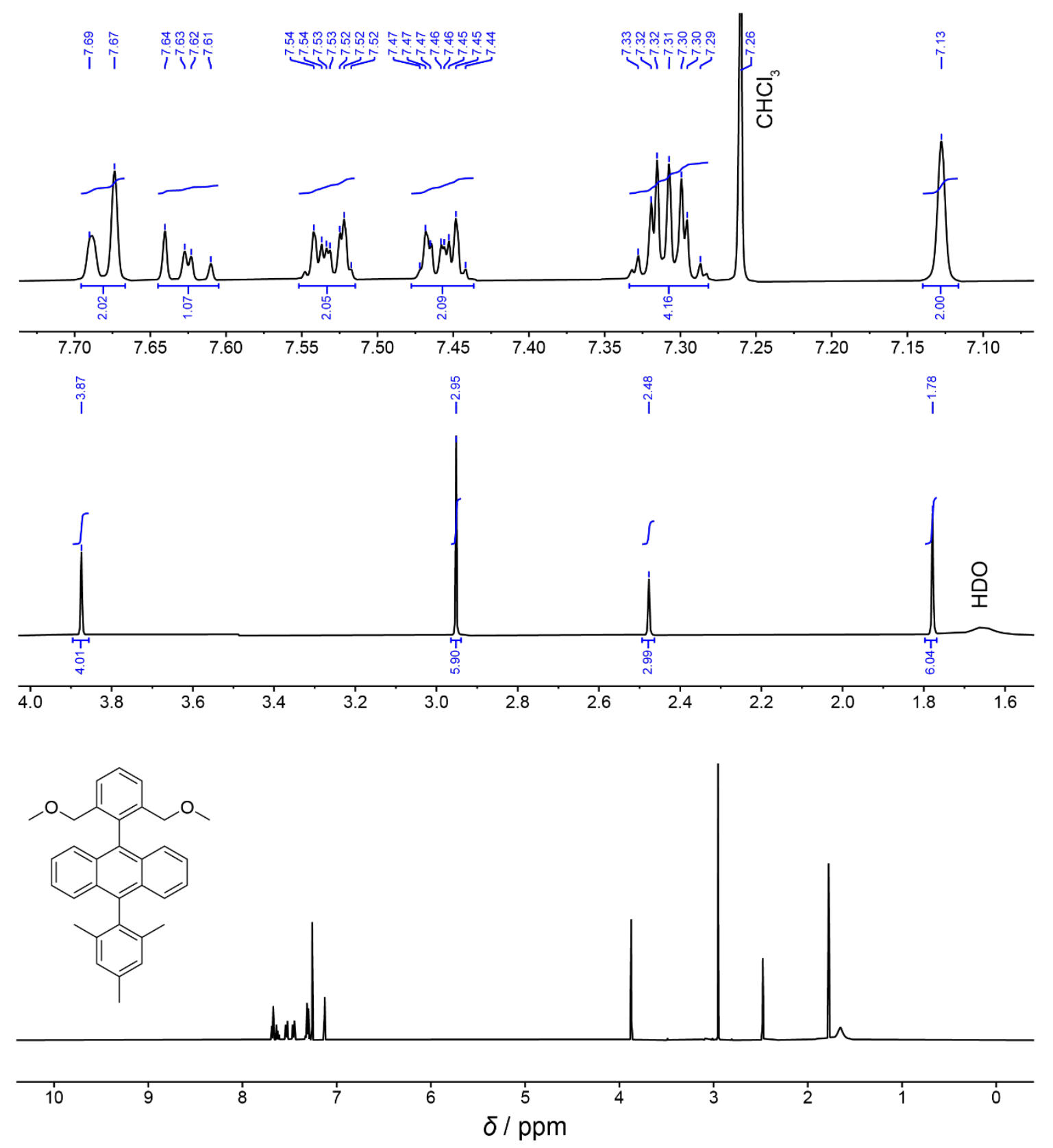


${ }^{13} \mathrm{C} \mathrm{NMR} \mathrm{/} 126 \mathrm{MHz} / \mathrm{CDCl}_{3}$

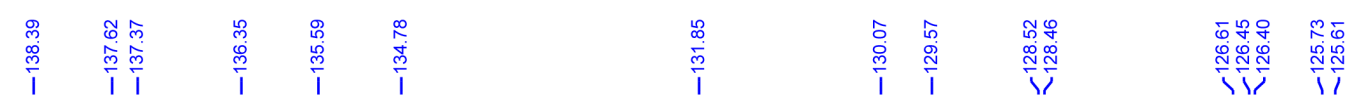
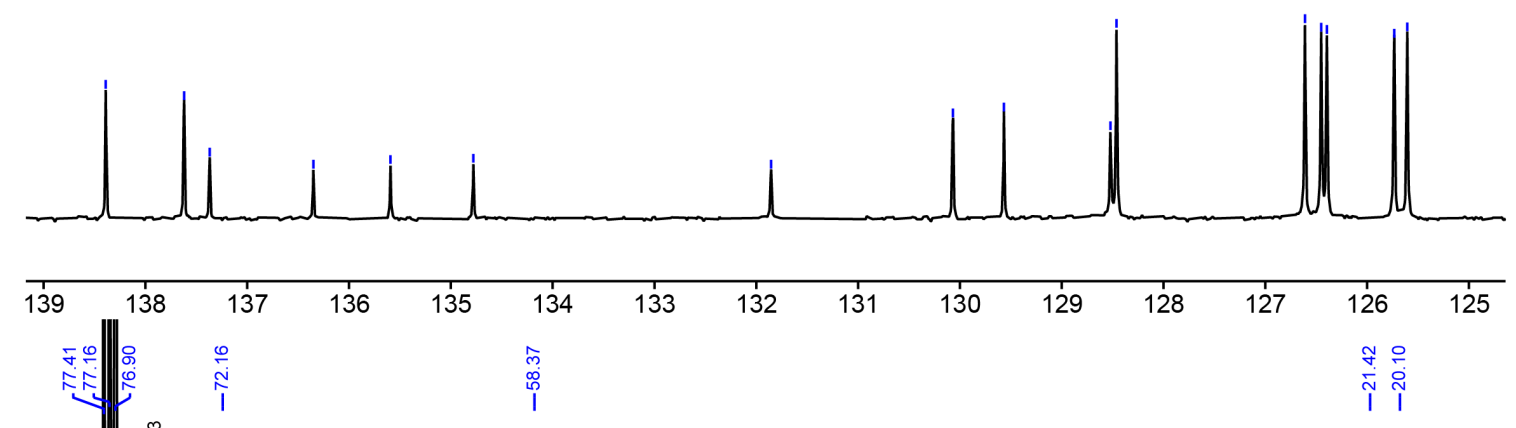

$\overline{0}^{m}$
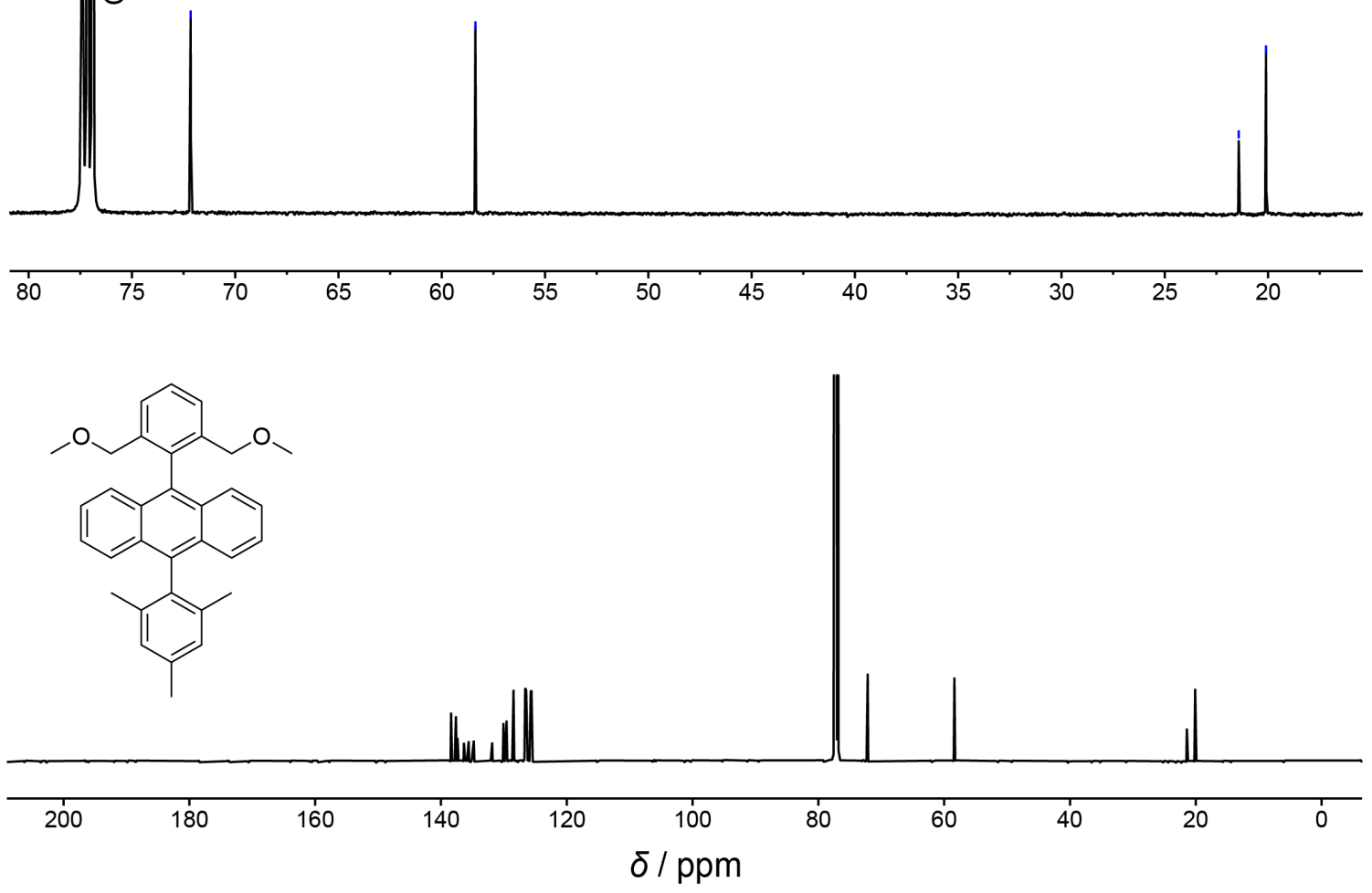


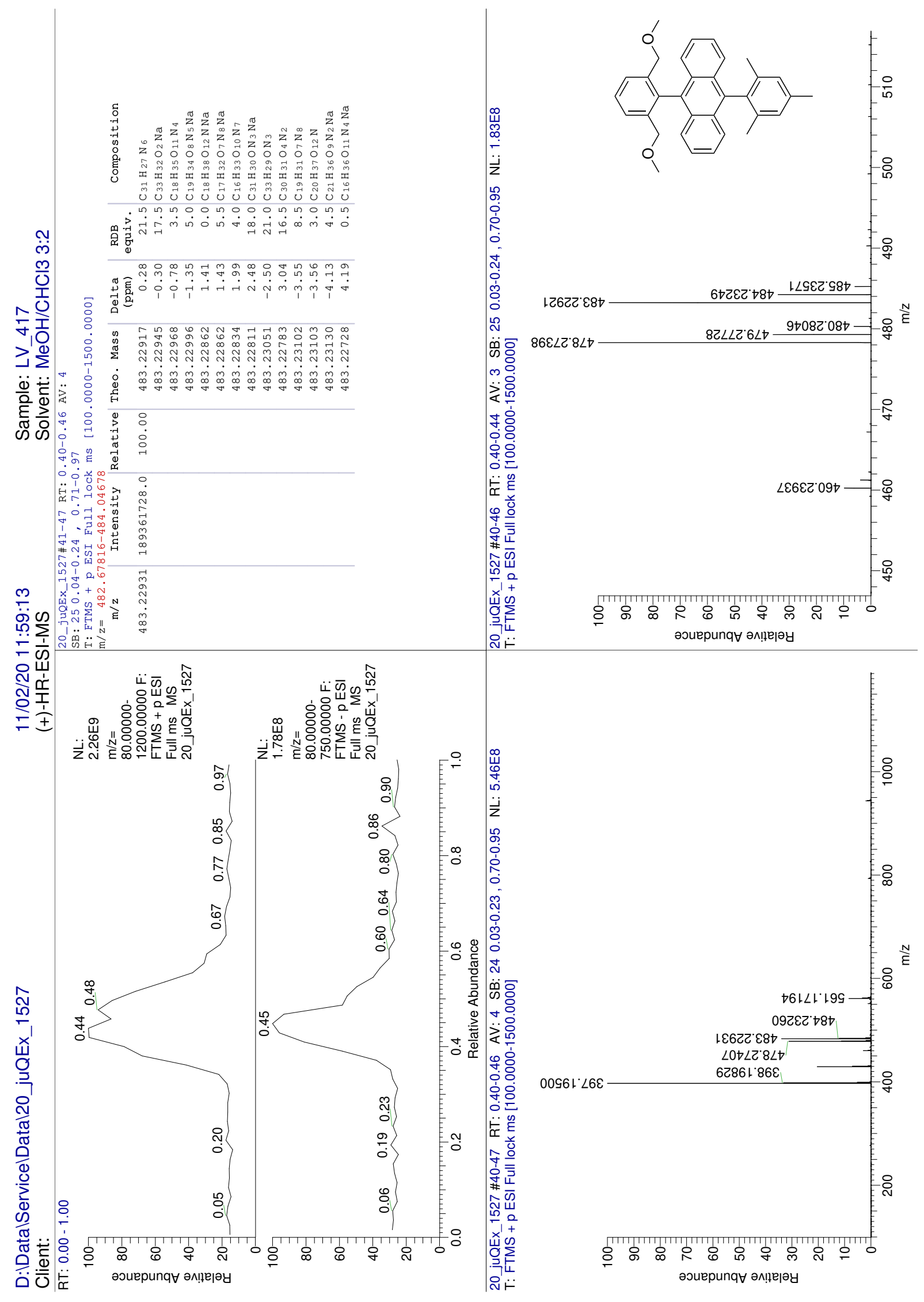


${ }^{1} \mathrm{H} \mathrm{NMR} / 400 \mathrm{MHz} / \mathrm{CDCl}_{3}$
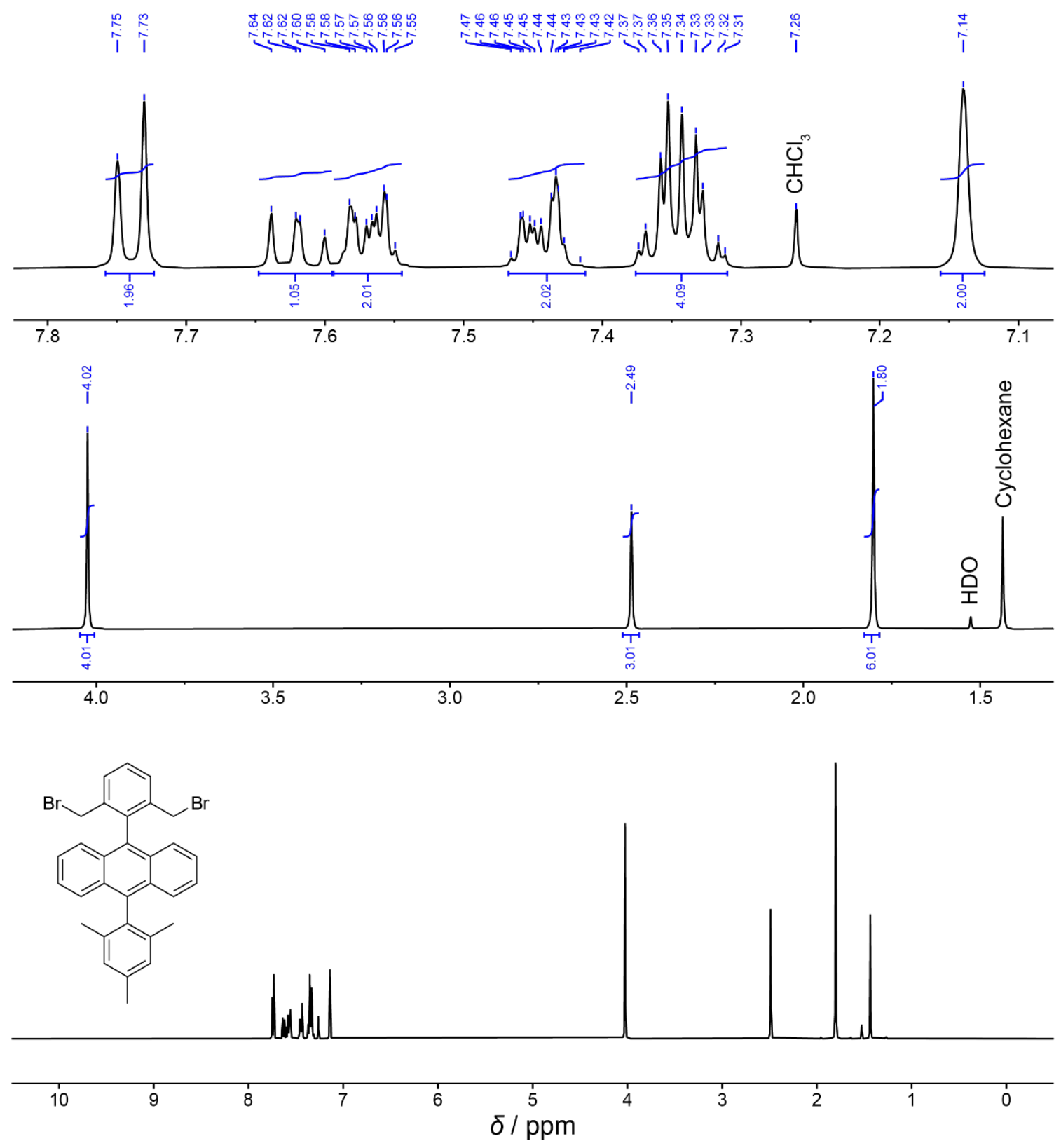
${ }^{13} \mathrm{C} \mathrm{NMR} / 101 \mathrm{MHz} / \mathrm{CDCl}_{3}$
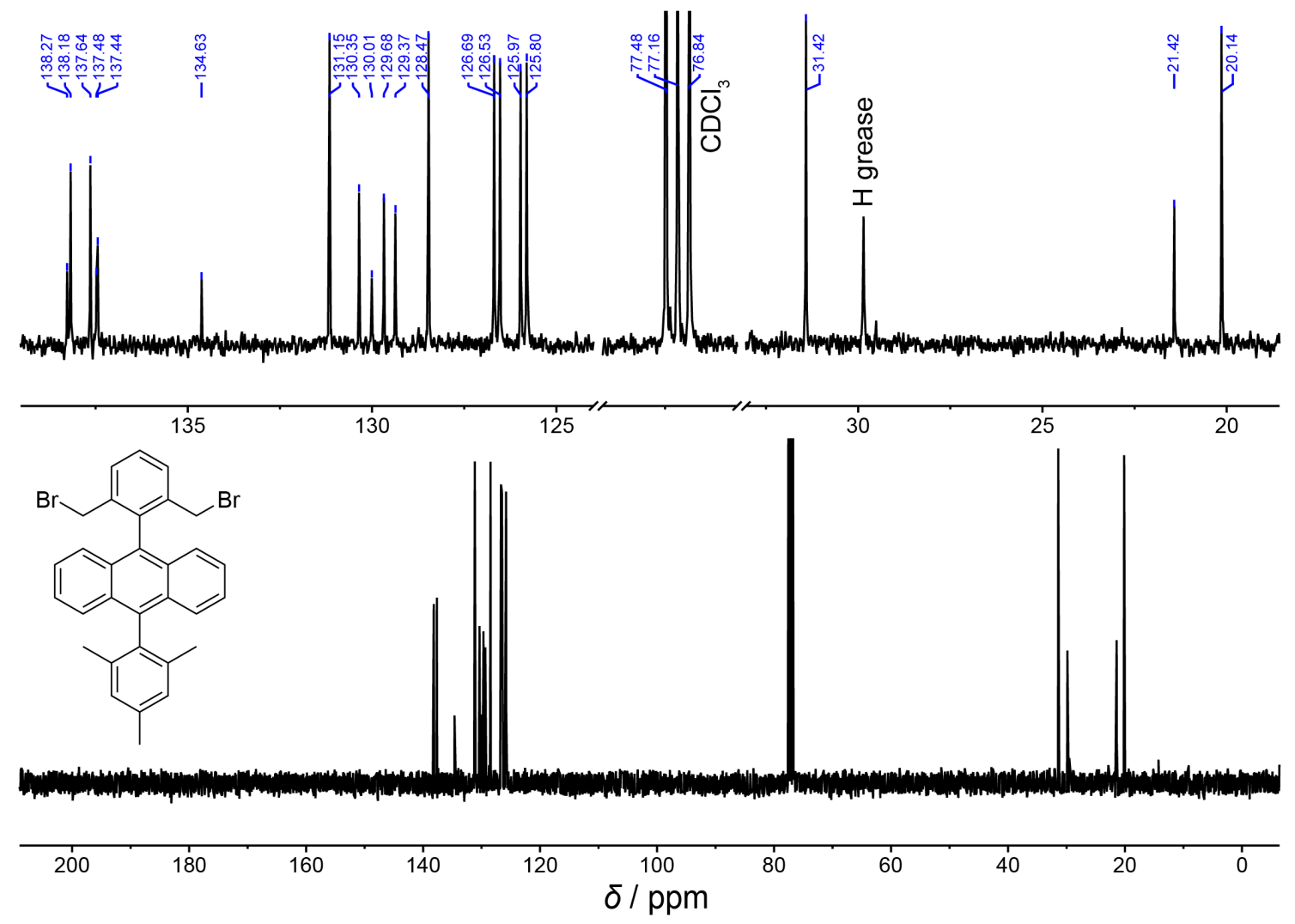


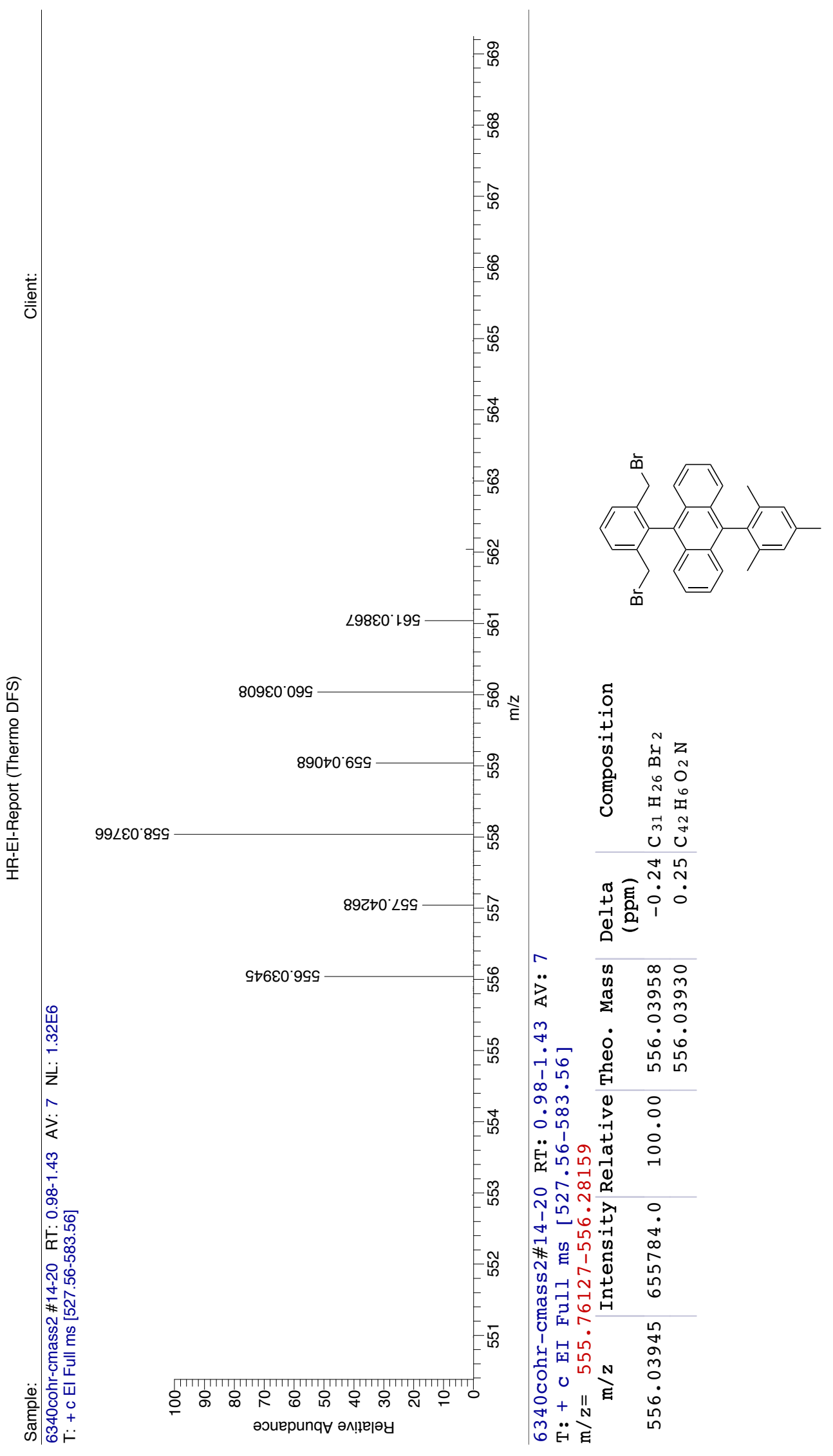


${ }^{1} \mathrm{H} \mathrm{NMR} \mathrm{/} 400 \mathrm{MHz} / \mathrm{CDCl}_{3}$

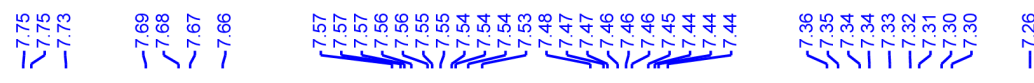

$\stackrel{\substack{n \\ i}}{i}$

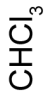
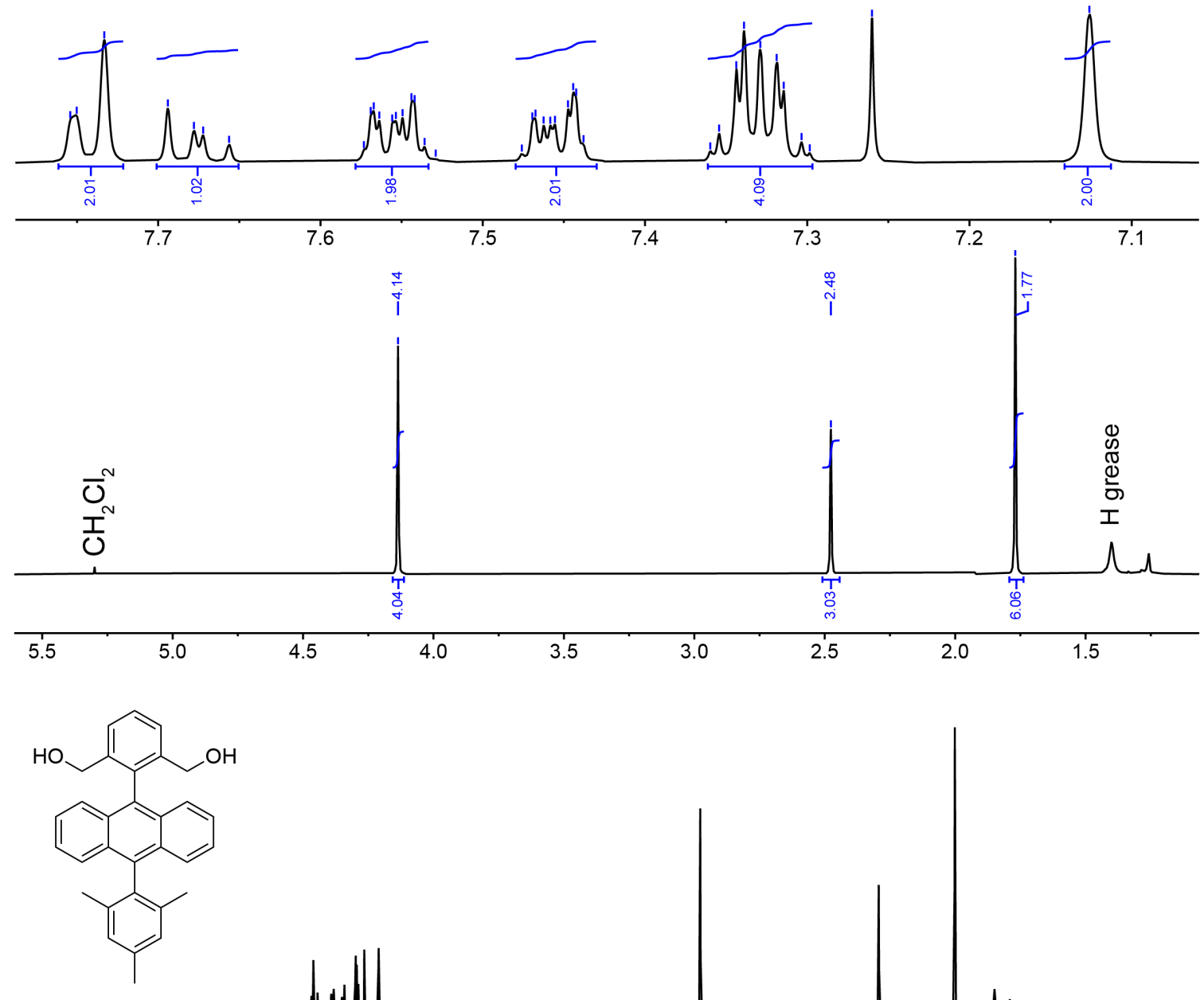

wull
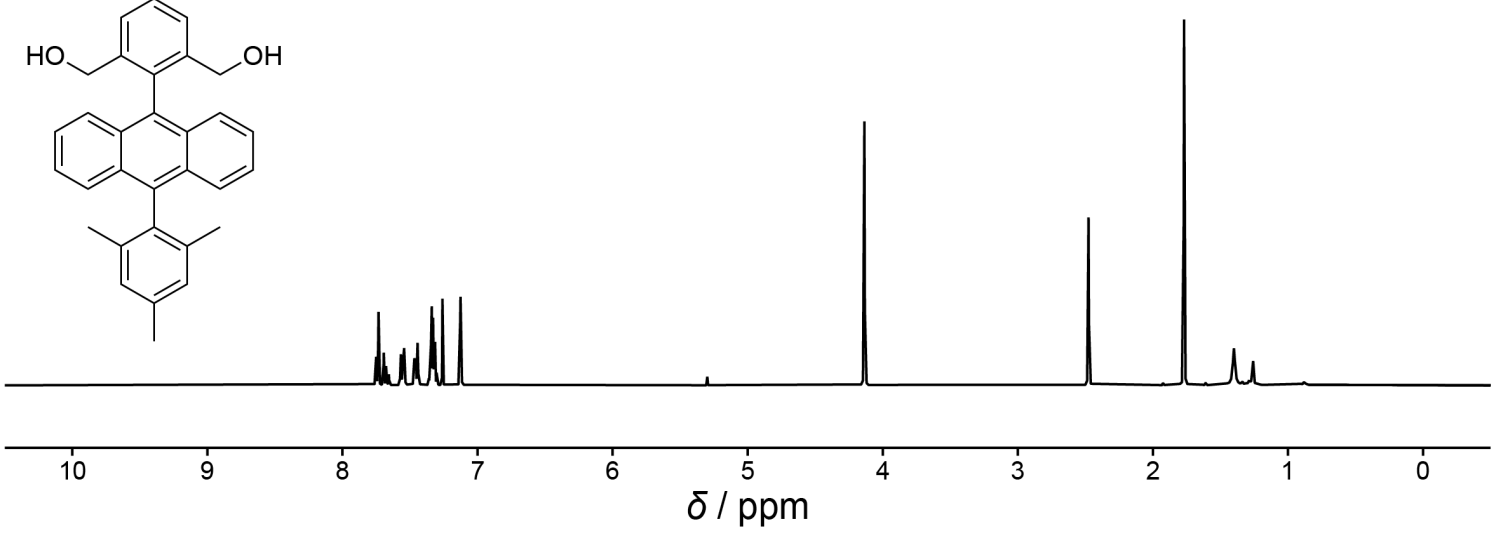
${ }^{13} \mathrm{C} \mathrm{NMR} \mathrm{/} 101 \mathrm{MHz} / \mathrm{CDCl}_{3}$

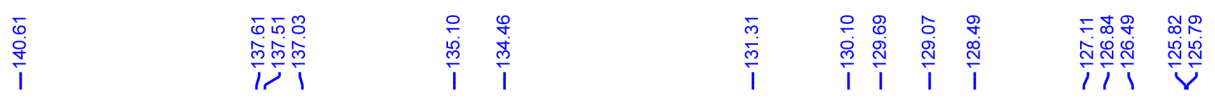

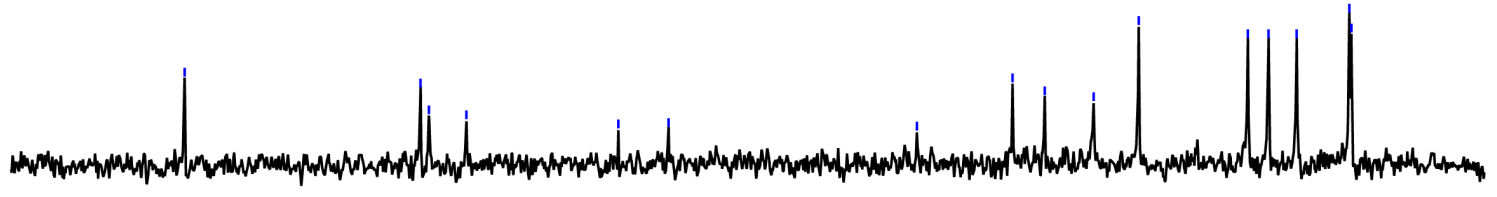
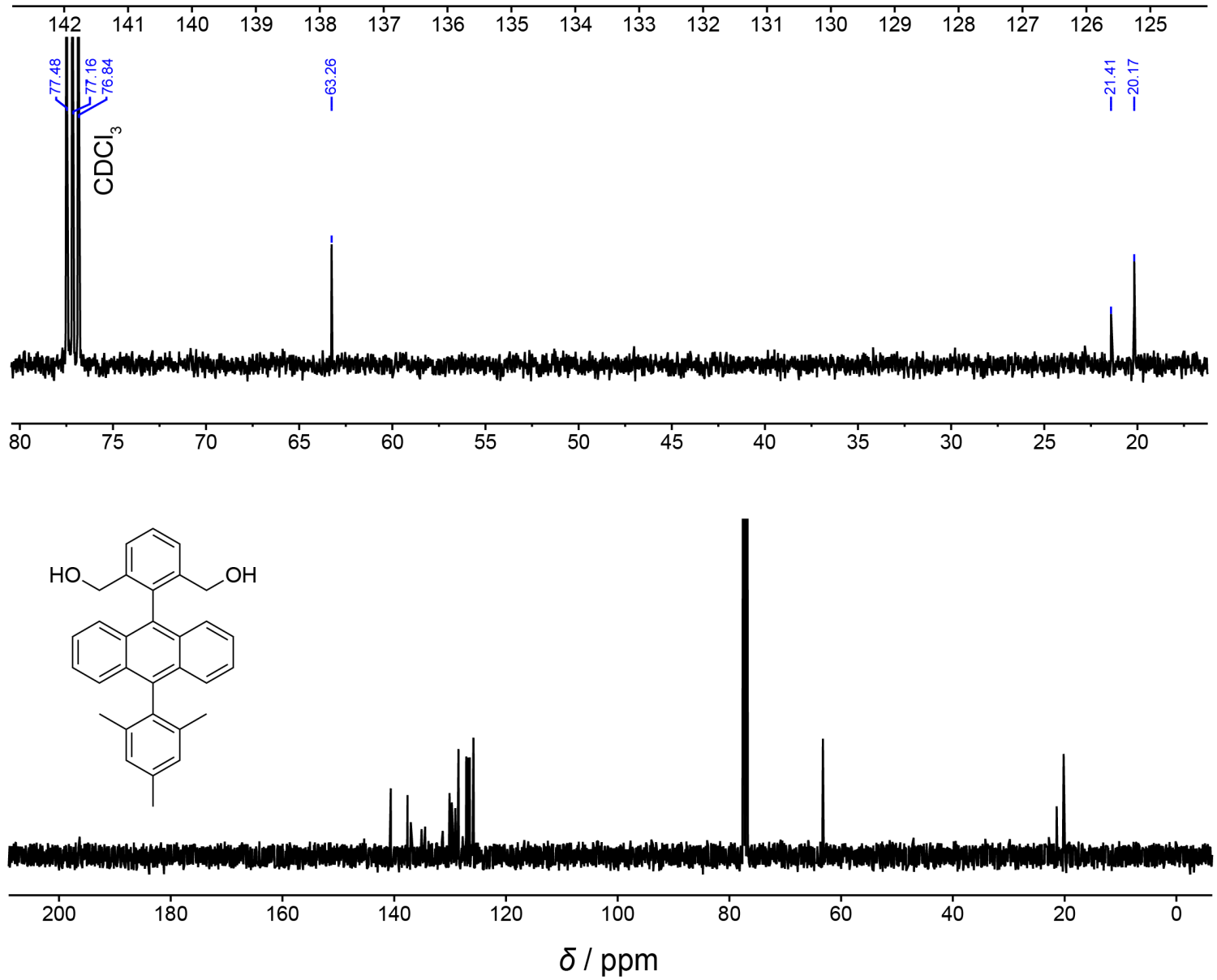


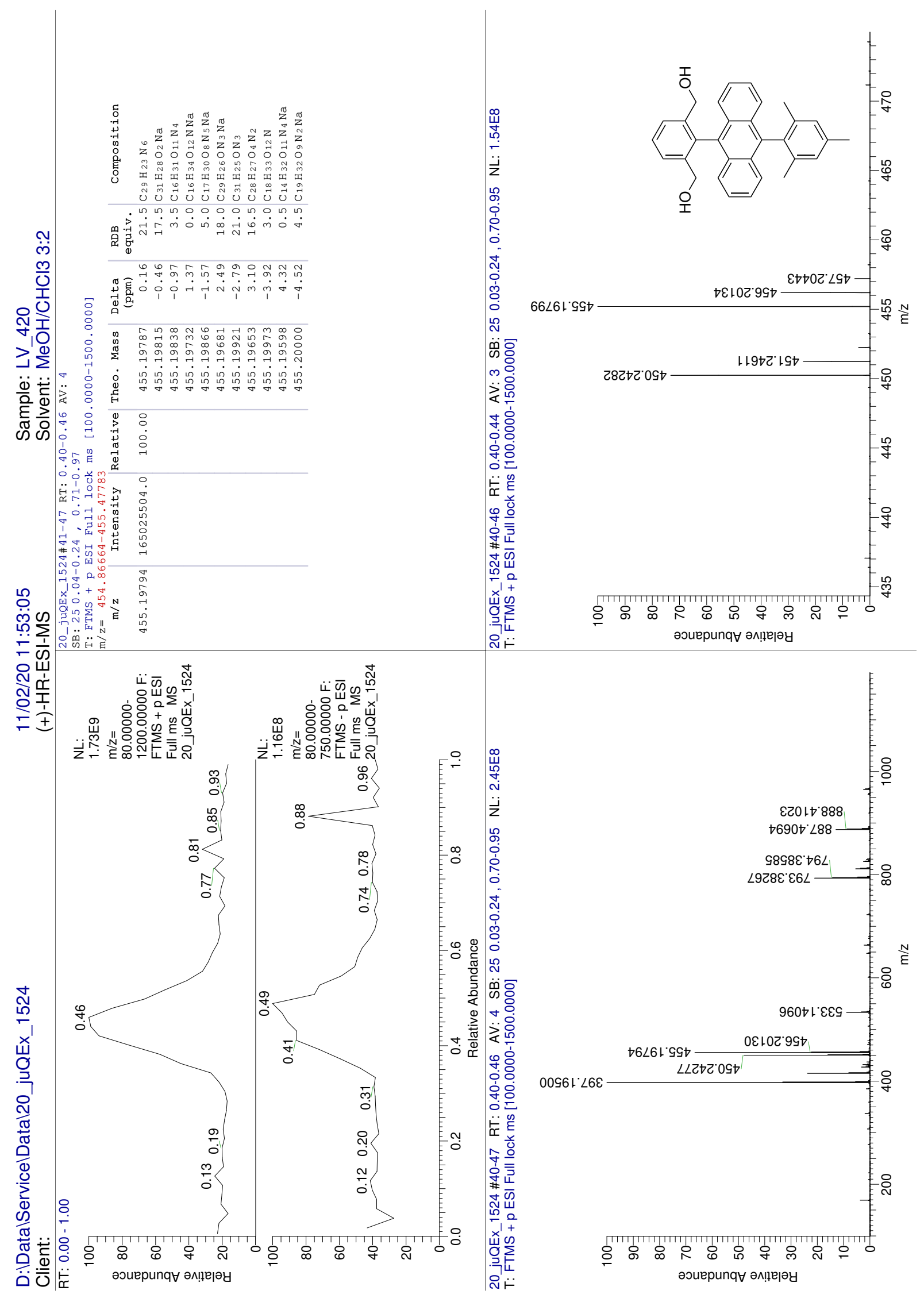


${ }^{1} \mathrm{H} \mathrm{NMR} / 400 \mathrm{MHz} / \mathrm{CDCl}_{3}$
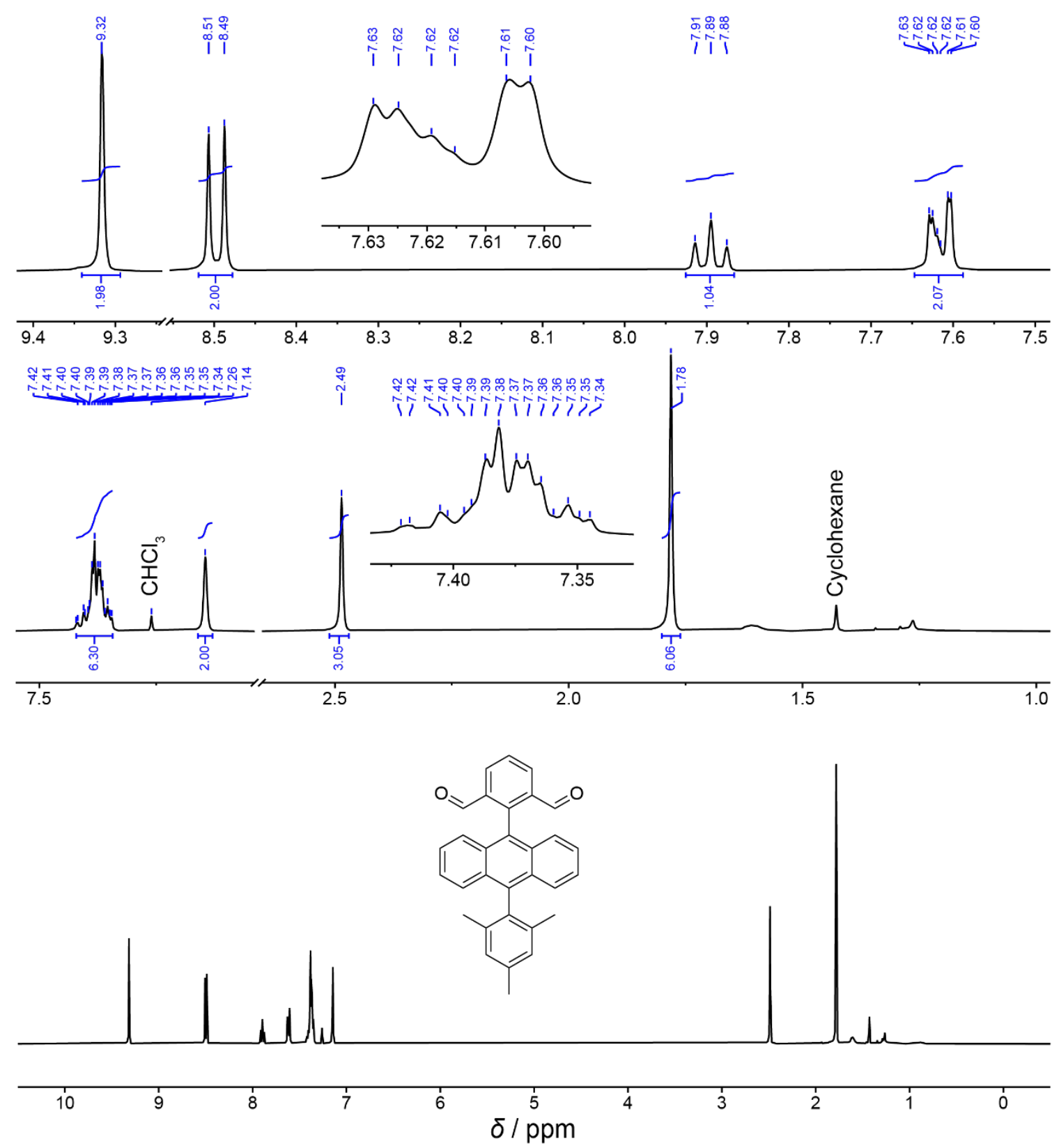
${ }^{13} \mathrm{C} \mathrm{NMR} \mathrm{/} 101 \mathrm{MHz} / \mathrm{CDCl}_{3}$

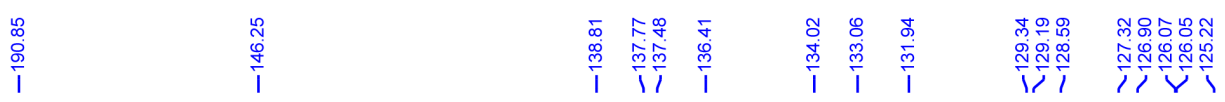
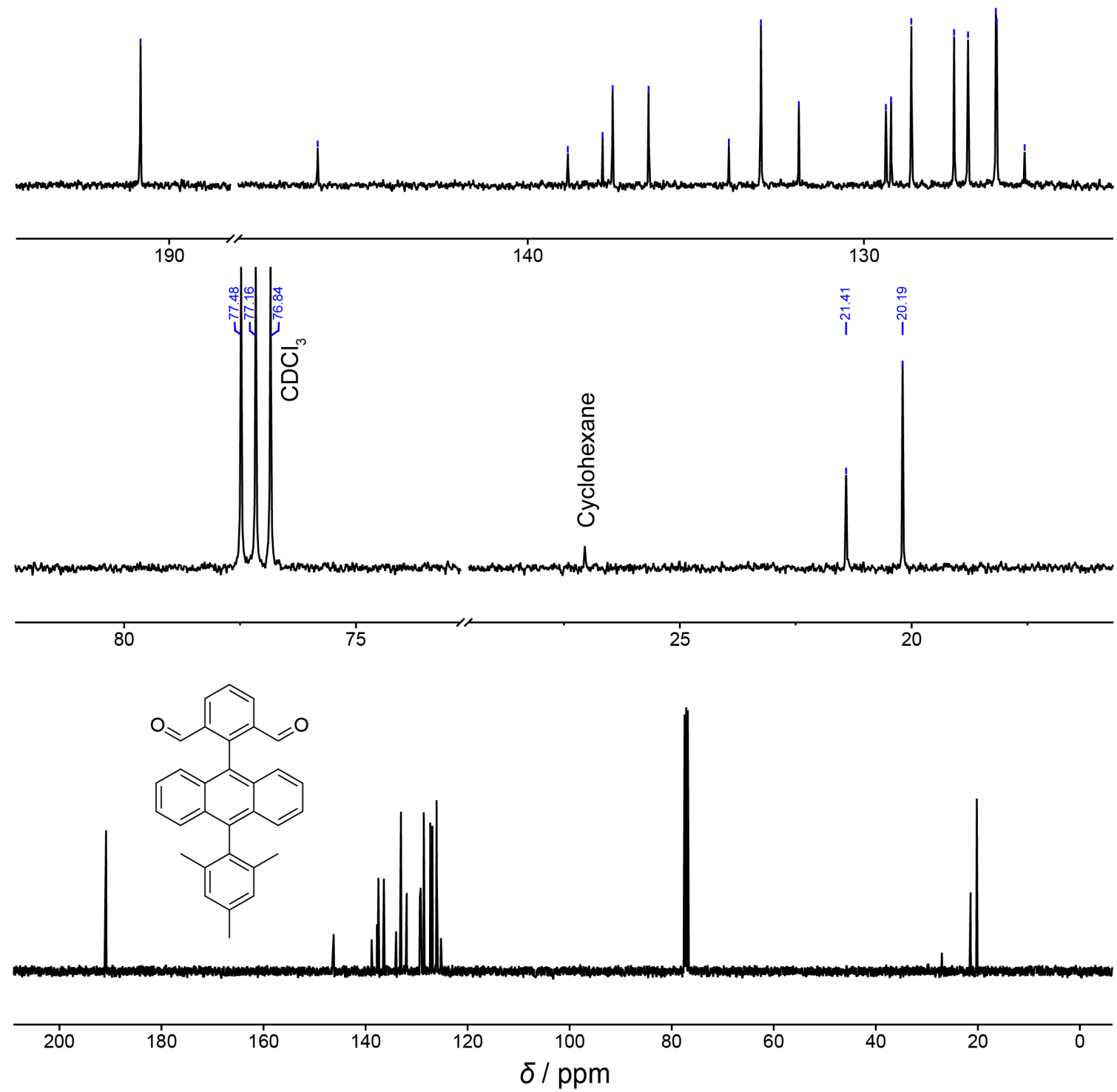


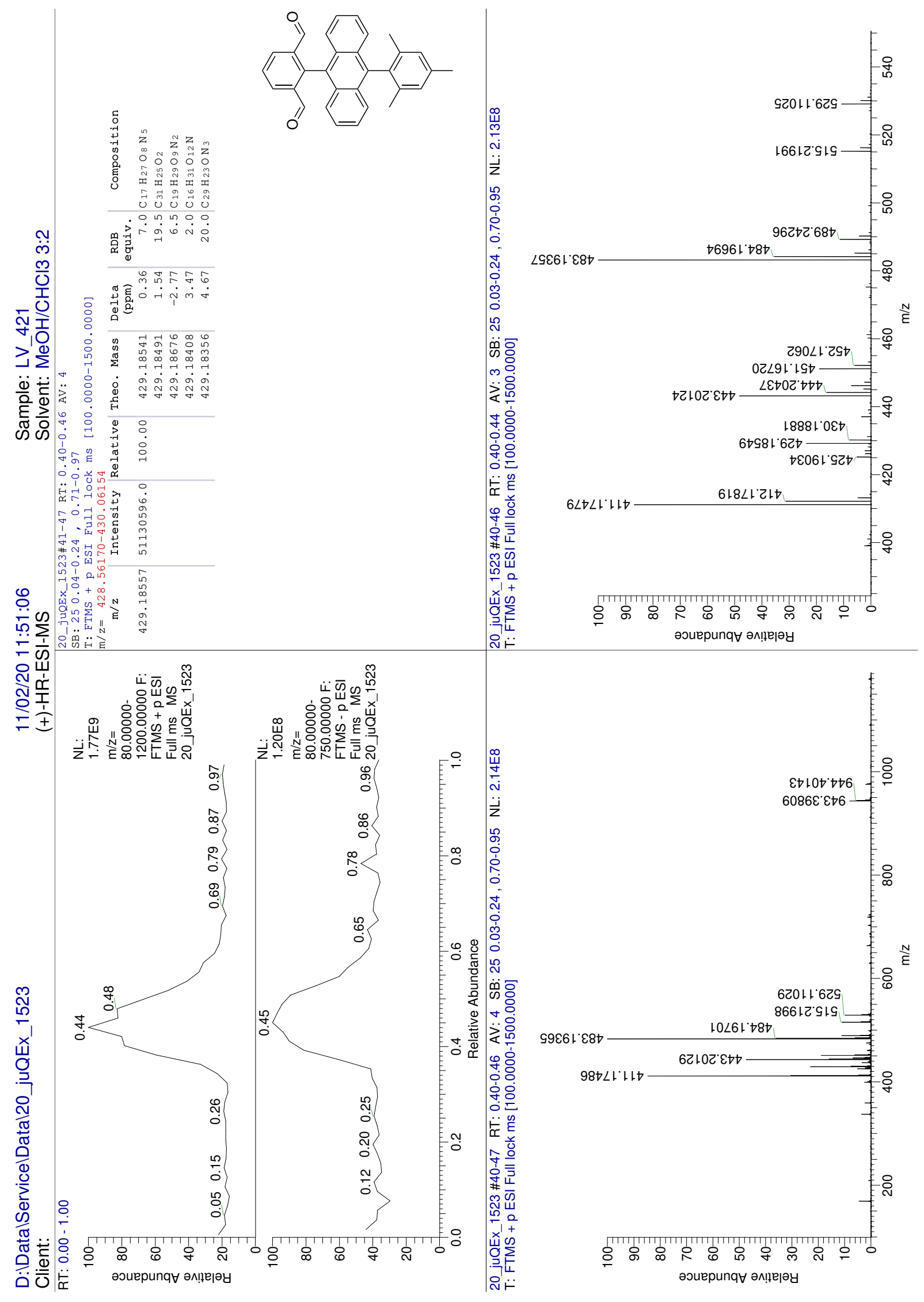


${ }^{1} \mathrm{H} \mathrm{NMR} / 600 \mathrm{MHz} / \mathrm{CD}_{2} \mathrm{Cl}_{2}$

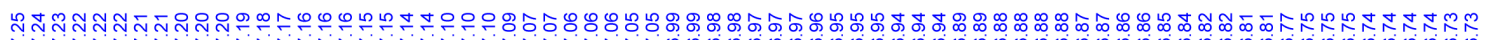

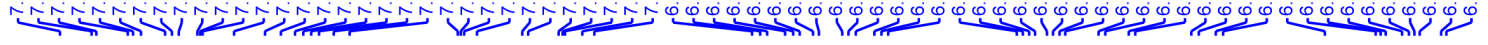
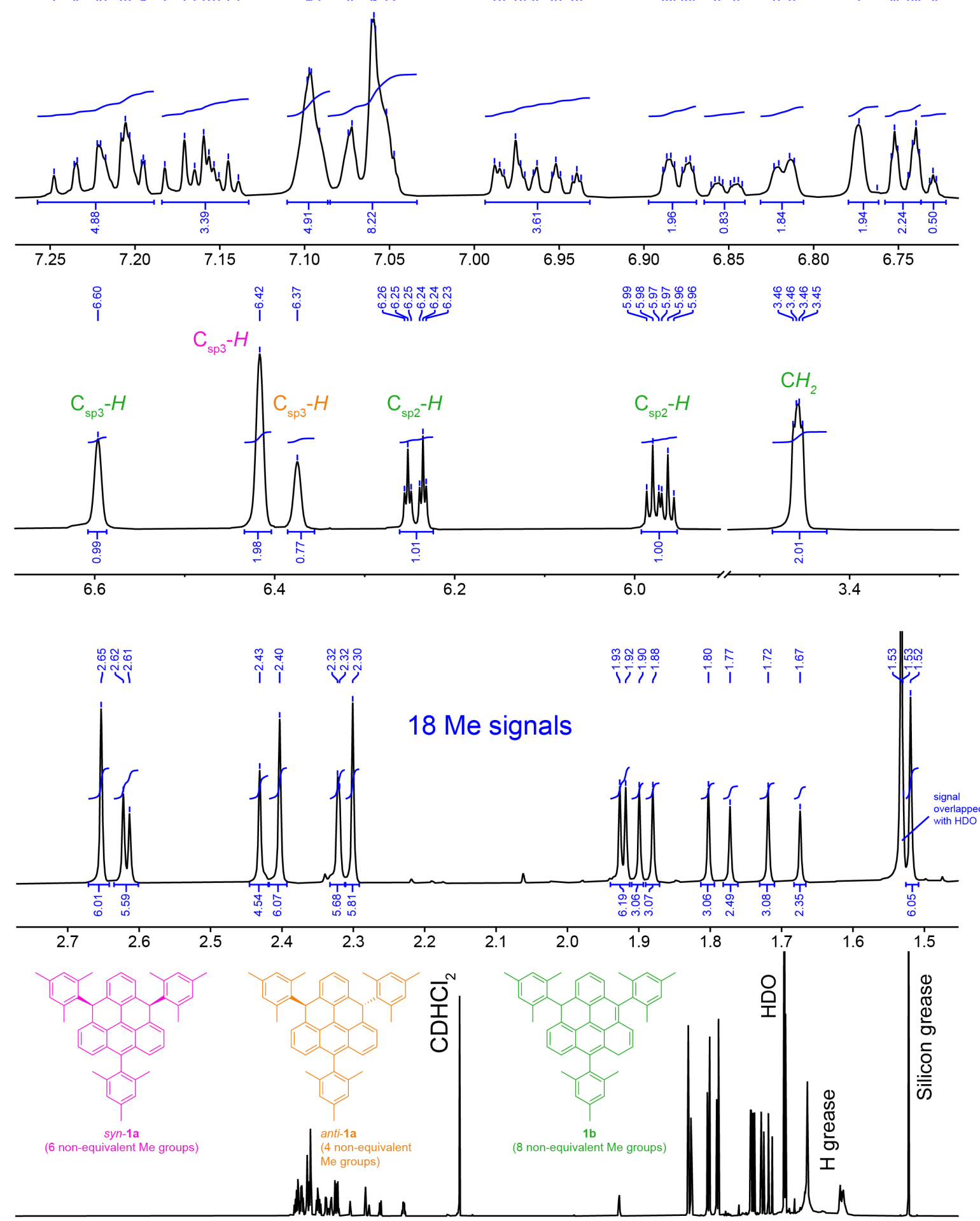

\begin{tabular}{lllllllllll}
1 & 10 & 9 & 8 & 7 & 6 & 5 & 1 & 1 & 1 & 1 \\
\hline
\end{tabular} 
${ }^{13} \mathrm{C} \mathrm{NMR} \mathrm{/} 151 \mathrm{MHz} / \mathrm{CD}_{2} \mathrm{Cl}_{2}$

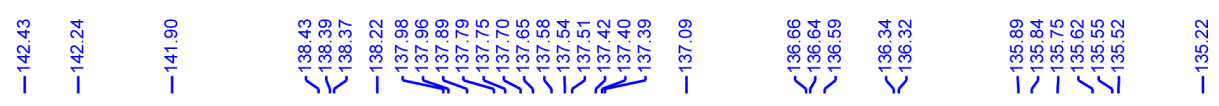
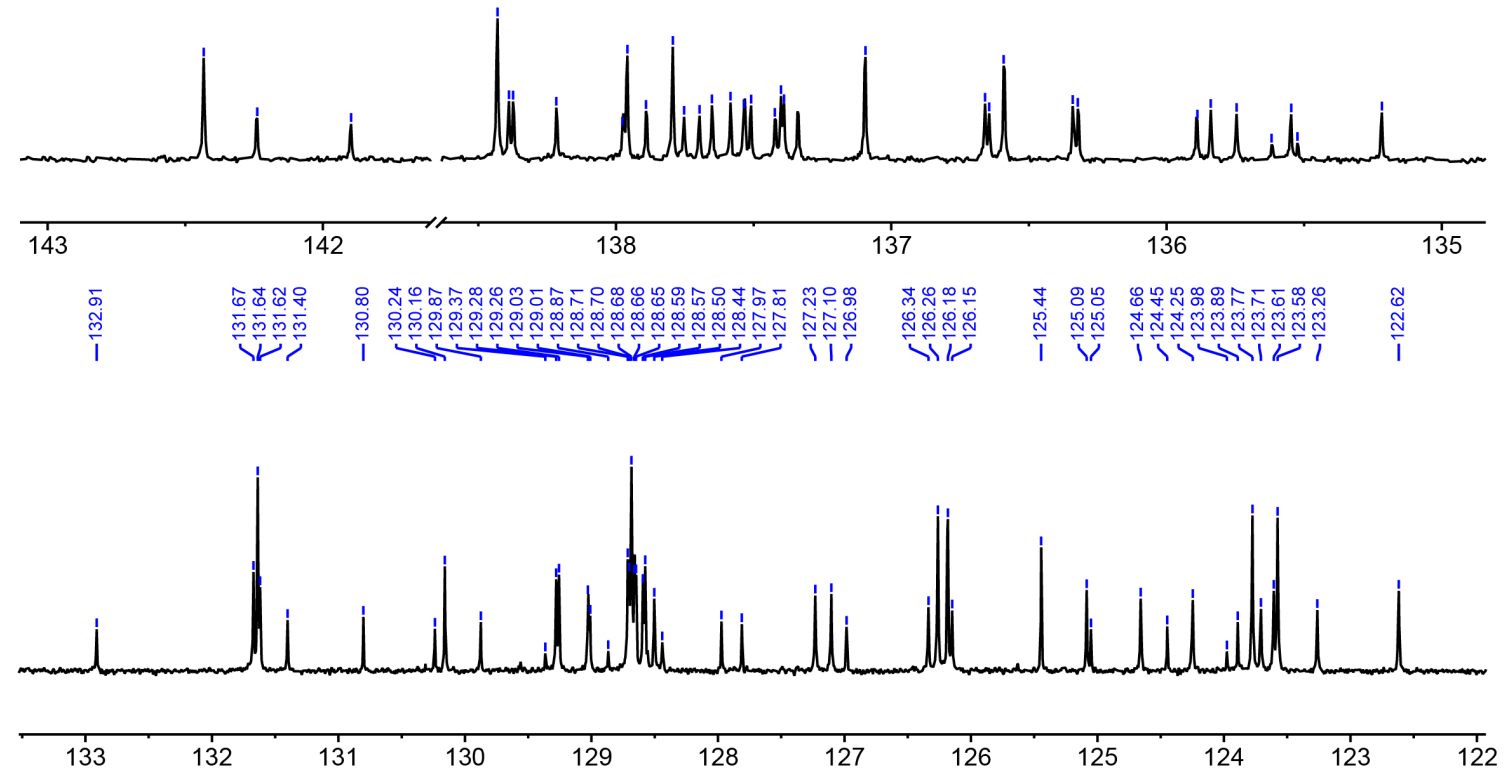

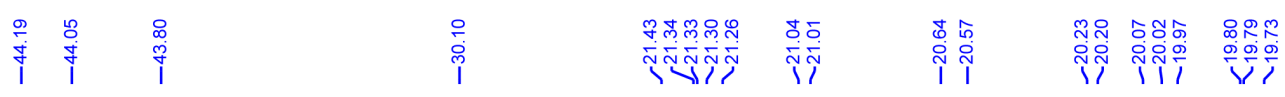
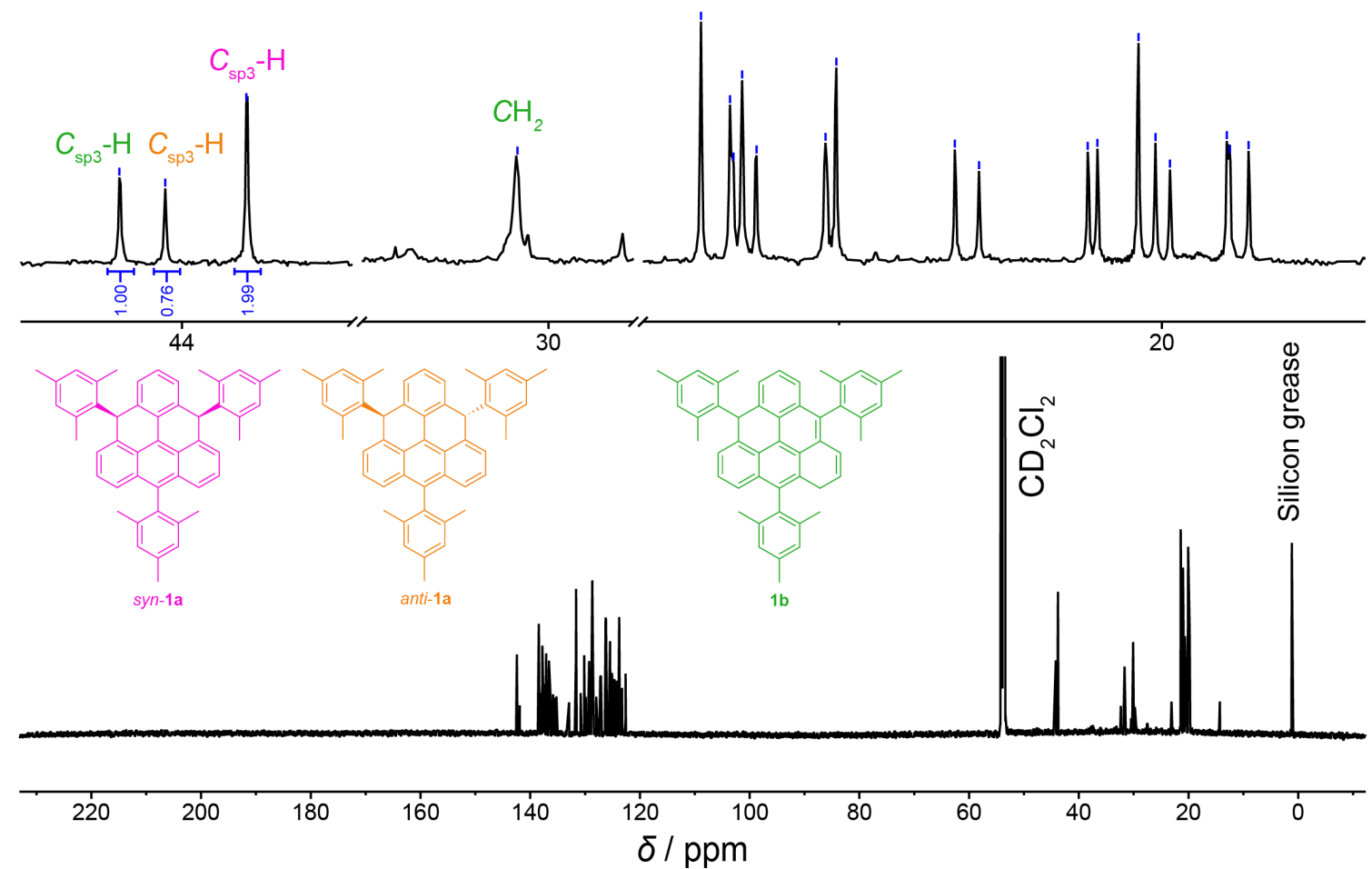


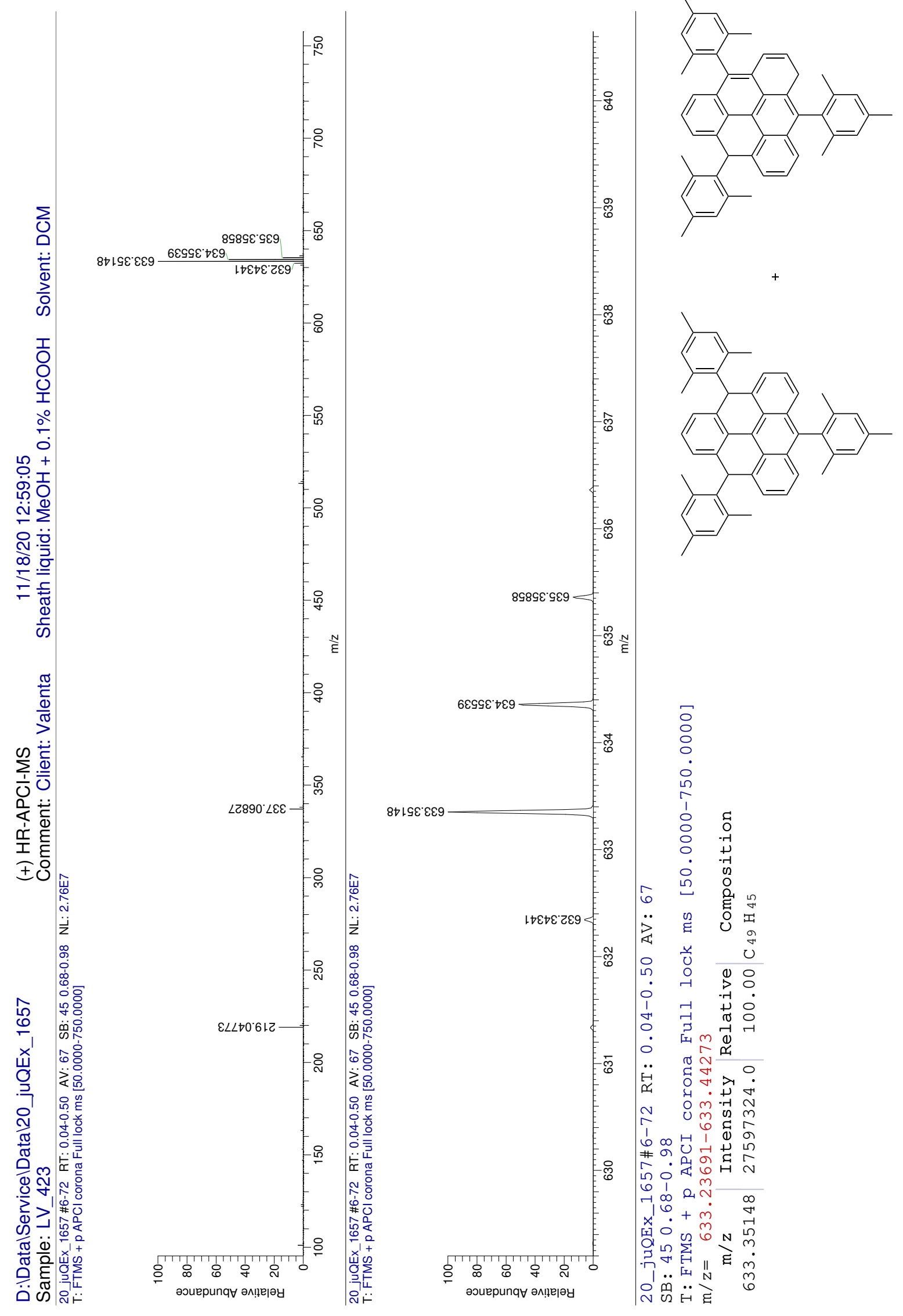




\section{S8. Cartesian coordinates}

\section{$\mathbf{1 a}^{\prime}, E_{\mathrm{el}}=-846.826514$ Hartree}

\begin{tabular}{|c|c|c|c|}
\hline C & 3.557730 & 1.202350 & -0.074584 \\
\hline C & 2.165225 & 1.215267 & 0.017674 \\
\hline C & 1.450303 & -0.000003 & 0.045274 \\
\hline C & 2.165220 & -1.215275 & 0.017674 \\
\hline C & 3.557725 & -1.202364 & -0.074584 \\
\hline C & 4.258826 & -0.000008 & -0.128761 \\
\hline C & -0.023222 & 0.000000 & 0.068403 \\
\hline C & -0.733462 & -1.226213 & 0.047939 \\
\hline C & -0.733457 & 1.226216 & 0.047939 \\
\hline C & -0.053840 & 2.488060 & 0.047485 \\
\hline C & -0.779630 & 3.656498 & -0.003988 \\
\hline C & -2.198162 & 3.649762 & -0.039635 \\
\hline C & -2.879954 & 2.462456 & -0.029992 \\
\hline C & -2.177087 & 1.220709 & 0.007136 \\
\hline C & -2.177092 & -1.220700 & 0.007136 \\
\hline C & -2.879964 & -2.462444 & -0.029992 \\
\hline C & -2.198177 & -3.649754 & -0.039635 \\
\hline C & -0.779645 & -3.656495 & -0.003988 \\
\hline C & -0.053850 & -2.488060 & 0.047485 \\
\hline C & -2.858070 & 0.000006 & -0.007542 \\
\hline C & 1.453581 & 2.543042 & 0.136023 \\
\hline $\mathrm{C}$ & 1.453571 & -2.543048 & 0.136023 \\
\hline $\mathrm{H}$ & 4.096027 & 2.147570 & -0.101464 \\
\hline $\mathrm{H}$ & 4.096019 & -2.147586 & -0.101465 \\
\hline $\mathrm{H}$ & 5.342681 & -0.000010 & -0.206406 \\
\hline $\mathrm{H}$ & -0.254136 & 4.609356 & -0.011475 \\
\hline $\mathrm{H}$ & -2.736231 & 4.593281 & -0.075309 \\
\hline $\mathrm{H}$ & -3.966636 & 2.442287 & -0.056581 \\
\hline $\mathrm{H}$ & -3.966645 & -2.442272 & -0.056581 \\
\hline $\mathrm{H}$ & -2.736249 & -4.593270 & -0.075309 \\
\hline $\mathrm{H}$ & -0.254155 & -4.609355 & 0.01147 \\
\hline
\end{tabular}




$\begin{array}{cccc}\mathrm{H} & -3.945468 & 0.000008 & -0.040896 \\ \mathrm{H} & 1.841892 & 3.235311 & -0.623604 \\ \mathrm{H} & 1.732785 & 2.995540 & 1.100847 \\ \mathrm{H} & 1.841880 & -3.235319 & -0.623604 \\ \mathrm{H} & 1.732773 & -2.995547 & 1.100847\end{array}$

$\mathbf{1 b}^{\prime}, E_{\mathrm{el}}=-846.828300$ Hartree

\begin{tabular}{|c|c|c|c|}
\hline $\mathrm{C}$ & -0.550462 & 3.547950 & 0.091806 \\
\hline $\mathrm{C}$ & -0.595141 & 2.164069 & 0.039420 \\
\hline C & 0.617550 & 1.426344 & 0.050974 \\
\hline C & 1.861305 & 2.122762 & 0.116368 \\
\hline $\mathrm{C}$ & 1.863476 & 3.536974 & 0.168545 \\
\hline C & 0.675450 & 4.237598 & 0.156383 \\
\hline C & 0.621015 & -0.011405 & -0.001920 \\
\hline C & 1.843003 & -0.712650 & 0.011241 \\
\hline $\mathrm{C}$ & -0.627281 & -0.735462 & -0.068489 \\
\hline C & -1.870799 & -0.056958 & -0.083163 \\
\hline $\mathrm{C}$ & -3.047750 & -0.789817 & -0.147787 \\
\hline $\mathrm{C}$ & -3.030148 & -2.194634 & -0.199057 \\
\hline $\mathrm{C}$ & -1.826640 & -2.871711 & -0.185599 \\
\hline $\mathrm{C}$ & -0.606320 & -2.161276 & -0.120412 \\
\hline $\mathrm{C}$ & 1.840597 & -2.157167 & -0.042092 \\
\hline $\mathrm{C}$ & 3.115750 & -2.867335 & -0.027559 \\
\hline $\mathrm{C}$ & 4.294543 & -2.233684 & 0.033420 \\
\hline $\mathrm{C}$ & 4.412406 & -0.738701 & 0.092308 \\
\hline C & 3.087239 & 0.004463 & 0.077411 \\
\hline $\mathrm{C}$ & 0.650160 & -2.835950 & -0.105149 \\
\hline C & -1.931019 & 1.454950 & -0.029315 \\
\hline C & 3.073085 & 1.373522 & 0.127444 \\
\hline $\mathrm{H}$ & -1.481052 & 4.111970 & 0.082843 \\
\hline $\mathrm{H}$ & 2.815352 & 4.060177 & 0.218262 \\
\hline $\mathrm{H}$ & 0.679618 & 5.323635 & 0.196511 \\
\hline $\mathrm{H}$ & -4.001317 & -0.265710 & -0 \\
\hline
\end{tabular}




$\begin{array}{lrrr}\mathrm{H} & -3.966650 & -2.743688 & -0.249221 \\ \mathrm{H} & -1.801441 & -3.958042 & -0.224882 \\ \mathrm{H} & 3.077850 & -3.953988 & -0.068822 \\ \mathrm{H} & 5.221926 & -2.802269 & 0.042071 \\ \mathrm{H} & 5.036836 & -0.392335 & -0.746796 \\ \mathrm{H} & 4.981300 & -0.456482 & 0.992692 \\ \mathrm{H} & 0.653905 & -3.923432 & -0.145110 \\ \mathrm{H} & -2.540334 & 1.756461 & 0.835347 \\ \mathrm{H} & -2.484851 & 1.820718 & -0.906409 \\ \mathrm{H} & 4.013040 & 1.921104 & 0.177644\end{array}$

syn-1a, $E_{\mathrm{el}}=-1893.817329$ Hartree

$\begin{array}{llll}\text { C } & 2.333637 & 3.680572 & 1.208025 \\ \text { C } & 2.174755 & 3.692545 & -0.198553 \\ \text { C } & 2.703929 & 4.769248 & -0.941216 \\ \text { C } & 3.375150 & 5.804184 & -0.275059 \\ \text { C } & 3.539429 & 5.809398 & 1.108926 \\ \text { C } & 3.010545 & 4.733659 & 1.828388 \\ \text { C } & 1.439250 & 2.553898 & -0.917839 \\ \text { C } & 2.162043 & 1.214272 & -0.835111 \\ \text { C } & 1.444846 & -0.001507 & -0.770423 \\ \text { C } & -0.019818 & -0.000148 & -0.605926 \\ \text { C } & -0.723993 & 1.225569 & -0.495088 \\ \text { C } & -0.046201 & 2.488825 & -0.581125 \\ \text { C } & -0.726209 & -1.224536 & -0.494588 \\ \text { C } & -0.050706 & -2.489061 & -0.580073 \\ \text { C } & 1.434584 & -2.556934 & -0.916992 \\ \text { C } & 2.159823 & -1.218612 & -0.834706 \\ \text { C } & 3.554848 & 1.198471 & -0.939358 \\ \text { C } & 4.253445 & -0.004105 & -0.984154 \\ \text { C } & 3.552642 & -1.205383 & -0.939133 \\ \text { C } & -2.153054 & 1.222455 & -0.269339 \\ \text { C } & -0.002515 & -0.162685\end{array}$




\begin{tabular}{|c|c|c|c|}
\hline $\mathrm{C}$ & -2.155253 & -1.218733 & -0.268726 \\
\hline C & -2.841126 & -2.467699 & -0.147817 \\
\hline $\mathrm{C}$ & -2.162266 & -3.652860 & -0.229681 \\
\hline $\mathrm{C}$ & -0.762523 & -3.659981 & -0.443122 \\
\hline $\mathrm{C}$ & -2.836716 & 2.472714 & -0.149204 \\
\hline C & -2.155728 & 3.656615 & -0.231786 \\
\hline $\mathrm{C}$ & -0.755959 & 3.661099 & -0.445081 \\
\hline $\mathrm{C}$ & -4.337908 & 0.003671 & 0.067189 \\
\hline $\mathrm{C}$ & -5.224682 & 0.006589 & -1.030658 \\
\hline C & -6.603552 & 0.011312 & -0.794462 \\
\hline C & -7.132375 & 0.010362 & 0.499043 \\
\hline $\mathrm{C}$ & -6.237709 & 0.011525 & 1.572631 \\
\hline $\mathrm{C}$ & -4.851931 & 0.006799 & 1.381604 \\
\hline $\mathrm{C}$ & -4.704970 & 0.009039 & -2.451079 \\
\hline $\mathrm{C}$ & -8.625640 & -0.017058 & 0.729974 \\
\hline $\mathrm{C}$ & -3.927623 & 0.009449 & 2.578770 \\
\hline $\mathrm{C}$ & 2.577722 & 4.856118 & -2.450667 \\
\hline $\mathrm{C}$ & 4.248358 & 6.942209 & 1.813985 \\
\hline $\mathrm{C}$ & 1.795060 & 2.560817 & 2.070555 \\
\hline $\mathrm{H}$ & 4.093171 & 2.140585 & -0.979367 \\
\hline $\mathrm{H}$ & 4.089172 & -2.148519 & -0.979147 \\
\hline $\mathrm{H}$ & 5.337410 & -0.005094 & -1.061717 \\
\hline $\mathrm{H}$ & -0.230523 & 4.609984 & -0.497905 \\
\hline $\mathrm{H}$ & -2.684414 & 4.601040 & -0.132584 \\
\hline $\mathrm{H}$ & -3.908641 & 2.463996 & 0.014047 \\
\hline $\mathrm{H}$ & -3.913010 & -2.456876 & 0.015518 \\
\hline $\mathrm{H}$ & -2.692587 & -4.596295 & -0.129771 \\
\hline $\mathrm{H}$ & -0.238811 & -4.609856 & -0.495201 \\
\hline $\mathrm{H}$ & 1.465256 & 2.799117 & -1.987775 \\
\hline $\mathrm{H}$ & 1.460087 & -2.802392 & -1.986891 \\
\hline $\mathrm{C}$ & 2.168453 & -3.696560 & -0.197601 \\
\hline $\mathrm{H}$ & -7.281509 & 0.017177 & -1.646138 \\
\hline $\mathrm{H}$ & -6.626926 & 0.017573 & 2.589240 \\
\hline
\end{tabular}




\begin{tabular}{|c|c|c|c|}
\hline $\mathrm{H}$ & 3.779623 & 6.627589 & -0.860529 \\
\hline $\mathrm{H}$ & 3.128040 & 4.710557 & 2.910452 \\
\hline $\mathrm{H}$ & -3.273820 & -0.870595 & 2.583609 \\
\hline $\mathrm{H}$ & -3.273796 & 0.889497 & 2.580324 \\
\hline $\mathrm{H}$ & -4.498478 & 0.011145 & 3.512575 \\
\hline $\mathrm{H}$ & -5.531160 & 0.010530 & -3.168919 \\
\hline $\mathrm{H}$ & -4.082105 & 0.889015 & -2.650197 \\
\hline $\mathrm{H}$ & -4.082947 & -0.870881 & -2.653014 \\
\hline $\mathrm{H}$ & -8.896244 & 0.484173 & 1.665623 \\
\hline $\mathrm{H}$ & -9.166933 & 0.473692 & -0.086111 \\
\hline $\mathrm{H}$ & -9.000652 & -1.047548 & 0.794207 \\
\hline $\mathrm{H}$ & 4.976524 & 6.567983 & 2.543258 \\
\hline $\mathrm{H}$ & 4.781440 & 7.583710 & 1.104819 \\
\hline $\mathrm{H}$ & 3.540460 & 7.576046 & 2.364265 \\
\hline $\mathrm{H}$ & 2.230552 & 1.593174 & 1.798155 \\
\hline $\mathrm{H}$ & 2.022130 & 2.745870 & 3.125053 \\
\hline $\mathrm{H}$ & 0.708671 & 2.460960 & 1.973142 \\
\hline $\mathrm{H}$ & 3.048455 & 5.772326 & -2.819929 \\
\hline $\mathrm{H}$ & 3.063532 & 4.013548 & -2.958713 \\
\hline $\mathrm{H}$ & 1.531258 & 4.872737 & -2.780269 \\
\hline $\mathrm{C}$ & 2.327901 & -3.684387 & 1.208916 \\
\hline $\mathrm{C}$ & 3.000401 & -4.740039 & 1.829707 \\
\hline C & 3.527364 & -5.816812 & 1.110374 \\
\hline C & 3.357858 & -5.814447 & -0.272987 \\
\hline C & 2.690912 & -4.777014 & -0.939559 \\
\hline $\mathrm{C}$ & 1.790150 & -2.564232 & 2.071443 \\
\hline $\mathrm{H}$ & 3.114274 & -4.719097 & 2.912202 \\
\hline $\mathrm{C}$ & 4.266160 & -6.932673 & 1.811789 \\
\hline $\mathrm{H}$ & 3.753666 & -6.642727 & -0.857498 \\
\hline C & 2.557526 & -4.867823 & -2.448161 \\
\hline $\mathrm{H}$ & 2.017366 & -2.749289 & 3.125909 \\
\hline $\mathrm{H}$ & 2.226468 & -1.597029 & 1.798806 \\
\hline $\mathrm{H}$ & 0.703833 & -2.463393 & 1.974247 \\
\hline
\end{tabular}




$\begin{array}{llll}\mathrm{H} & 3.046414 & -4.029734 & -2.960666 \\ \mathrm{H} & 3.021287 & -5.787898 & -2.816630 \\ \mathrm{H} & 1.509655 & -4.879000 & -2.773465 \\ \mathrm{H} & 4.425135 & -7.787457 & 1.146445 \\ \mathrm{H} & 5.251966 & -6.600507 & 2.163245 \\ \mathrm{H} & 3.715896 & -7.287771 & 2.691130\end{array}$

anti-1a, $E_{\mathrm{el}}=-1893.817395$ Hartree

\begin{tabular}{|c|c|c|c|}
\hline C & 2.351157 & 3.982119 & 1.105279 \\
\hline $\mathrm{C}$ & 2.287690 & 3.669874 & -0.274020 \\
\hline $\mathrm{C}$ & 2.889365 & 4.542741 & -1.205105 \\
\hline $\mathrm{C}$ & 3.538203 & 5.698761 & -0.749043 \\
\hline C & 3.609504 & 6.022187 & 0.604745 \\
\hline $\mathrm{C}$ & 3.008521 & 5.145600 & 1.513031 \\
\hline $\mathrm{C}$ & 1.575331 & 2.401679 & -0.762454 \\
\hline C & 2.255452 & 1.113275 & -0.313660 \\
\hline $\mathrm{C}$ & 1.504602 & -0.041560 & 0.000948 \\
\hline $\mathrm{C}$ & 0.031712 & -0.000928 & 0.000427 \\
\hline C & -0.648593 & 1.216533 & -0.253208 \\
\hline C & 0.067833 & 2.428866 & -0.535727 \\
\hline C & -0.714859 & -1.179003 & 0.253684 \\
\hline C & -0.066562 & -2.429069 & 0.536318 \\
\hline $\mathrm{C}$ & 1.440054 & -2.485219 & 0.763673 \\
\hline $\mathrm{C}$ & 2.190413 & -1.235980 & 0.316155 \\
\hline $\mathrm{C}$ & 3.651222 & 1.060542 & -0.309965 \\
\hline $\mathrm{C}$ & 4.319956 & -0.119090 & 0.002460 \\
\hline $\mathrm{C}$ & 3.586980 & -1.260137 & 0.314018 \\
\hline C & -2.093951 & 1.259546 & -0.216290 \\
\hline $\mathrm{C}$ & -2.835062 & 0.078246 & -0.000175 \\
\hline C & -2.160380 & -1.142166 & 0.216173 \\
\hline C & -2.887201 & -2.357761 & 0.414082 \\
\hline $\mathrm{C}$ & -2.233263 & -3.537537 & 0.643982 \\
\hline $\mathrm{C}$ & -0.818962 & -3.568935 & 0.712089 \\
\hline
\end{tabular}




\begin{tabular}{|c|c|c|c|}
\hline C & -2.752505 & 2.513384 & -0.414617 \\
\hline $\mathrm{C}$ & -2.034340 & 3.655208 & -0.644508 \\
\hline C & -0.620441 & 3.608469 & -0.712093 \\
\hline C & -4.335998 & 0.119484 & -0.000397 \\
\hline C & -5.049642 & -0.054930 & -1.205410 \\
\hline $\mathrm{C}$ & -6.447680 & -0.009763 & -1.183527 \\
\hline C & -7.162462 & 0.201790 & -0.001498 \\
\hline $\mathrm{C}$ & -6.437337 & 0.376826 & 1.180239 \\
\hline $\mathrm{C}$ & -5.039167 & 0.337779 & 1.203661 \\
\hline $\mathrm{C}$ & -4.325038 & -0.285316 & -2.512895 \\
\hline C & -8.673660 & 0.215323 & 0.002971 \\
\hline $\mathrm{C}$ & -4.303121 & 0.534033 & 2.510323 \\
\hline $\mathrm{C}$ & 2.864673 & 4.280619 & -2.699255 \\
\hline $\mathrm{C}$ & 4.295707 & 7.282091 & 1.078807 \\
\hline C & 1.731833 & 3.094695 & 2.162165 \\
\hline $\mathrm{H}$ & 4.215323 & 1.957655 & -0.546652 \\
\hline $\mathrm{H}$ & 4.100585 & -2.186964 & 0.551204 \\
\hline $\mathrm{H}$ & 5.406269 & -0.148991 & 0.003086 \\
\hline $\mathrm{H}$ & -0.068161 & 4.522324 & -0.909517 \\
\hline $\mathrm{H}$ & -2.544870 & 4.604160 & -0.786499 \\
\hline $\mathrm{H}$ & -3.835880 & 2.541764 & -0.378253 \\
\hline $\mathrm{H}$ & -3.970468 & -2.326196 & 0.377294 \\
\hline $\mathrm{H}$ & -2.795439 & -4.456900 & 0.785578 \\
\hline $\mathrm{H}$ & -0.318032 & -4.511934 & 0.909446 \\
\hline $\mathrm{H}$ & 1.682170 & 2.390515 & -1.855282 \\
\hline C & 2.081491 & -3.790395 & 0.274331 \\
\hline $\mathrm{H}$ & 1.546938 & -2.480934 & 1.856540 \\
\hline $\mathrm{H}$ & -6.991346 & -0.142272 & -2.117272 \\
\hline $\mathrm{H}$ & -6.972828 & 0.549976 & 2.112060 \\
\hline $\mathrm{H}$ & 3.999329 & 6.362212 & -1.478122 \\
\hline $\mathrm{H}$ & 3.051806 & 5.372690 & 2.576879 \\
\hline $\mathrm{H}$ & -3.626494 & 1.395511 & 2.465801 \\
\hline $\mathrm{H}$ & -5.005810 & 0.698484 & 3.333162 \\
\hline
\end{tabular}




\begin{tabular}{|c|c|c|c|}
\hline $\mathrm{H}$ & -3.688220 & -0.338615 & 2.760002 \\
\hline $\mathrm{H}$ & -5.035452 & -0.408880 & -3.336257 \\
\hline $\mathrm{H}$ & -3.663885 & 0.553720 & -2.759604 \\
\hline $\mathrm{H}$ & -3.695921 & -1.182209 & -2.471335 \\
\hline $\mathrm{H}$ & -9.066789 & 0.861271 & 0.795491 \\
\hline $\mathrm{H}$ & -9.074579 & 0.569540 & -0.952876 \\
\hline $\mathrm{H}$ & -9.081250 & -0.790527 & 0.172681 \\
\hline $\mathrm{H}$ & 4.969589 & 7.080006 & 1.919768 \\
\hline $\mathrm{H}$ & 4.884590 & 7.742241 & 0.278760 \\
\hline $\mathrm{H}$ & 3.567820 & 8.028347 & 1.423648 \\
\hline $\mathrm{H}$ & 2.183878 & 2.096840 & 2.169362 \\
\hline $\mathrm{H}$ & 1.866985 & 3.531433 & 3.156564 \\
\hline $\mathrm{H}$ & 0.657632 & 2.957687 & 1.998285 \\
\hline $\mathrm{H}$ & 3.377589 & 5.084879 & -3.235412 \\
\hline $\mathrm{H}$ & 3.365229 & 3.341320 & -2.966172 \\
\hline $\mathrm{H}$ & 1.842621 & 4.226350 & -3.094750 \\
\hline $\mathrm{C}$ & 2.632564 & -4.696595 & 1.204904 \\
\hline $\mathrm{C}$ & 3.216520 & -5.886379 & 0.748000 \\
\hline C & 3.271176 & -6.211595 & -0.606140 \\
\hline $\mathrm{C}$ & 2.720998 & -5.301745 & -1.513899 \\
\hline $\mathrm{C}$ & 2.129062 & -4.103935 & -1.105305 \\
\hline $\mathrm{C}$ & 2.620807 & -4.435394 & 2.699375 \\
\hline $\mathrm{H}$ & 3.639158 & -6.575402 & 1.476687 \\
\hline C & 3.886444 & -7.507290 & -1.081101 \\
\hline $\mathrm{H}$ & 2.752743 & -5.529563 & -2.577999 \\
\hline $\mathrm{C}$ & 1.561784 & -3.181826 & -2.161712 \\
\hline $\mathrm{H}$ & 3.118204 & -8.212134 & -1.425560 \\
\hline $\mathrm{H}$ & 4.569789 & -7.342433 & -1.922536 \\
\hline $\mathrm{H}$ & 4.449627 & -7.999522 & -0.281643 \\
\hline $\mathrm{H}$ & 3.087315 & -5.267758 & 3.235025 \\
\hline $\mathrm{H}$ & 3.172800 & -3.525900 & 2.968091 \\
\hline $\mathrm{H}$ & 1.602930 & -4.324539 & 3.093822 \\
\hline $\mathrm{H}$ & 2.071737 & -2.212270 & -2.169481 \\
\hline
\end{tabular}




$\begin{array}{llll}\mathrm{H} & 1.670094 & -3.625832 & -3.156179 \\ \mathrm{H} & 0.497674 & -2.981868 & -1.996845\end{array}$

\section{1b, $E_{\mathrm{el}}=-1893.826979$ Hartree}

\begin{tabular}{|c|c|c|c|}
\hline C & -2.649728 & -0.987746 & -0.085497 \\
\hline C & -2.443577 & 0.425815 & -0.255801 \\
\hline $\mathrm{C}$ & -1.115801 & 0.935352 & -0.389592 \\
\hline $\mathrm{C}$ & -0.000039 & 0.028823 & -0.314835 \\
\hline $\mathrm{C}$ & -0.226732 & -1.349252 & -0.131724 \\
\hline C & -1.573986 & -1.851309 & -0.032201 \\
\hline $\mathrm{C}$ & -3.536159 & 1.327917 & -0.299741 \\
\hline $\mathrm{C}$ & -3.324204 & 2.679749 & -0.466084 \\
\hline $\mathrm{C}$ & -2.017624 & 3.178955 & -0.604807 \\
\hline $\mathrm{C}$ & -0.920827 & 2.331947 & -0.574521 \\
\hline $\mathrm{C}$ & 1.351525 & 0.532038 & -0.390815 \\
\hline $\mathrm{C}$ & 1.609863 & 1.915811 & -0.576622 \\
\hline $\mathrm{C}$ & 0.470842 & 2.895008 & -0.848967 \\
\hline $\mathrm{C}$ & 2.448397 & -0.373939 & -0.258143 \\
\hline $\mathrm{C}$ & 2.197913 & -1.782565 & -0.085528 \\
\hline $\mathrm{C}$ & 0.899455 & -2.256270 & -0.030714 \\
\hline $\mathrm{C}$ & -1.832397 & -3.338910 & 0.139914 \\
\hline $\mathrm{C}$ & -0.603751 & -4.186629 & 0.216461 \\
\hline $\mathrm{C}$ & 0.634579 & -3.683952 & 0.140184 \\
\hline $\mathrm{C}$ & 3.769616 & 0.134523 & -0.304699 \\
\hline $\mathrm{C}$ & 3.999305 & 1.484438 & -0.473834 \\
\hline $\mathrm{C}$ & 2.920416 & 2.371721 & -0.611376 \\
\hline $\mathrm{H}$ & -1.862440 & 4.246091 & -0.733358 \\
\hline $\mathrm{H}$ & -4.543762 & 0.939173 & -0.199152 \\
\hline $\mathrm{H}$ & -4.167539 & 3.364830 & -0.493611 \\
\hline $\mathrm{H}$ & 3.110987 & 3.432814 & -0.742039 \\
\hline $\mathrm{H}$ & 5.017039 & 1.864665 & -0.503905 \\
\hline $\mathrm{H}$ & 4.601770 & -0.553531 & -0.204279 \\
\hline $\mathrm{H}$ & 1.493243 & -4.344052 & 0.204554 \\
\hline
\end{tabular}




\begin{tabular}{|c|c|c|c|}
\hline $\mathrm{H}$ & -0.750353 & -5.257481 & 0.341606 \\
\hline $\mathrm{H}$ & -2.446278 & -3.507181 & 1.038316 \\
\hline $\mathrm{H}$ & -2.472264 & -3.700234 & -0.680689 \\
\hline C & 3.366475 & -2.719778 & 0.032180 \\
\hline $\mathrm{H}$ & 0.493068 & 3.032739 & -1.937879 \\
\hline C & 0.699102 & 4.282120 & -0.234903 \\
\hline C & -4.050270 & -1.517362 & 0.031738 \\
\hline C & -4.762513 & -1.899692 & -1.124680 \\
\hline C & -6.061966 & -2.400717 & -0.992052 \\
\hline C & -6.679468 & -2.534031 & 0.254481 \\
\hline C & -5.962722 & -2.136411 & 1.386407 \\
\hline C & -4.661369 & -1.630592 & 1.298567 \\
\hline C & -4.148939 & -1.757450 & -2.500287 \\
\hline $\mathrm{H}$ & -6.606790 & -2.690337 & -1.888879 \\
\hline C & -8.071631 & -3.109169 & 0.376576 \\
\hline $\mathrm{H}$ & -6.429213 & -2.217387 & 2.366632 \\
\hline $\mathrm{C}$ & -3.937208 & -1.197248 & 2.554277 \\
\hline C & 3.915203 & -3.012399 & 1.298898 \\
\hline $\mathrm{C}$ & 5.012594 & -3.875772 & 1.384776 \\
\hline C & 5.583249 & -4.461435 & 0.251513 \\
\hline $\mathrm{C}$ & 5.028261 & -4.155384 & -0.993997 \\
\hline C & 3.931494 & -3.296914 & -1.124992 \\
\hline C & 3.333300 & -2.408320 & 2.557519 \\
\hline $\mathrm{H}$ & 5.432771 & -4.094150 & 2.364974 \\
\hline $\mathrm{C}$ & 6.748833 & -5.415897 & 0.371362 \\
\hline $\mathrm{H}$ & 5.460707 & -4.594599 & -1.891278 \\
\hline $\mathrm{C}$ & 3.367321 & -3.001596 & -2.496909 \\
\hline $\mathrm{H}$ & -8.600599 & -2.699101 & 1.243690 \\
\hline $\mathrm{H}$ & -8.671566 & -2.900829 & -0.515879 \\
\hline $\mathrm{H}$ & -8.043121 & -4.200251 & 0.500585 \\
\hline $\mathrm{H}$ & -2.997071 & -1.744111 & 2.693868 \\
\hline $\mathrm{H}$ & -3.677396 & -0.132580 & 2.519062 \\
\hline $\mathrm{H}$ & -4.557880 & -1.364081 & 3.440106 \\
\hline
\end{tabular}




\begin{tabular}{|c|c|c|c|}
\hline $\mathrm{H}$ & -4.836495 & -2.114676 & -3.273223 \\
\hline $\mathrm{H}$ & -3.903888 & -0.712089 & -2.722674 \\
\hline $\mathrm{H}$ & -3.214715 & -2.324089 & -2.592435 \\
\hline $\mathrm{H}$ & 7.385143 & -5.386094 & -0.519759 \\
\hline $\mathrm{H}$ & 7.372235 & -5.180753 & 1.240808 \\
\hline $\mathrm{H}$ & 6.405263 & -6.452542 & 0.489737 \\
\hline 11 & 3.910178 & -2.709231 & 3.437624 \\
\hline $\mathrm{H}$ & 3.328025 & -1.313024 & 2.513743 \\
\hline $\mathrm{H}$ & 2.294307 & -2.723477 & 2.711249 \\
\hline $\mathrm{H}$ & 3.370288 & -1.926498 & -2.710872 \\
\hline $\mathrm{H}$ & 3.950905 & -3.503301 & -3.275138 \\
\hline $\mathrm{H}$ & 2.327478 & -3.338354 & -2.584996 \\
\hline C & 0.730757 & 4.458758 & 1.169167 \\
\hline $\mathrm{C}$ & 0.939022 & 5.737479 & 1.692584 \\
\hline C & 1.120723 & 6.858462 & 0.877386 \\
\hline C & 1.083263 & 6.666771 & -0.502713 \\
\hline C & 0.877390 & 5.403065 & -1.073324 \\
\hline C & 0.543329 & 3.306544 & 2.131110 \\
\hline $\mathrm{H}$ & 0.958568 & 5.859745 & 2.774179 \\
\hline C & 1.366283 & 8.223706 & 1.476361 \\
\hline $\mathrm{H}$ & 1.217030 & 7.522865 & -1.161206 \\
\hline C & 0.852769 & 5.298712 & -2.586701 \\
\hline $\mathrm{H}$ & 0.601365 & 3.657955 & 3.165985 \\
\hline $\mathrm{H}$ & -0.428123 & 2.818904 & 1.995830 \\
\hline $\mathrm{H}$ & 1.309410 & 2.535626 & 1.994681 \\
\hline $\mathrm{H}$ & -0.104473 & 4.915764 & -2.962262 \\
\hline $\mathrm{H}$ & 1.008053 & 6.283045 & -3.038770 \\
\hline $\mathrm{H}$ & 1.639086 & 4.636869 & -2.971035 \\
\hline 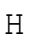 & 1.240637 & 9.016144 & 0.731396 \\
\hline $\mathrm{H}$ & 0.678786 & 8.427876 & 2.305507 \\
\hline H & 2.385404 & 8.307086 & 1.876783 \\
\hline
\end{tabular}


$\mathbf{8 a}^{\prime}, E_{\mathrm{el}}=-846.215774$ Hartree

\begin{tabular}{|c|c|c|c|}
\hline $\mathrm{C}$ & 2.234066 & 3.016926 & -0.067709 \\
\hline C & 1.837711 & 1.656347 & -0.057702 \\
\hline $\mathrm{C}$ & 0.434248 & 1.349774 & -0.037035 \\
\hline C & -0.526441 & 2.400471 & -0.026864 \\
\hline C & -0.076146 & 3.743570 & -0.037430 \\
\hline C & 1.285540 & 4.036601 & -0.057563 \\
\hline$C$ & -0.002314 & -0.005607 & -0.026644 \\
\hline C & -1.393731 & -0.306631 & -0.006198 \\
\hline C & 0.960048 & -1.061034 & -0.036672 \\
\hline C & 2.361666 & -0.754387 & -0.057314 \\
\hline C & 3.290465 & -1.825108 & -0.066966 \\
\hline C & 2.855075 & -3.146224 & -0.056530 \\
\hline $\mathrm{C}$ & 1.493585 & -3.447806 & -0.036400 \\
\hline 0 & 0.526244 & -2.417397 & -0.026185 \\
\hline C & -1.814850 & -1.682195 & 0.004200 \\
\hline $\mathrm{C}$ & -3.245473 & -1.975599 & 0.025182 \\
\hline $\mathrm{C}$ & -4.175843 & -1.011311 & 0.035047 \\
\hline $\mathrm{C}$ & -3.836268 & 0.451972 & 0.025481 \\
\hline $\mathrm{C}$ & -2.347912 & 0.755450 & 0.003794 \\
\hline C & -0.874131 & -2.687905 & -0.005699 \\
\hline C & 2.768752 & 0.597446 & -0.067383 \\
\hline $\mathrm{C}$ & -1.908840 & 2.061371 & -0.006438 \\
\hline $\mathrm{H}$ & 3.294560 & 3.255014 & -0.083515 \\
\hline $\mathrm{H}$ & -0.809478 & 4.545927 & -0.029589 \\
\hline $\mathrm{H}$ & 1.611964 & 5.073249 & -0.065463 \\
\hline $\mathrm{H}$ & 4.353436 & -1.598227 & -0.082728 \\
\hline $\mathrm{H}$ & 3.583759 & -3.952556 & -0.064150 \\
\hline $\mathrm{H}$ & 1.162053 & -4.483039 & -0.028330 \\
\hline $\mathrm{H}$ & -3.539102 & -3.023210 & 0.032730 \\
\hline $\mathrm{H}$ & -5.232135 & -1.270816 & 0.050670 \\
\hline $\mathrm{H}$ & -4.298142 & 0.935661 & 0.901114 \\
\hline $\mathrm{H}$ & -4.322275 & 0.929812 & -0.840245 \\
\hline
\end{tabular}




$\begin{array}{crrr}\mathrm{H} & -1.201082 & -3.725784 & 0.002280 \\ \mathrm{H} & 3.831577 & 0.828168 & -0.082741 \\ \mathrm{H} & -2.636165 & 2.871721 & 0.001242\end{array}$

$\mathbf{8 b}^{\prime}, E_{\mathrm{el}}=-846.219465$ Hartree

\begin{tabular}{|c|c|c|c|}
\hline C & 2.198123 & 3.034445 & -0.004917 \\
\hline C & 1.824428 & 1.698795 & -0.004591 \\
\hline C & 0.449167 & 1.357474 & -0.025644 \\
\hline C & -0.534902 & 2.400788 & -0.047039 \\
\hline C & -0.106545 & 3.754896 & -0.046576 \\
\hline C & 1.235498 & 4.063706 & -0.025868 \\
\hline C & 0.021318 & -0.018490 & -0.026027 \\
\hline C & -1.352389 & -0.325363 & -0.047201 \\
\hline C & 0.993647 & -1.081687 & -0.004837 \\
\hline C & 2.383431 & -0.805300 & 0.016721 \\
\hline C & 3.289611 & -1.855049 & 0.036634 \\
\hline C & 2.856189 & -3.196211 & 0.035969 \\
\hline C & 1.510322 & -3.487846 & 0.015294 \\
\hline C & 0.546879 & -2.444631 & -0.005594 \\
\hline $\mathrm{C}$ & -1.793709 & -1.699568 & -0.047866 \\
\hline $\mathrm{C}$ & -3.190003 & -1.975601 & -0.069618 \\
\hline C & -4.124819 & -0.944780 & -0.090317 \\
\hline $\mathrm{C}$ & -3.717350 & 0.386016 & -0.089836 \\
\hline C & -2.336316 & 0.730387 & -0.068531 \\
\hline $\mathrm{C}$ & -0.838114 & -2.719908 & -0.027063 \\
\hline $\mathrm{C}$ & 2.889060 & 0.622144 & 0.018253 \\
\hline $\mathrm{C}$ & -1.905337 & 2.060512 & -0.068009 \\
\hline $\mathrm{H}$ & 3.255188 & 3.291765 & 0.011316 \\
\hline $\mathrm{H}$ & -0.857232 & 4.541130 & -0.062867 \\
\hline $\mathrm{H}$ & 1.558751 & 5.101248 & -0.025587 \\
\hline $\mathrm{H}$ & 4.355703 & -1.638138 & 0.053114 \\
\hline $\mathrm{H}$ & 3.589991 & -3.997616 & 0.051849 \\
\hline $\mathrm{H}$ & 1.165267 & -4.518834 & 0.0 \\
\hline
\end{tabular}




$\begin{array}{lrrr}\mathrm{H} & -3.516278 & -3.012325 & -0.069463 \\ \mathrm{H} & -5.185370 & -1.181813 & -0.106603 \\ \mathrm{H} & -4.453567 & 1.185401 & -0.105652 \\ \mathrm{H} & -1.167817 & -3.756534 & -0.027425 \\ \mathrm{H} & 3.557753 & 0.764107 & -0.843341 \\ \mathrm{H} & 3.528764 & 0.772465 & 0.900202 \\ \mathrm{H} & -2.644664 & 2.858263 & -0.084219\end{array}$

8a, $E_{\mathrm{el}}=-1893.223777$ Hartree

\begin{tabular}{|c|c|c|c|}
\hline C & 2.201126 & 1.790569 & -0.0000 \\
\hline C & 0.862575 & 2.313992 & -0.0000 \\
\hline C & -0.242577 & 1.412577 & -0.0000 \\
\hline C & -0.008080 & 0.007646 & -0.0000 \\
\hline $\mathrm{C}$ & 1.323558 & -0.493678 & -0.0000 \\
\hline $\mathrm{C}$ & 2.424288 & 0.421260 & -0.0000 \\
\hline C & 0.610009 & 3.708751 & -0.000 \\
\hline C & -0.692842 & 4.195672 & -0.000 \\
\hline C & -1.778735 & 3.327089 & -0.0000 \\
\hline C & -1.588505 & 1.921702 & -0.000 \\
\hline C & -1.114005 & -0.895488 & -0.0000 \\
\hline $\mathrm{C}$ & -2.458702 & -0.387096 & 0.000 \\
\hline $\mathrm{C}$ & -2.689205 & 1.019251 & -0.0000 \\
\hline $\mathrm{C}$ & -0.881623 & -2.303230 & 0.0000 \\
\hline $\mathrm{C}$ & 0.470436 & -2.801526 & 0.000 \\
\hline $\mathrm{C}$ & 1.541810 & -1.919177 & -0.000 \\
\hline C & 3.852260 & -0.097704 & -0.0000 \\
\hline $\mathrm{C}$ & 3.976924 & -1.588665 & -0.000 \\
\hline $\mathrm{C}$ & 2.919709 & -2.410408 & -0.0000 \\
\hline C & -1.992887 & -3.179226 & 0.0000 \\
\hline $\mathrm{C}$ & -3.293363 & -2.682445 & 0.0000 \\
\hline $\mathrm{C}$ & -3.532264 & -1.314097 & 0.0000 \\
\hline $\mathrm{H}$ & -2.789606 & 3.719924 & -0.0000 \\
\hline $\mathrm{H}$ & 1.448392 & 4.396746 & 000 \\
\hline
\end{tabular}




\begin{tabular}{|c|c|c|c|}
\hline $\mathrm{H}$ & -0.864699 & 5.268983 & -0.000118 \\
\hline $\mathrm{H}$ & -4.549746 & -0.938775 & 0.000083 \\
\hline $\mathrm{H}$ & -4.131830 & -3.374147 & 0.000107 \\
\hline $\mathrm{H}$ & -1.820574 & -4.249781 & 0.000064 \\
\hline $\mathrm{H}$ & 3.066251 & -3.485512 & -0.000030 \\
\hline $\mathrm{H}$ & 4.984888 & -1.998348 & -0.000043 \\
\hline $\mathrm{H}$ & 4.396510 & 0.312563 & -0.865124 \\
\hline $\mathrm{H}$ & 4.396507 & 0.312565 & 0.865048 \\
\hline C & 0.697273 & -4.286453 & 0.000011 \\
\hline C & -4.091863 & 1.548161 & 0.000017 \\
\hline C & 3.362690 & 2.741933 & -0.000027 \\
\hline C & 0.800617 & -4.987473 & -1.220385 \\
\hline C & 1.005303 & -6.371170 & -1.197606 \\
\hline C & 1.107104 & -7.084096 & 0.000032 \\
\hline C & 1.005350 & -6.371145 & 1.197660 \\
\hline C & 0.800665 & -4.987447 & 1.220418 \\
\hline C & 0.703303 & -4.263281 & -2.544705 \\
\hline $\mathrm{H}$ & 1.088051 & -6.904779 & -2.142812 \\
\hline C & 1.295049 & -8.583629 & 0.000045 \\
\hline $\mathrm{H}$ & 1.088136 & -6.904734 & 2.142874 \\
\hline C & 0.703402 & -4.263228 & 2.544726 \\
\hline C & -4.754033 & 1.800430 & -1.220690 \\
\hline C & -6.061394 & 2.297423 & -1.197712 \\
\hline C & -6.735625 & 2.550126 & 0.000057 \\
\hline C & -6.061281 & 2.297653 & 1.197778 \\
\hline C & -4.753896 & 1.800648 & 1.220721 \\
\hline C & -4.068274 & 1.544945 & -2.544352 \\
\hline $\mathrm{H}$ & -6.564708 & 2.493034 & -2.142915 \\
\hline C & -8.159502 & 3.056523 & 0.000017 \\
\hline $\mathrm{H}$ & -6.564498 & 2.493438 & 2.142992 \\
\hline C & -4.068031 & 1.545397 & 2.544373 \\
\hline C & 3.909813 & 3.192211 & 1.220233 \\
\hline C & 4.999329 & 4.069447 & 1.197637 \\
\hline
\end{tabular}




\begin{tabular}{|c|c|c|c|}
\hline C & 5.564509 & 4.515932 & 0.000030 \\
\hline C & 4.999370 & 4.069476 & -1.197601 \\
\hline C & 3.909850 & 3.192239 & -1.220254 \\
\hline $\mathrm{C}$ & 3.324108 & 2.755215 & 2.545008 \\
\hline $\mathrm{H}$ & 5.413981 & 4.415590 & 2.142747 \\
\hline C & 6.762627 & 5.436955 & 0.000075 \\
\hline $\mathrm{H}$ & 5.414057 & 4.415637 & -2.142689 \\
\hline $\mathrm{C}$ & 3.324183 & 2.755284 & -2.545059 \\
\hline $\mathrm{H}$ & -0.241141 & -3.714300 & 2.634965 \\
\hline $\mathrm{H}$ & 0.766637 & -4.967452 & 3.380161 \\
\hline $\mathrm{H}$ & 1.508484 & -3.527929 & 2.661606 \\
\hline $\mathrm{H}$ & 1.844405 & -8.919156 & 0.886315 \\
\hline $\mathrm{H}$ & 0.329177 & -9.106835 & 0.000069 \\
\hline $\mathrm{H}$ & 1.844370 & -8.919175 & -0.886241 \\
\hline $\mathrm{H}$ & 0.766505 & -4.967524 & -3.380127 \\
\hline $\mathrm{H}$ & -0.241244 & -3.714355 & -2.634919 \\
\hline $\mathrm{H}$ & 1.508380 & -3.527986 & -2.661633 \\
\hline $\mathrm{H}$ & -3.153963 & 2.142308 & 2.645532 \\
\hline $\mathrm{H}$ & -4.728350 & 1.794596 & 3.380860 \\
\hline $\mathrm{H}$ & -3.772874 & 0.494595 & 2.647943 \\
\hline $\mathrm{H}$ & -4.728643 & 1.794044 & -3.380830 \\
\hline $\mathrm{H}$ & -3.154188 & 2.141801 & -2.645666 \\
\hline $\mathrm{H}$ & -3.773169 & 0.494115 & -2.647781 \\
\hline $\mathrm{H}$ & -8.369740 & 3.662867 & 0.887684 \\
\hline $\mathrm{H}$ & -8.368066 & 3.667482 & -0.884896 \\
\hline $\mathrm{H}$ & -8.878294 & 2.225877 & -0.002875 \\
\hline $\mathrm{H}$ & 6.774300 & 6.080232 & -0.886410 \\
\hline $\mathrm{H}$ & 6.773747 & 6.080865 & 0.886110 \\
\hline $\mathrm{H}$ & 7.702638 & 4.868622 & 0.000580 \\
\hline $\mathrm{H}$ & 3.882904 & 3.187952 & 3.380601 \\
\hline $\mathrm{H}$ & 2.277051 & 3.066106 & 2.641568 \\
\hline $\mathrm{H}$ & 3.338209 & 1.664732 & 2.659164 \\
\hline $\mathrm{H}$ & 3.338172 & 1.664799 & -2.659199 \\
\hline
\end{tabular}




$\begin{array}{llll}\mathrm{H} & 2.277165 & 3.066287 & -2.641689 \\ \mathrm{H} & 3.883075 & 3.187952 & -3.380624\end{array}$

\section{$\mathbf{8 b}, E_{\mathrm{el}}=-1893.219439$ Hartree}

\begin{tabular}{|c|c|c|c|}
\hline C & 2.484574 & -1.391885 & -0.083771 \\
\hline $\mathrm{C}$ & 2.486692 & 0.023062 & -0.257010 \\
\hline C & 1.246986 & 0.735959 & -0.389685 \\
\hline C & 0.000109 & 0.017935 & -0.311508 \\
\hline C & 0.008277 & -1.377285 & -0.123698 \\
\hline C & 1.260960 & -2.093448 & -0.022682 \\
\hline $\mathrm{C}$ & 3.706305 & 0.754150 & -0.307570 \\
\hline C & 3.701922 & 2.119731 & -0.478170 \\
\hline $\mathrm{C}$ & 2.485203 & 2.813038 & -0.615325 \\
\hline C & 1.270962 & 2.143452 & -0.578862 \\
\hline C & -1.255099 & 0.721258 & -0.390006 \\
\hline $\mathrm{C}$ & -1.295563 & 2.128350 & -0.579315 \\
\hline $\mathrm{C}$ & -0.016854 & 2.916714 & -0.851496 \\
\hline $\mathrm{C}$ & -2.486385 & -0.006152 & -0.257679 \\
\hline $\mathrm{C}$ & -2.467691 & -1.420965 & -0.084344 \\
\hline C & -1.235936 & -2.108105 & -0.022942 \\
\hline C & 1.229542 & -3.507380 & 0.147463 \\
\hline C & 0.024781 & -4.195280 & 0.225652 \\
\hline $\mathrm{C}$ & -1.187956 & -3.521567 & 0.147231 \\
\hline $\mathrm{C}$ & -3.714495 & 0.710533 & -0.308763 \\
\hline $\mathrm{C}$ & -3.726121 & 2.076034 & -0.479691 \\
\hline C & -2.517592 & 2.783575 & -0.616519 \\
\hline H & 2.494583 & 3.890839 & -0.747202 \\
\hline $\mathrm{H}$ & 4.642674 & 0.216316 & -0.207755 \\
\hline $\mathrm{H}$ & 4.639549 & 2.668424 & -0.510451 \\
\hline $\mathrm{H}$ & -2.539548 & 3.861140 & -0.748844 \\
\hline $\mathrm{H}$ & -4.670139 & 2.613628 & -0.512521 \\
\hline $\mathrm{H}$ & -4.644507 & 0.161738 & -0.209192 \\
\hline $\mathrm{H}$ & -2.120524 & -4.070058 & 0.217672 \\
\hline
\end{tabular}




\begin{tabular}{|c|c|c|c|}
\hline $\mathrm{H}$ & 0.031103 & -5.274584 & 0.354669 \\
\hline $\mathrm{H}$ & 2.168468 & -4.044889 & 0.218087 \\
\hline $\mathrm{C}$ & -3.758939 & -2.175692 & 0.032650 \\
\hline C & -0.025412 & 4.321725 & -0.235709 \\
\hline $\mathrm{H}$ & -0.017560 & 3.057321 & -1.940184 \\
\hline C & 3.784568 & -2.131402 & 0.033505 \\
\hline C & -4.394061 & -2.676551 & -1.123975 \\
\hline $\mathrm{C}$ & -5.596405 & -3.379289 & -0.992093 \\
\hline $\mathrm{C}$ & -6.192221 & -3.598616 & 0.252853 \\
\hline C & -5.545816 & -3.097748 & 1.386134 \\
\hline C & -4.342265 & -2.390030 & 1.299875 \\
\hline $\mathrm{C}$ & -3.790317 & -2.468299 & -2.495026 \\
\hline $\mathrm{H}$ & -6.078681 & -3.766102 & -1.888067 \\
\hline $\mathrm{C}$ & -7.508354 & -4.332409 & 0.367738 \\
\hline $\mathrm{H}$ & -5.988247 & -3.262225 & 2.367042 \\
\hline $\mathrm{C}$ & -3.682375 & -1.870930 & 2.557927 \\
\hline $\mathrm{C}$ & 4.370072 & -2.338938 & 1.300869 \\
\hline $\mathrm{C}$ & 5.581824 & -3.032466 & 1.387384 \\
\hline $\mathrm{C}$ & 6.234342 & -3.525658 & 0.254227 \\
\hline $\mathrm{C}$ & 5.636295 & -3.313284 & -0.990843 \\
\hline $\mathrm{C}$ & 4.425802 & -2.624706 & -1.122984 \\
\hline $\mathrm{C}$ & 3.703844 & -1.827647 & 2.558779 \\
\hline $\mathrm{H}$ & 6.025920 & -3.191785 & 2.368394 \\
\hline $\mathrm{C}$ & 7.558954 & -4.243975 & 0.369448 \\
\hline $\mathrm{H}$ & 6.123298 & -3.694361 & -1.886716 \\
\hline $\mathrm{C}$ & 3.819997 & -2.423479 & -2.494174 \\
\hline $\mathrm{H}$ & -3.557487 & -0.782167 & 2.526665 \\
\hline $\mathrm{H}$ & -4.279007 & -2.117095 & 3.441809 \\
\hline $\mathrm{H}$ & -2.682843 & -2.300320 & 2.694381 \\
\hline $\mathrm{H}$ & -4.419134 & -2.916406 & -3.270664 \\
\hline $\mathrm{H}$ & -3.675803 & -1.402743 & -2.726228 \\
\hline $\mathrm{H}$ & -2.792510 & -2.916806 & -2.567673 \\
\hline $\mathrm{H}$ & -7.591494 & -4.859928 & 1.324105 \\
\hline
\end{tabular}




\begin{tabular}{|c|c|c|c|}
\hline $\mathrm{H}$ & -8.358278 & -3.639362 & 0.304868 \\
\hline $\mathrm{H}$ & -7.629844 & -5.066673 & -0.435950 \\
\hline $\mathrm{H}$ & 4.302978 & -2.067057 & 3.442825 \\
\hline $\mathrm{H}$ & 3.566474 & -0.740385 & 2.527617 \\
\hline $\mathrm{H}$ & 2.709269 & -2.268511 & 2.694846 \\
\hline $\mathrm{H}$ & 2.827472 & -2.883520 & -2.567047 \\
\hline $\mathrm{H}$ & 3.693190 & -1.359321 & -2.725409 \\
\hline $\mathrm{H}$ & 4.454145 & -2.864266 & -3.269664 \\
\hline $\mathrm{H}$ & 7.690346 & -4.974952 & -0.435668 \\
\hline $\mathrm{H}$ & 8.400649 & -3.540711 & 0.309408 \\
\hline $\mathrm{H}$ & 7.646983 & -4.772592 & 1.324778 \\
\hline C & -0.029117 & 5.457641 & -1.072783 \\
\hline $\mathrm{C}$ & -0.035268 & 6.737331 & -0.500470 \\
\hline C & -0.039622 & 6.930770 & 0.879807 \\
\hline C & -0.033153 & 5.794095 & 1.693682 \\
\hline C & -0.026996 & 4.499270 & 1.168717 \\
\hline C & -0.024186 & 5.352620 & -2.586315 \\
\hline $\mathrm{H}$ & -0.036069 & 7.604630 & -1.157839 \\
\hline $\mathrm{C}$ & -0.066030 & 8.316680 & 1.481047 \\
\hline $\mathrm{H}$ & -0.031925 & 5.916579 & 2.775426 \\
\hline C & -0.019726 & 3.330757 & 2.129240 \\
\hline $\mathrm{H}$ & 0.864278 & 2.698511 & 1.992829 \\
\hline $\mathrm{H}$ & -0.021801 & 3.685667 & 3.164515 \\
\hline $\mathrm{H}$ & -0.896174 & 2.688040 & 1.992980 \\
\hline $\mathrm{H}$ & -0.026821 & 6.349661 & -3.037141 \\
\hline $\mathrm{H}$ & 0.861764 & 4.827186 & -2.964527 \\
\hline $\mathrm{H}$ & -0.903958 & 4.820421 & -2.969489 \\
\hline $\mathrm{H}$ & 0.673588 & 8.420081 & 2.283781 \\
\hline $\mathrm{H}$ & 0.144571 & 9.083438 & 0.728500 \\
\hline $\mathrm{H}$ & -1.047273 & 8.544236 & 1.918108 \\
\hline
\end{tabular}


Triangulene, $E_{\mathrm{el}}=-845.611885$ Hartree

\begin{tabular}{|c|c|c|c|}
\hline C & 2.827647 & -2.478299 & 0.000000 \\
\hline C & 2.827647 & 2.478299 & 0.000000 \\
\hline C & 0.730027 & -3.689033 & 0.000000 \\
\hline C & 0.730027 & 3.689033 & 0.000000 \\
\hline $\mathrm{C}$ & 0.710571 & -1.233519 & 0.000000 \\
\hline C & 0.710571 & 1.233519 & 0.000000 \\
\hline $\mathrm{C}$ & 2.122598 & -3.679240 & 0.000000 \\
\hline C & 2.122598 & 3.679240 & 0.000000 \\
\hline C & 2.143882 & -1.232629 & 0.000000 \\
\hline C & 2.143882 & 1.232629 & 0.000000 \\
\hline $\mathrm{C}$ & -2.141959 & -1.241941 & 0.000000 \\
\hline C & -2.141959 & 1.241941 & 0.000000 \\
\hline C & -0.007029 & 2.474650 & 0.000000 \\
\hline C & -0.007029 & -2.474650 & 0.000000 \\
\hline C & -1.426266 & 0.000000 & 0.000000 \\
\hline C & 2.827857 & 0.000000 & 0.000000 \\
\hline $\mathrm{C}$ & -4.250127 & 0.000000 & 0.000000 \\
\hline $\mathrm{C}$ & -0.001840 & 0.000000 & 0.000000 \\
\hline C & -3.562793 & -1.210959 & 0.000000 \\
\hline C & -3.562793 & 1.210959 & 0.000000 \\
\hline C & -1.416515 & -2.450324 & 0.000000 \\
\hline $\mathrm{C}$ & -1.416515 & 2.450324 & 0.000000 \\
\hline $\mathrm{H}$ & 3.915519 & 0.000000 & 0.000000 \\
\hline $\mathrm{H}$ & -5.336973 & 0.000000 & 0.000000 \\
\hline $\mathrm{H}$ & 0.188706 & -4.631692 & 0.000000 \\
\hline $\mathrm{H}$ & 0.188706 & 4.631692 & 0.000000 \\
\hline $\mathrm{H}$ & 2.665855 & -4.620514 & 0.000000 \\
\hline $\mathrm{H}$ & 2.665855 & 4.620514 & 0.000000 \\
\hline $\mathrm{H}$ & 3.914561 & 2.479737 & 0.000000 \\
\hline $\mathrm{H}$ & 3.914561 & -2.479737 & 0.000000 \\
\hline $\mathrm{H}$ & -4.108366 & -2.151078 & 0.000000 \\
\hline $\mathrm{H}$ & -4.108366 & 2.151078 & 0.000000 \\
\hline
\end{tabular}




$\begin{array}{lrrr}\mathrm{H} & -1.960270 & -3.392459 & 0.000000 \\ \mathrm{H} & -1.960270 & 3.392459 & 0.000000\end{array}$

Mes3-Tr, $E_{\mathrm{el}}=-1892.620998$ Hartree

\begin{tabular}{|c|c|c|c|}
\hline C & 2.755601 & 0.761098 & -0.000002 \\
\hline C & 1.742695 & 1.760124 & 0.000001 \\
\hline C & 0.358105 & 1.378489 & 0.00000 \\
\hline $\mathrm{C}$ & 0.000061 & 0.000062 & 0.00000 \\
\hline C & 1.014798 & -0.999227 & -0.00000 \\
\hline C & 2.398989 & -0.616176 & -0.00000 \\
\hline C & 3.387510 & -1.638350 & -0.00000 \\
\hline C & 3.027339 & -2.981174 & -0.00001 \\
\hline C & 1.690198 & -3.361865 & -0.00001 \\
\hline $\mathrm{C}$ & 0.653007 & -2.389135 & -0.00000 \\
\hline C & -1.372715 & -0.379078 & 0.000001 \\
\hline C & -1.733075 & -1.769347 & 0.000000 \\
\hline C & -0.718628 & -2.766819 & -0.000002 \\
\hline $\mathrm{C}$ & -3.112555 & -2.114364 & 0.000002 \\
\hline C & -4.095396 & -1.131043 & 0.000004 \\
\hline $\mathrm{C}$ & -3.756524 & 0.217306 & 0.00000 \\
\hline C & -2.395522 & 0.629195 & 0.00000 \\
\hline C & -0.665723 & 2.385711 & 0.000004 \\
\hline $\mathrm{C}$ & -2.036783 & 2.005914 & 0.00000 \\
\hline $\mathrm{C}$ & 2.066497 & 3.144731 & 0.00000 \\
\hline C & 1.068233 & 4.112383 & 0.00000 \\
\hline $\mathrm{C}$ & -0.274770 & 3.752884 & 0.00000 \\
\hline $\mathrm{C}$ & -1.095428 & -4.218325 & 0.0000 \\
\hline $\mathrm{H}$ & 1.341488 & 5.164445 & 0.00000 \\
\hline $\mathrm{H}$ & -4.533151 & 0.974049 & 0.0000 \\
\hline $\mathrm{H}$ & 4.434276 & -1.355315 & -0.000011 \\
\hline $\mathrm{H}$ & -5.143135 & -1.420433 & 0.0000 \\
\hline $\mathrm{H}$ & 3.801825 & -3.743851 & -0.00001 \\
\hline $\mathrm{H}$ & 1.423122 & -4.412809 & -0.0000 \\
\hline
\end{tabular}




\begin{tabular}{|c|c|c|c|}
\hline $\mathrm{H}$ & -3.390799 & -3.162417 & 0.000002 \\
\hline $\mathrm{H}$ & -1.043289 & 4.517878 & 0.000007 \\
\hline $\mathrm{H}$ & 3.110174 & 3.438933 & 0.000003 \\
\hline$c$ & -3.105477 & 3.057928 & 0.000001 \\
\hline 0 & 4.201040 & 1.160527 & -0.000001 \\
\hline 0 & -1.275888 & -4.903413 & -1.220747 \\
\hline 0 & -1.630988 & -6.256252 & -1.197735 \\
\hline$c$ & -1.810434 & -6.953590 & 0.000005 \\
\hline C & -1.630975 & -6.256251 & 1.197742 \\
\hline O & -1.275874 & -4.903413 & 1.220749 \\
\hline O & -1.095015 & -4.194708 & -2.544652 \\
\hline $\mathrm{H}$ & -1.772067 & -6.777477 & -2.142921 \\
\hline C & -2.162616 & -8.423208 & 0.000007 \\
\hline $\mathrm{H}$ & -1.772043 & -6.777476 & 2.142929 \\
\hline C & -1.094987 & -4.194708 & 2.544652 \\
\hline C & 4.884563 & 1.346795 & 1.220749 \\
\hline $\mathrm{C}$ & 6.233711 & 1.715659 & 1.197742 \\
\hline $\mathrm{C}$ & 6.927351 & 1.908905 & 0.000001 \\
\hline $\mathrm{C}$ & 6.233713 & 1.715658 & -1.197741 \\
\hline $\mathrm{C}$ & 4.884565 & 1.346794 & -1.220750 \\
\hline $\mathrm{C}$ & 4.180317 & 1.149187 & 2.544640 \\
\hline $\mathrm{H}$ & 6.755647 & 1.854083 & 2.142928 \\
\hline $\mathrm{C}$ & 8.376182 & 2.338674 & 0.000002 \\
\hline $\mathrm{H}$ & 6.755650 & 1.854082 & -2.142927 \\
\hline $\mathrm{C}$ & 4.180321 & 1.149185 & -2.544642 \\
\hline C & -3.608657 & 3.556638 & -1.220748 \\
\hline C & -4.602980 & 4.540300 & -1.197743 \\
\hline $\mathrm{C}$ & -5.117333 & 5.044209 & -0.000004 \\
\hline C & -4.602982 & 4.540303 & 1.197738 \\
\hline C & -3.608659 & 3.556642 & 1.220748 \\
\hline C & -3.085144 & 3.045809 & -2.544638 \\
\hline $\mathrm{H}$ & -4.983936 & 4.922984 & -2.142930 \\
\hline $\mathrm{C}$ & -6.214295 & 6.083672 & -0.000006 \\
\hline
\end{tabular}




\begin{tabular}{|c|c|c|c|}
\hline $\mathrm{H}$ & -4.983940 & 4.922990 & 2.142923 \\
\hline C & -3.085148 & 3.045817 & 2.544641 \\
\hline $\mathrm{H}$ & -2.745529 & -8.696117 & 0.886307 \\
\hline $\mathrm{H}$ & -2.745553 & -8.696114 & -0.886279 \\
\hline $\mathrm{H}$ & -1.260221 & -9.049546 & -0.000007 \\
\hline $\mathrm{H}$ & -1.273549 & -4.877889 & -3.380814 \\
\hline $\mathrm{H}$ & -1.785003 & -3.348718 & -2.646009 \\
\hline $\mathrm{H}$ & -0.081297 & -3.790341 & -2.649080 \\
\hline $\mathrm{H}$ & -1.784971 & -3.348714 & 2.646014 \\
\hline $\mathrm{H}$ & -1.273516 & -4.877887 & 3.380816 \\
\hline $\mathrm{H}$ & -0.081266 & -3.790344 & 2.649070 \\
\hline $\mathrm{H}$ & 8.903981 & 1.970279 & -0.886288 \\
\hline $\mathrm{H}$ & 8.467443 & 3.433337 & -0.000005 \\
\hline $\mathrm{H}$ & 8.903976 & 1.970290 & 0.886299 \\
\hline $\mathrm{H}$ & 3.792039 & 0.128863 & -2.645780 \\
\hline $\mathrm{H}$ & 3.323683 & 1.825412 & -2.649252 \\
\hline $\mathrm{H}$ & 4.861382 & 1.335570 & -3.380820 \\
\hline $\mathrm{H}$ & 4.861378 & 1.335569 & 3.380819 \\
\hline $\mathrm{H}$ & 3.323681 & 1.825415 & 2.649250 \\
\hline $\mathrm{H}$ & 3.792032 & 0.128866 & 2.645777 \\
\hline $\mathrm{H}$ & -6.159373 & 6.724982 & 0.886279 \\
\hline $\mathrm{H}$ & -6.159389 & 6.724961 & -0.886308 \\
\hline $\mathrm{H}$ & -7.207770 & 5.615032 & 0.000008 \\
\hline $\mathrm{H}$ & -2.007586 & 3.220869 & 2.646020 \\
\hline $\mathrm{H}$ & -3.587772 & 3.541753 & 3.380819 \\
\hline $\mathrm{H}$ & -3.241304 & 1.965649 & 2.649004 \\
\hline $\mathrm{H}$ & -3.587764 & 3.541744 & -3.380819 \\
\hline $\mathrm{H}$ & -2.007582 & 3.220856 & -2.646015 \\
\hline $\mathrm{H}$ & -3.241304 & 1.965641 & -2.649000 \\
\hline
\end{tabular}




\section{S9. References}

1. Ribar, P., Valenta, L., Šolomek, T. \& Juríček, M. Rules of nucleophilic additions to zigzag nanographene diones. Angew. Chem. Int. Ed. 60, 13521-13528 (2021).

2. Holt, C. J., Wentworth, K. J. \& Johnson, R. P. A short and efficient synthesis of the [3]triangulene ring system. Angew. Chem. Int. Ed. 58, 15793-15796 (2019).

3. Gu, Y., Wu, X., Gopalakrishna, T. Y., Phan, H. \& Wu, J. Graphene-like molecules with four zigzag edges. Angew. Chem. Int. Ed. 57, 6541-6545 (2018).

4. van de Kuil, L. A. et al. Electronic tuning of arylnickel(II) complexes by para substitution of the terdentate monoanionic 2,6-bis[(dimethylamino)methyl]phenyl ligand. Organometallics 13, 468-477 (1994).

5. Fulmer, G. R. et al. NMR chemical shifts of trace impurities: common laboratory solvents, organics, and gases in deuterated solvents relevant to the organometallic chemist. Organometallics 29, 2176-2179 (2010).

6. Li, G.-Q., Yamamoto, Y. \& Miyaura, N. Synthesis of tetra-ortho-substituted biaryls using aryltriolborates. Synlett 2011, 1769-1773 (2011).

7. Boyd, T. J. \& Schrock, R. R. Sulfonation and epoxidation of substituted polynorbornenes and construction of light-emitting devices. Macromolecules 32, 66086618 (1999).

8. Yamaguchi, K., Fukui, H. \& Fueno, T. Molecular orbital (MO) theory for magnetically interacting organic compounds. Ab-initio MO calculations of the effective exchange integrals for cyclophane-type carbene dimers. Chem. Lett. 15, 625-628 (1986).

9. Nishino, M., Yamanaka, S., Yoshioka, Y. \& Yamaguchi, K. Theoretical approaches to direct exchange couplings between divalent chromium ions in naked dimers, tetramers, and clusters. J. Phys. Chem. A 101, 705-712 (1997).

10. Das, A., Müller, T., Plasser, F. \& Lischka, H. Polyradical character of triangular nonKekulé structures, zethrenes, p-quinodimethane-linked bisphenalenyl, and the Clar goblet in comparison: An extended multireference study. J. Phys. Chem. A 120, 16251636 (2016). 